
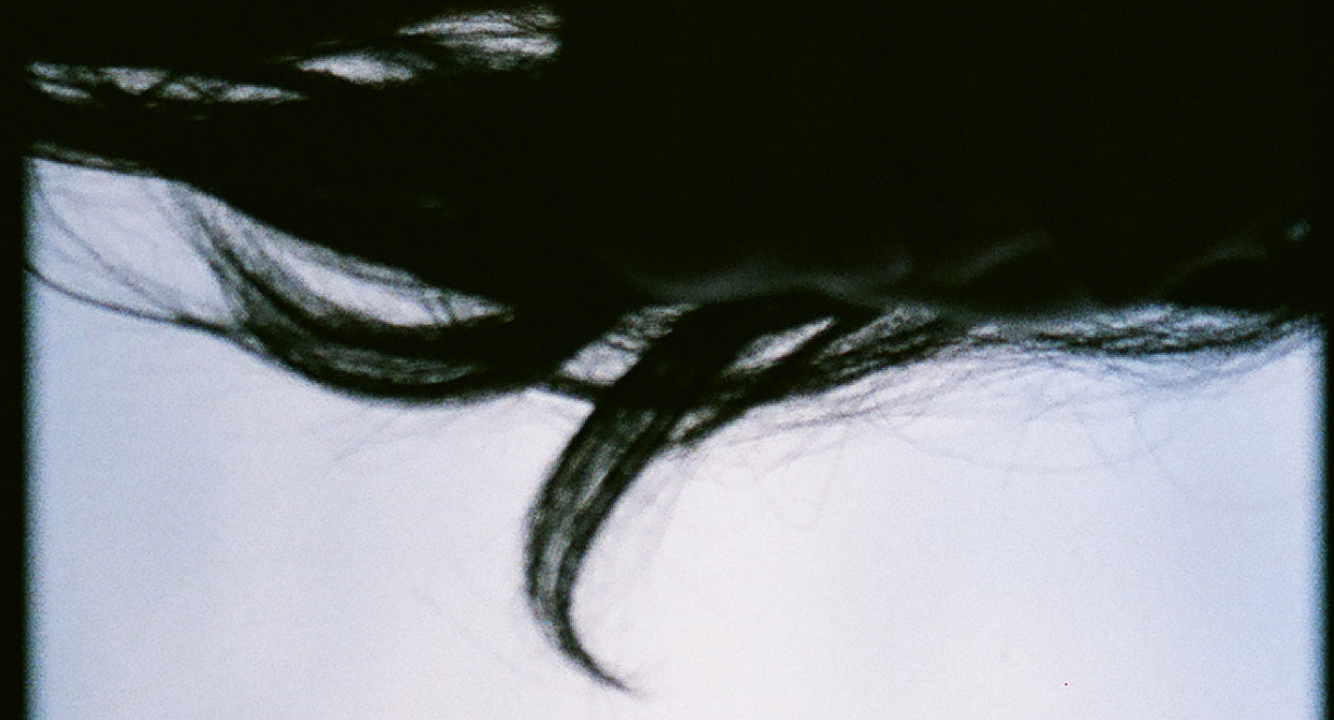

SOLO/

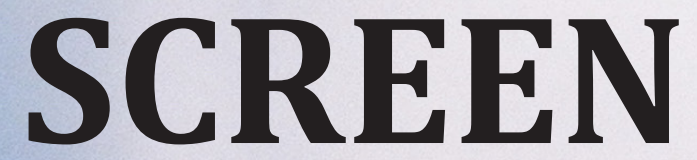

Volume 8 | Spring 2017

The International Journal of Screendance 



\section{The International Journal of Screendance}

Spring 2017 • Volume 8

ISSN 2154-6878

\section{EDITORS}

Harmony Bench and Simon Ellis

REVIEWS EDITOR

Tamara Tomić-Vajagić

EDITORIAL ASSISTANT

Carol Breen 
Cover Image and Design

Carol Breen

\section{Publication Design}

Harmony Bench and Simon Ellis, after Barry Roal Carlsen, University of Wisconsin-Madison

The International Journal of Screendance is published by The Ohio State University Libraries with support from Centre for Dance Research (C-DaRE), Coventry University

ISSN 2154-6878

Website: http://screendancejournal.org 


\section{The International Journal of Screendance Editorial Board}

\author{
DR. ANN COOPER ALBRIGHT \\ Professor of Theater and Dance \\ Oberlin College \\ ELLEN BROMBERG \\ Associate Professor, Department of \\ Modern Dance \\ University of Utah \\ DR. HARMONY BENCH \\ Assistant Professor, Department of Dance \\ The Ohio State University \\ DR. ERIN BRANNIGAN \\ Senior Lecturer, Dance \\ University of New South Wales \\ DR. SIMON ELLIS \\ Senior Research Fellow \\ Centre for Dance Research (C-DaRE) \\ Coventry University \\ DR. FRANK GRAY \\ Director of Screen Archive South East \\ (SASE) \\ University of Brighton \\ CLAUDIA KAPPENBERG \\ Principal Lecturer, Performance and \\ Visual Art; School of Arts and Media \\ University of Brighton
}

\author{
KATRINA MCPHERSON \\ Independent artist \\ Glenferness, UK
}

MIRANDA PENNELL

Independent film and video artist

London, UK

DOUGLAS ROSENBERG

Professor of Art, Department of Art

University of Wisconsin-Madison

DR. THERON SCHMIDT

Lecturer in Theatre and Performance

Studies, School of the Arts \& Media

UNSW Australia

\section{SILVINA SZPERLING}

Director, Internacional Festival de

Videodanza

Buenos Aires, Argentina

DR. SARAH WHATLEY

Professor of Dance, Coventry School of

Art and Design

Coventry University

DR. MARISA ZANOTTI

Senior Lecturer, Dance

University of Chichester 



\section{Table of Contents: Solo/Screen}

IJSD Volume 8

1 Editorial: Solo/Screen

Harmony Bench and Simon Ellis

Articles

11 Going Nowhere: Screendance and the Time of Dying Anna Macdonald

29 Intimate Encounters: Screendance and Surveillance John White

47 Movements of Media in Yvonne Rainer's Hand Movie (1966) and Richard Serra's Hand Catching Lead (1968)

Kyle Bukhari

70 Anarchitextures: Intermedial Encounters On The Screen

Ariadne Mikou

Provocations and Viewpoints

93 Screendance Self/portraits

Hetty Blades

104 Visual Politics in American Dance Film: Representation and Disparity Cara Hagan

113 Influences

Tracie Mitchell

Interviews

121 Starting with Sight: A Conversation between Rosemary Lee and Anna Heighway

Rosemary Lee, Anna Heighway

134 An Interview with Eiko Otake Rosemary Candelario, Eiko Otake 
Reviews

145 A Steady Pulse: Restaging Lucinda Childs, 1963-78 by The Pew Center for Arts and Heritage

Marie-Louise Crawley

149 The Oxford Handbook of Screendance Studies edited by Douglas Rosenberg Katja Vaghi

153 Art in Motion: Current Research in Screendance edited by Franck Boulégue and Marisa C. Hayes

Carol Breen

159 Dance on Camera at 45

Harmony Bench 


\section{Editorial: Solo/Screen}

Harmony Bench, The Ohio State University

Simon Ellis, C-Dare (Centre for Dance Research), Coventry University

Keywords: screendance, editorial, solo performance, alone

This volume did not start out as a themed issue, but similarities will emerge among any collection of essays when ideas and authors find themselves in proximity to one another. In our open call, we asked for screendance artists and scholars working at the intersection of film, dance, visual arts, and media arts to "expand and critique contemporary notions of screen-based images and changing choreographic practices, and [to] engage with theories and philosophies from interdisciplinary fields." 1 An unanticipated commonality emerged among the contributions responding to this open invitation: solo performance.

There is, no doubt, an economy of means at work in solo performance. Holly Hughes suggests that contemporary artists have turned to solo performance due to a lack of financial support: "solos are all [theaters] can (barely) afford to produce." 2 But as we see in the essays gathered here, the stakes and implications of dancing alone for a camera has a great deal to do with the time period in which that framing of the self takes place. What does it mean, for example, to conduct aesthetic experiments in a solo form during and after a political season in which 'going it alone' was a dominant theme? The success of the Brexit vote in the UK and Donald Trump's presidency in the US-the two countries where we and a majority of our contributing authors are based-strike us as a particularly salient backdrop for querying solo performance. How does the impulse to create solos resonate with national and ideological isolationism and self-aggrandizement? In an article on solo theatrical productions, Jonathan Kalb notes that "Solo performance is, of course, a field rife with selfindulgence and incipient monumental egotism." ${ }_{3}$ Does solo performance reflect an impulse to withdraw from the world and amplify the self? Or conversely, does solo performance offer a space from which to critique such withdrawal? David Romàn, for example, describes solo performance as "one of the few forms of artistic expression that registers as democratic: nearly anyone can do it and nearly everyone does." 4 To that end, we might also wonder if solo performance is more about exclusion than it is about exclusivity - if solo performance presents itself as a necessary avenue for female artists and artists of color who face discriminatory casting practices and who may view solo performance as a viable alternative. 
Perhaps before advancing any moral or political judgments about solo performance, we should clarify what we think solo performance is. Rebecca Schneider offers a straightforward definition: "From a theater and dance perspective, we can understand solo performance to be, simply, a single body performing on a stage (or in any space). We might add to this that in solo performance as it developed in the latter half of the twentieth century, the single body increasingly performed in a piece authored and/or choreographed and/or staged and/or designed by that single body." 5 Ramsay Burt concurs, noting that solo modern dance is distinctive for performers' use of "dance material that is created on and by themselves." 6 In her introduction to an edited collection on solo dance, On Stage Alone, Claudia Gitleman reminds readers of the centrality of the solo artist to the development of modern dance, including the canonical figures Loïe Fuller, Isadora Duncan, Ruth St. Denis, and Maud Allan-female performers who all achieved notoriety as solo performers.7 At least in the late 20th and early 21 st centuries, there is an understanding that a solo is not only a performance given by an individual, but that the performance has been authored by that individual. A solo performance is thus different from a dramatic soliloquy or balletic variation in that solo performance is fundamentally an expression of self rather than an interpretation of a role.

With its emphasis on the self, an argument can certainly be made for the solo form as an unabashedly egomaniacal endeavor, but with Trisha Brown's death earlier this year, we are also reminded of her solo dances, with and without camera, and the ways she challenged the reduction of the solo to an individual ego. In particular, Johnathan Demme's 1986 film of the 1979 piece Accumulation with Talking Plus Watermotor undoes any quick assertion of the solo giving aesthetic form to the self as a priori. This film was deeply influential for both Harmony and Simon, as well as the larger screendance field. The dance itself was an intellectual feat, combining Brown's fluid motion with the challenge of alternating between two choreographies and talking at the same time. The film is warm and familiar, welcoming the viewer into Brown's studio space while also unraveling the mythic functions of both the studio and the screen. Demme's camera undermines the studio as a sacred space of creation and refuses to mask the apparatuses of filmmaking which appear in the frame. More interesting for this editorial, however, is the surprise of dancers quietly entering the space and watching Brown, and how their entering and watching becomes another kind of performance for camera. Brown may be the only one who is dancing, and her dancing may conventionally be called a solo, but Deeme's film begs the question"Does one really dance alone in a solo?"8

In La danse en solo: Une figure singulière de la modernité, a volume collating talks from a 2001 symposium of the same name at the Centre National de la Danse in France, the authors repeatedly remark upon a paradox within solo performance. The solo performer may be dancing by themselves, but at the same time, they are never alone: 
the solo is a representation of the world (Ropa), a creation of the world (Monnier and Nancy), multiple (Pradier), and collective (Schneider).9 "There is no solo in itself," declares Jean-Marie Pradier.10 The solo is a synecdoche. For Schneider, the solo is a "becoming ensemble" — not a totality, but a togetherness manifested through "citing other work, co-opting other work, creating an action by acting or reacting, enacting or re-enacting, making of the single body a stage across which whole histories (the multitudes) are brought to bear." 11

The possibility of solos as multitudes resonates with screendance practices, where the relationship between camera and dancer already multiplies the self on screen (as Hetty Blades argues in this volume), as well as the prominent method of practice-asresearch, which encourages a depth of practice achieved through reaching from the self toward society. Practice-as-research is an increasingly common approach to conducting research in the UK, Australia, Canada, New Zealand, and Europe, and is growing in the United States. A key principle of the method is critical self-reflection (questioning one's own practice) and such reflection is built into iterations of artistic practice. At its best, this critical attitude makes possible new processes and ways of understanding that extend beyond the artist-researcher's personal curiosity. At its worst, it produces solipsistic work existing within a bubble of self-importance such as Kalb critiques above. Though practice-as-research is full of creative and intellectual possibility, limited resources for postgraduate and postdoctoral artist-researchers that enforce small scale-and often solo-projects exacerbates any tendencies toward self-indulgence.

Regardless of the conditions of the development of artistic work within or outside of the academy, when producing solo work (or work that is some kind of negotiation with the self), the question remains: how does this version or understanding of the self contribute to-or change-how we understand others, or even ourselves in relation to others?

The question is most exciting when artists (or people not even identifying as artists) are making films, working quickly and unselfconsciously with readily available hardware and software technologies. Australian student Anastassia Krstevska's 17-second film (originally posted to Facebook ${ }_{12}$ ) When old men tell me to smile more, I scowl so hard my scowl melts off my face to produce another scowl which melts off my face to produce art $t_{13}$ gets to the heart of the self on film. She seems to be saying, "Here I am, this is me, and then this is me as well, and well, here I am again showing you all just how much of me there is." It's laced with humor and irony, and while openly political it carries energy and hope that elevate it beyond cynicism.

London dance-artist Ellie Sikorski's Wonderful Woman ${ }_{14}$ displays a similarly playful attitude to the self. In the film/music video Sikorski's replications of her nonchalant, cool self are deliciously lazy. It is bare-bones film-making, and her confidence and 
willingness to perform a kind of corporeal disengagement or boredom while the edit is screaming "Here I am" is both absurd and generous.

Of course neither Krstevska nor Sikorski are making screendances narrowly construed, but their work (and play) is delicately choreographic in its sensitivity to rhythm, space, time, and image. Perhaps their lack of interest in categories or nomenclature in order "to produce art" reveals a politics of identity and self that resists singularities. It is a dizzying politics in which we are each finding our way own in relation to social technologies, screens, and the moving image.

The articles, provocations, and interviews in this volume likewise present the solo as a paradoxical vehicle for expressing an artistic identity or self that opens onto political questions of identity and belonging, and philosophical questions of space, time, movement, and perception.

Anna Macdonald opens this volumes with a meditation on that ultimate act undertaken alone: death. She focuses on a temporal suspension of progress in the ways bodies onscreen can seemingly move without going anywhere. She draws upon the Hollywood musical Singin' in the Rain (1952) and her own work Walk (2016), made in the wake of her mother's death, to explore what she calls moving stillness. Both films offer viewers an intensified now, a temporality of an extreme, distilled, or thick present that collapses past and future, thereby inhibiting progress, which Macdonald likens to the Kairos of death. Comparing her own solo film with Gene Kelly's exuberant solo dancing, Macdonald suggests that film's ability to blur the distinction between motion and cessation of motion is consolidated in screendance's specific relationships to a moving body in time.

Kyle Bukhari takes us in a different direction with his analysis of Yvonne Rainer's film Hand Movie (1966) and Richard Serra's film Hand Catching Lead (1968) - two virtuosic examples of solo performance for screen. Bukhari is interested in how these films point to a movement of media. Both films take the artist as the presumed subject of the film and concentrate the artists' identities not in their faces, as might be expected in the solo performance genre, but in their hands and the activities their hands undertake in self-exploration (Rainer) or action (Serra). Bukhari uses these films to think through each artist's aesthetic migration from one artistic medium to another. Rainer hailed from dance, Serra from sculpture. Both found a pivot-point in film that allowed them to test the boundaries of their own disciplines and to explore alternate avenues for advancing choreographic and sculptural ideas.

John White focuses more on the solo viewer (voyeur) than solo performer in his articulation of screen-based intimacies and the camera as a tool of surveillance in Katrina McPherson's film The Truth. The way a camera can bring a dancer into proximity to a viewer holds promise for White, in that the relationship, along with the rhythmic aspects of editing, can foster empathy on the part of the viewer. White is 
interested in the entanglements of intimacy with surveillance, however, and finds that a camera tracking dancers' bodies and particularly the use of close-ups can amplify emotional connection by placing the viewer in the position of voyeur. Like Bukhari, White draws attention to the ways the dancers' bodies are framed so as to emphasize body parts and trajectories over the coherence of identity. But for White, the surveillance-style approach used in The Truth creates the sense of a private show for an individual viewer.

Like Bukhari, Ariadne Mikou focuses on intermediality in her consideration of the impacts of built environments on film projection and mobile spectatorship. In some of the filmed components of her project of performance-architecture there is a goggled solo presence on screen, circling, round and round, looking down some kind of rabbit hole, watching us-the audience-reconfigure the space. It is her interest in the spaces between audiences and choreographic materials that provokes her suggestion that-like choreography_screendance is an expanded field.

In our Provocations and Viewpoints section, Hetty Blades looks at Polly Hudson's Viser-al (2015) and Jonathan Burrows, Matteo Fargion, and Hugo Glendinning's 52 Portraits (2016) through the lens of the self-portrait, and asks us to consider how selfrepresentation is problematized through the mix of authorial voices in the collaborative work of filmmaking. Cara Hagan likewise draws our attention to representation through the visual politics of dance onscreen. She reflects on the American Dance Festival's series Movies by Movers, which she curates, and documents demographic trends in what is submitted and subsequently screened at this festival. Tracie Mitchell provides us with the tour of dance online for this volume. She narrates her own explorations as an artist while pulling out works that were particularly influential to the development of her own practice.

Anna Heighway has interviewed Rosemary Lee, and Rosemary Candelario has interview Eiko Otake for this issue. Both interviews offer perspective into the artists' work and collaboration with others. Heighway and Lee discuss the intense visuality of Lee's work, particularly the film Liquid Gold is the Air (2014), and Candelario and Eiko examine the intricacies of a collaborative artistic life and Eiko's recent forays into solo work with A Body in Places (2014-17).

Four reviews in this volume give readers an opportunity to further consider how artists, curators, and scholars are currently shaping the field of screendance. MarieLouise Crawley reflects on the 2015 online danceworkbook from The Pew Center for Arts and Heritage, A Steady Pulse: Restaging Lucinda Childs, 1963-78. Katja Vaghi reviews the 2016 Oxford Handbook of Screendance Studies edited by Douglas Rosenberg. Carol Breen examines the 2015 bilingual publication Art in Motion: Current Research in Screendance edited by Franck Boulégue and Marisa C. Hayes. And Harmony Bench 
reviews the 2017 New York City Dance on Camera Festival in its 45th year of screening dances for camera.

We encourage readers to consider the stakes and politics of dancing alone, and the contexts in which such dancing occurs. What kinds of relationships do solo performances establish between self and society? How do solo performances reflect artists' political orientations? When is solo performance a creative strategy borne of economic necessity, or of representational politics? Who gets to dance alone and who is forced to? And if solo performers are not alone even when they dance by themselves, who (or what) constitutes their silent collaborators, their co-conspirators, their witnesses, their audiences? Who decides whether solo performance is defiant or indulgent? And what is the place of the screen in solo performance? By what procedures does the screen facilitate opening a self onto the world? As it becomes increasingly common for individuals to turn their cameras on themselves and post the results for the world to see online, what can screendance offer to the theorization of self and screen?

With long-standing screendance festivals and a growing body of literature, the screendance field is at an exciting moment in its own evolution. Thanks to video sharing on the internet, dance onscreen is becoming less of an exception and more of a rule. Screendance scholarship is manifesting the need and desire for an international conversation more attentive to screen practices outside a dominant white EuroAmerican norm. We are therefore happy to announce that Volume 9 of the International Journal of Screendance will be guest-edited by Melissa Blanco Borelli (Royal Holloway University of London) and Raquel Monroe (Columbia College Chicago) on the theme Screening the Skin: Issues of Race and Nation in Screendance. Volume 9 will be published in Spring 2018.

Finally, we'd like to thank the many individuals who have helped put this issue together: Claire Ridge at C-DaRE, and to our assistant editor Carol Breen also at CDaRE. Thanks also to our Reviews Editor Tamara Tomić-Vajagić, and to Maureen Walsh and The Ohio State University for their ongoing commitments to IJSD's digital platform and distribution.

\section{Biographies}

Harmony Bench is Assistant Professor of Dance at The Ohio State University, where she is affiliated faculty with Theatre; Women's, Gender, and Sexuality Studies; and Translational Data Analytics. She co-edits The International Journal of Screendance with Simon Ellis. She is currently working on a database of early 20th century touring dance 
companies and, with Kate Elswit, exploring the touring and travel of choreographer Katherine Dunham. These projects in progress can be found at Movement on the Move.

Email: bench.9@osu.edu

Website: http://www.harmonybench.com

Simon Ellis is a choreographer, dancer, film-maker, dramaturge and teacher. He is from New Zealand but now lives in London, and is a Senior Research Fellow at the Centre for Dance Research at Coventry University. He is particularly interested in the limits and possibilities of collaboration in choreographic processes.

Email: simonkellis@gmail.com

Website: http://www.skellis.info

\section{Notes}

1 "International Journal of Screendance Volume 8: Call for Papers."

2 Holly Hughes and David Román, "O Solo Homo," 2.

3 Johnathan Kalb, "Documentary Solo Performance," 14.

4 Hughes and Román, 1.

${ }_{5}$ Rebecca Schneider, "Solo Solo Solo," 32.

6 Ramsay Burt, "Alone into the World," 34-35.

7 See Claudia Gitleman, "Introduction."

8 "Danse-t-on vraiment seul dans un solo?" Remy Bernard, "Solos-Multitudes," 37.

Translation Bench's.

9 See La danse en solo.

10 "Il n'y a pas de solo en soi." Jean-Marie Pradier, "Les Multiples du Un," 64. Translation Bench's.

${ }_{11}$ Schneider, 40-41.

12 Krstevska's Facebook post can be found here.

13 See "Diva."

${ }_{14}$ See "Wonderful Woman." 


\section{References}

Burt, Ramsay. "Alone into the World: Reflections on Solos from 1919 by Vaslav Nijinksy and Mary Wigman." In Claudia Gitelman and Barbara Palfy (Eds.) On Stage Alone:

Soloists and the Modern Dance Canon. Gainesville: University Press of Florida, 2012. 31-54. https://doi.org/10.5744/florida/9780813040257.003.0003

“Diva.” Dir. Anastassia Krstevska. YouTube. May 31, 2017.

https://www.youtube.com/watch?v=hQBmOgB9d9c

Gitelman, Claudia. "Introduction." In Claudia Gitelman and Barbara Palfy (Eds.) On Stage Alone: Soloists and the Modern Dance Canon. Gainesville: University Press of Florida, 2012. 1-6. https://doi.org/10.5744/florida/9780813040257.003.0001

Hughes, Holly and David Román. "O Solo Homo: An Introductory Conversation." In Holly Hughes and David Román (Eds.) O Solo Homo: The New Queer Performance. New York: Grove Press, 1998. 1-15.

"International Journal of Screendance Volume 8: Call for Papers." Centre for Screendance. May 17, 2016.

https://screendance.wordpress.com/2016/05/17/international-journal-ofscreendance-volume-8-call-for-papers/

Kalb, Jonathan. "Documentary Solo Performance: The Politics of the Mirrored Self." Theater 31.3 (Fall 2001): 13-29. https://doi.org/10.1215/01610775-31-3-13

La Danse en Solo: Une Figure Singulière de la Modernité. Claire Rousier (Ed.) Paris: Centre National de la Danse, 2012.

Pradier, Jean-Marie. "Les Multiples du Un." In Claire Rousier (Ed.) La Danse en Solo: Une Figure Singulière de la Modernité. Paris: Centre National de la Danse, 2012. 63-76.

Rémy, Bernard. "Solos-Multitudes." In Claire Rousier (Ed.) La Danse en Solo: Une Figure Singulière de la Modernité. Paris: Centre National de la Danse, 2012. 37-49.

Schneider, Rebecca. "Solo Solo Solo." In Gavin Butt (Ed.) After Criticism: New Responses to Art and Performance. Oxford: Blackwell, 2005. 23-47.

https://doi.org/10.1002/9780470774243.ch1

“Wonderful Woman." Dir. Eleanor Sikorski. 2017. YouTube.

https://www.youtube.com/watch?v=qYJ3I-TJU1g 
ARTICLES 



\title{
Going Nowhere: Screendance and the Time of Dying
}

Anna Macdonald, Manchester Metropolitan University

\begin{abstract}
This article considers a particular temporality-referred to as a state of moving stillness-within two different events: the screendance body that moves without appearing to get anywhere, and the dying body that moves but is not moving to anywhere. It focuses on Singin' in the Rain (1952) directed by Kelly and Donen and a practice as research screendance project, made by the author, entitled Walk (2016). By placing events from art and life together here, alongside contemporary philosophies of temporality, the article works to illuminate something of the complex relationship between movement, time, and progression in each one, throwing light on the role that art, and screendance in particular, can play in our relationship to mortality.
\end{abstract}

Keywords: screendance, time, dying, Deleuze, Singin' in the Rain, Walk

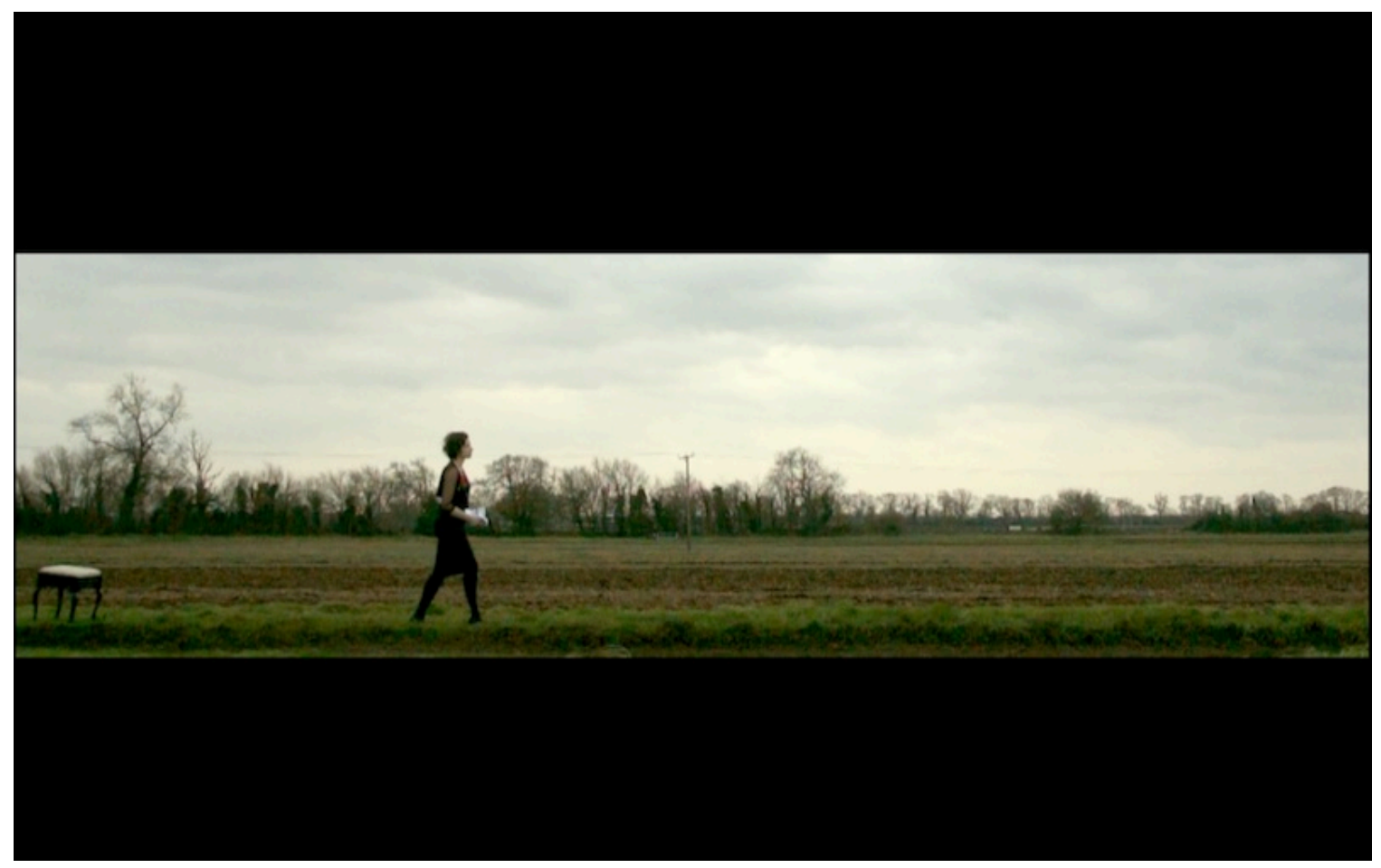

Walk (film still), Credit: Anna Macdonald 
As Sherril Dodds points out in her discussion of the body onscreen, the screendance body is one that carefully constructs, and is constructed through, time.1 It therefore offers a useful model for thinking through time in the living body, not as a homogenous given, but as a variable state operating in different ways during different parts of our lives. In this writing, I consider a particular temporality-that I call a state of moving stillness-within two different events: the screendance body that moves without appearing to get anywhere, and the dying body that moves but is not moving to anywhere. Placing these two events from art and life together here, alongside contemporary philosophies of temporality, works to illuminate something of the complex relationship between movement, time, and progression in each one, and has the potential to throw some light on the role that art, and screendance in particular, plays in our relationship to mortality.

Movement and stillness are the fundamental forms of life and death and as such, as Sutil and Melo point out when writing about the relationship of visual media and temporality, form the foundations of philosophical conceptions of time reaching from Plato to Deleuze.2 It is not an achievable or desired aim to track these complex philosophical trajectories here. Instead I refer to a broad shift from stillness to movement within philosophical thought, which Kappenberg identifies as being significant to filmic constructions of time. Kappenberg describes this as a move "from classic philosophy that believed in the eternal order of things, to a new, modern philosophy based on the idea of mobility, the new, and the singular." 3 This shift is described further by Brannigan (after Bergson and Deleuze) as a move from time as a series of spatialized, immobile instants (stillness) and time as one of undifferentiated and constant flow (movement).4

This temporal distinction between movement and stillness has been mined in the psychoanalytically underpinned work of film writers such as Mulvey and Doane, in their exploration of the spectre of still images within the forward moving apparatus of film.5 Movement and stillness is also, arguably, the starting point of all dance and is focused on in the psychoanalytically and phenomenologically informed work of writers such as Phelan and Horton Fraleigh amongst many others.6 This article, however, focuses on the possibility of a state that operates between these polarized positions of movement and stillness, a moving stillness as it were, as a way of understanding both screendance and dying as a state of in-between, distinct from that of life or death.7 As such this article considers what certain examples of screendance might add to that which Røssaak refers to as "a turn to the in-between" (orig. emphasis) in the field of stillness and motion studies.8

The focus of this paper emerged when I heard the philosopher Alphonso Lingis talking at a conference in 2015 and he described the time of dying as, "the time that goes nowhere, not even into nothingness." 9 There is a curious tension between movement and stillness, as well as space and time, in this evocative description of dying. At the 
time that I heard Lingis speak, my mother was dying and I was struck by how his thinking connected with my experience of her dying. For what I had imagined was a natural or instinctive event seemed in fact to be a confusing process, where distinctions between movement, stillness, life, and death were strangely unclear. Huge labor was demanded from everyone involved and no small part of this involved the struggle to work out, how we could move forwards when there were no next steps? How could we progress to nowhere?

Film theorist Justin Remes offers the "Cinema of Stasis," 10 with its emphasis on scenes that offer little or no easily perceived change, such as Michael Snow's seminal 1967 work Wavelength, as an example of moving stillness in film.11 Here we can see stillness defined, not as an absence of movement but rather, resonating with Lingis' description of dying, in terms of an absence of progression. I am a dance and movingimage artist and my research into the relationship between movement, progression, and time within screendance began with the making of Walk 12 three months after my mother's death. My practice works both as a way of thinking through experience and embodying ideas, falling under the broad ambit of what Smith and Dean refer to as performative research 13 and I reflect here on the findings of Walk alongside another, rather more famous, dance for the screen called Singin' in the Rain.14

While it might be rather surprising to look at such disparate works in the context of dying, there are two key reasons for doing so. The first is that both works offer a distinct "aestheticization of time" 15 that invites comparison with the first temporal frame I draw on here, which is that of Deleuze's distinction between images that create movement and images that create stillness.16 The second reason is that these films have a particular temporal relationship to my mother's time of dying, for one occupies the shared space of our past and the other a singular point in the, as it was then, future. The co-presence of both (as memory and projection) in this time therefore offers an interesting echo of the second key conceptualization of time that I draw on, which is philosopher Gary Peters' identification of the time of dying as an "intensified now" that draws the future and past into the present.17

I begin by exploring the idea of moving to somewhere, in relation to filmic constructions of linearity framed by and in relation to Deleuze's movement image with its causal sensory-motor schema.18 I focus here on the continuity editing of Singin' in the Rain and the horizontal framing of Walk's singular, static shot. Next I look at movement that does not appear to get anywhere. This section makes reference to Deleuze's "interval," a time that hovers between the 'has been' and the 'not yet,' which Brannigan, Hayes, and Kappenberg all cite in their examination of time and movement in screendance. 19 Within this discussion I look first at movement that does not arrive anywhere, focusing on the jump cuts in Walk. Then I explore movement that does not go to anywhere, movement that has the potential to offer a sense of permanence and 
reliability, with reference to the physical and compositional acts of centering and balance in both works.

The final section, drawing on the work of palliative care specialist Ana Mendes, employs the image of a 'plateau' to articulate the sense of moving stillness that was so central to my experience of the time of my mother's dying. Here I describe a shift from Chronos (quantitative time) to Kairos (qualitative time) in the time before death, 20 and explore how this experience resonates with the temporality of both films. This leads to a final discussion of movement that is not about moving forwards (to the next step) but is rather about bringing the past and future into one temporal event combining both movement and stillness. Here, as mentioned above, I draw on Peters' philosophical consideration of the time of dying as one where the person dying consolidates a sense of themselves for the other through a condensing of past and future in a 'thickened' present. From this I consider the temporality of screendance, with its particular combination of movement and stillness, as a "structure of consolidation," a structure that is able to carry something of the lost event forward in time.21

\section{Going somewhere: 'I walk down the Lane'}

There is a sense of movement in Lingis' description of dying as "the time that goes nowhere" for here time is still 'going' and has not yet stopped.22 But this is a strange form of movement for it is a movement with no trajectory, movement that does not go anywhere. Moving to nowhere jars with bodily and cultural associations of movement with spatial/metaphorical progression. For when we need to solve a problem we ask, 'how can we move this forward?' When things happen, we ask, 'what now, what next?'-terms that imply the intrinsic possibility of a linear sense of progression. In fact, it can feel impossible to even conceive of moving to stillness such is the strong relationship between movement and the act of thought itself. As visual artist and theorist Yve Lomax writes, "[h]ow can I think stillness such that the movement of my thinking is not brought to a halt? (Would such a cessation be the death of me?)." 23

Part of the desire to move forwards is to leave, or move on from, the situation you are in, even if it means that it will end. As the psychoanalyst Caroline Garland writes "[a]ll pain comes from living ... and [t] he wish to avoid that pain, to end the struggle, can become very powerful." 24 Another factor, in a culture where capitalism and Chronos (clock time) combine is that our achievements are often measured in terms of what we have done with 'our time' and, as Mendes notes, a sense of impotentiality can arise when little time remains or there is a sense that little can be 'done.' 25 Related to this is the strong desire for affective action, or indeed any action that might counteract the sense of a contingent universe, as revealed through crisis. 
Early on in my mother's illness there was comfort to be found in the feeling of doing or 'going somewhere next' created by the "rational metaphysics" of the patterns and percentages of medical knowledge.26 For example, in a trial information leaflet my mother was given it said, 'over the course of your trial we will take seventy tablespoons of blood' and we were reassured at this stage by the thought of still having seventy spoons to go. The spatialized time of the medical diagrams and protocols created trajectories into the future. Lomax connects this spatialized time, this emphasis on Chronos, with processes of "controlling time and calculating security," 27 and for my mother and I these structures created a sense of order that worked to offset the sense of contingency that terminal illness evoked.

As we were counting spoons my mother and I often watched films together that we had watched before such as, Singin' in the Rain, a film musical made in 1952 starring the actor, director, and choreographer Gene Kelly. I write here about its most famous routine, which comes after the leading man has fallen in love and chooses to dance for pure joy in the rain. After kissing his new love goodnight, Kelly tells his driver to leave. He starts to walk home under his umbrella and then closes it, giving in to his joy and beginning to dance on the sidewalk and then in the road itself. All the while the rain falls heavily onto him filling up the already large puddles on the ground.

The spatial framing of Kelly within this sequence, and the way its different shots are put together, appear to embody entirely what Hayes refers to as "the human desire to move forwards in time and space." 28 One example of this is found in the sense of progression generated by its editing. There are only six cuts in the entire sequence most of which move, from stillness to action and close-up to long-shot. They maintain the spatial and temporal flow of the activity, working to punctuate the end of one action before the beginning of another. This continuity editing creates a sense of time as a continuous flow of events emphasizing, what Mulvey calls the "[l]inearity, causality and the ... unfolding, forward-moving direction of film." 29 It creates a sense of time and space as a unified whole, as if we were in the street with Kelly watching him dance.

In Kelly's dance we see movement that is going somewhere rather than nowhere, for instead of leaving the frame Kelly appears to simply step from one frame to another. The edits spatialize and construct time according to narrative logic in a way that resonates with what Deleuze calls the sensory-motor schema of action-a form of the movement image that he identifies as operating within classical cinema-where time is constructed and perceived through action. The edits generate a sense of movement from here to there and in doing so reassure us that this will lead to that. They follow the temporal logic of what Herzog (after Deleuze) calls "the action of narrative, of cause and effect, of rationality." 30 Although not sharing the same narrative demand as film musicals, as Sutil and Melo note, 31 this sensory-motor logic is arguably just as prevalent in contemporary screendance editing. For example, in edited sequences 
from influential works such as McPherson's There is a Place 32 despite the inclusion of overtly spatially and temporally distinct movement, a sense of forward trajectory is generated by the movement-based logic of force, flow, and response that hold them together. 33

The causal reassurance of Singin' in the Rain's edits is echoed in its carefully constructed choreographic structures that set up future trajectories as one step leads to another (a point I return to later). We are left in no doubt that counts five and six will lead to seven and eight, there are no hesitations to remind us of our mortality, and all is well with the world. As Peters writes, projections that are "confirmed in the now make manifest a deeply harmonious temporality that, within the dominant aesthetic of the West, is experienced as pleasure." 34 Kelly is so certain about the world, and his place at the center of it, he even teases us by preparing to jump off the curb into a huge puddle before changing his mind, evoking a small fear, a nice fear, like throwing a child up in the air and catching them again.

\section{https://vimeo.com/155039926}

Causal forms are also found in Walk, which is shot around the corner from where my mother used to live on a Fenland lane in East Anglia that I have walked, run, and cycled down thousands of times. Walk consists of a single, wide shot of this dark flat landscape; a black frame at the top and bottom of the screen emphasizes the horizontality of the shot. In it I am wearing a black dress and holding some papers and I sit at the left edge of the shot on a piano stool. After a while I stand and walk along the field, in some difficulty due to wearing heeled shoes, towards to the other end of the frame. The horizontal frame of its single shot coupled with the horizontal movement of the walk, work to create what film theorist Jacob Potempski describes as a "threshold of expectation." ${ }_{35}$ I move from left to right, from one edge of the frame to the other following a traditional-and irreversible-arrow of time which echoes the linear drive of film itself, where one image erases another as it leads to the next.

A piano stool marks the start of my walk and at the other end there is an edge waiting for me, a step to nowhere, just outside of the frame that remains in shot at all times.36 Looking back at this work now, I feel this visible end point both as a threat and something that creates a future trajectory that shapes and holds my movement within clear parameters. This resonates for me with the time right at the end of my mother's life, when the future space created by her trial had failed; but the sense of having somewhere to go next was re-created by the reassurance (and threat) of a place in a hospice. Peggy Phelan, writing about her experience of the grey time between life and death during her partner's terminal illness, suggests that there is a physical and metaphorical need for movement in order "to transform the act of dying into the fact of death." ${ }_{37}$ We all knew that the journey to the hospice would be too difficult but, 
perhaps, this visible end-point was a way of metaphorically conceptualizing the movement needed, according to Phelan, to move towards stillness.

I wonder whether if the urge for progression is held by external structures, even if these structures move us further towards the end of the film or the end of our lives, then people can get on with not going anywhere. In this light, the still predictability of Deleuze's sensory motor schema allows, conversely, for time to be experienced qualitatively rather than quantitatively. I have thought elsewhere about the role the psychoanalytic notion of holding might play in this but for now to speak it would be something like, 'I have somewhere to go to next so I can be easier being where I am.' 38 This process can be found, perhaps, in Walk where its clear spatial trajectory with no other actions, other than walking from one edge of the screen to the other, allows the viewer to focus on the action of walking itself, rather than on where the walker is going. Because of the fixed parameters of the frame I imagine Walk to be an instance of, what Loy refers to as event time, where "the time of an activity is integral to the activity itself." 39 Here the walk in question will take as long as it takes to complete responding to the schema of my body, as opposed to being subsidiary to an external time structure such as Kelly's rhythmic counts.

\section{Not going anywhere: 'Just singing and dancing in the rain'}

\section{(Not arriving)}

How does one move to nowhere? According to Lingis, the answer to this is the act of dance for he writes that "one goes somewhere to dance in order to move without getting anywhere." 40 Here Lingis appears to equate progression with the realisation of aims for he goes on to say that the "dancing the body-Axis is not orientated upon tasks and does not posit objectives." 41 A discussion of intentionality and movement is beyond the scope of this article, however, as Lingis himself notes, he is referring to recreational dancers rather than professionals who generally, even if working in improvised contexts, will have very clear intentions that they aim to realise. In Walk, for example, my physical score was to walk roughly twenty steps along the field before turning round to look back at my starting point. In the film, however, this aim is never realised as it continually jump-cuts back to earlier points in the trajectory and I am returned to the piano stool to begin the walk again. I move but do not get to anywhere. I never leave the frame and neither do I let go of the papers I am holding. The edit does not progress forwards in time and this does not lead to that, but rather back to this again. Even the apparent cut to a close-up reveals itself only to be a cut to a grainy expanded version of the original shot, rather than a progression to another point in time. In instances such as this, as film theorist Carl Wall writes, "[t]he sensorymotor link is broken and action becomes irrelevant. Movement no longer 'measures' time [as in Chronos] but is folded into time," an idea I will return to.42 
In a sense, Walk operates like a long animated GIF_-small loops made of a series of constantly repeating images taken out of their original sequential context.43 In Walk the walker keeps on moving towards a future that continually eludes her. She is in what Lomax describes, with reference to the Deleuzian concept of the interval (a form of the time image), as a place between "what is 'no longer' and what is 'not yet,"' 44 where all is moving but moving infinitely rather than moving to somewhere. It is this combination of movement and stillness, a moving stillness that I am drawn to here as a way of understanding my experience of the in-between space, the interstices of dying that I did not know existed before I encountered it.

(Not leaving)

Mendes describes the time of dying as "[t]he dimension of time where eternity can be touched in the here-and-now." ${ }_{45}$ Considering the possibility of a sense of permanence, within the context of immanent loss is interesting when considered in light of Lingis' movement to nowhere. For although his assertion implies that the dying person is leaving, there is an equally present sense of permanence in his statement for if one is 'moving to nowhere' then one is also not going anywhere. Indeed, these are the very words I use to reassure my children when they ask me whether I am going to die. "Don't worry," I say, "I'm not going anywhere." To return to Singin' in the Rain, until the dance number ends Kelly is also not going anywhere. For as each edit comes he simply steps from one frame to another, moving without leaving us for a moment. Despite the forward motion of the film, Kelly's movement never appears to get him anywhere. He moves but he moves nowhere, staying resolutely in the middle of the frame as the camera relentlessly tracks him through the space. Even when the camera pulls back and up to reveal the studio 'street' Kelly remains central-just dancing in a wider frame. The central framing throws attention on the form of his movement rather than its trajectory through space, in a way that I find reminiscent of the event time of Walk.

But of course Kelly's character does move, so what do I mean here by it feels as if he doesn't? Lingis writes of the indeterminacy of the body when he describes it as being "always on the verge of departing, about to move, to fall." 46 Here he alludes to the strong association between life, movement, and contingency. In Singin' in the Rain Kelly's body does not look indeterminate, it looks determinate, secure, predictable; we know where he is going and we trust that he will not fall. In this sense it creates a feeling of stillness. For example, watching Kelly dance is like watching the bubble in a spirit level. His centered form echoes his position in the center of the screen and he seems unable to be off-balance. His low center of gravity is accentuated by the horizontal pathways of his movement, his near-constant plié accentuating his relationship to the earth. The rain does not appear to make the pavement slippery and interestingly, there is no wind to accompany the rain, as it falls directly down, not once blowing into Kelly's face. The only reference to imbalance we see is when Kelly 
pretends to wobble his way along the curb, towards the end of the sequence, only to suavely balance on one leg directly afterwards.

There is considerable movement of the camera in this sequence but again, this movement tracks Kelly through space reinforcing a feeling of pattern, intention, a god, or at the very least a director, which reduces the sense of movement as an embodiment of contingency or liveness. Here we know exactly what we need to look at and all other life is not our concern as Kelly dances. This lack of progression is comforting and disturbing for Kelly is both a man at the center of the universe (a universe with a still, eternal order of things perhaps) and a butterfly moving just enough within the frame to avoid looking as if he is pinned to the wall.

Unlike the movement in Singin' in the Rain where part of the joy of the movement is the way it appears to transcend contingency, in Walk I am interested in the emotional affect of the contingent movement in the work. It was shot in a place that was emotionally significant rather than easy to film in, I was there on my own, it was freezing, and there happened to be a storm. As a result I struggle to maintain my balance, as I negotiate the uneven grass under my feet and the high buffeting winds. Looking back, despite the spirit level like horizontality of the shot, this movement has a vulnerability that I did not realize I was experiencing at the time. The film shares the compressed spatial centrality of Singin' in the Rain but here the dancer is framed within a static shot, the dead eye of the static camera drawing attention to itself as machine. This is the single static shot, where the camera appears to simply point at the world, that Doane describes as being the embodiment of contingency.47 As I have mentioned, in Walk there is an edge of the frame that the dancer can leave, fall out of or exit through. Unlike Kelly, whose edges and limits are constantly moved around him so that his movement appears limitless, here the constant possibility of an ending or exit remains clear.

\section{Plateaus and acts of consolidation}

As my mother's health declined, and the idea of death intensified, my sense of time changed and I began to experience each moment more as a horizontal landscape rather than a step on a linear descent. Each stage had a strangely reassuring sense of permanence, and we occupied it as if we were not going anywhere, as if we would stay there forever. As we ran out of time our experience began to feel more timeless. I was eight, it was after her death, I was twenty and I was also there in that moment. Mendes writes that during the end of life "one's commitment to Chronos (clock time) lessens and one seeks Kairos (lived time) and may begin to see time running backward as well as forward, with life spread out as on a landscape." 48 Later, I remembered thinking about a stabilizing image from Alexander technique, of a landscape running across my sternum as I walked to the front of the church at the funeral and later across the field in the film. 
These horizontal plateaus towards the end of my mother's life created a peculiar feeling that past and future were balanced in both directions, creating a place for us to rest in-between. They were both moving and still. Looking back, I now feel this place resonating with Deleuze's interval as a place of "becoming [which] never stops where it is but always goes in two directions at once." 49 I also recognise connections between Deleuze's interval and Mendes' articulation of a sense of time moving forwards and backwards in the time of dying. Both images are potentially alive in the flat, Fen landscape in Walk that gives the impression of going on unendingly beyond the frame in both directions. I also see them in the strange 'already there already' feel of the centered world of Singin' in the Rain, where we see no sky and have no sense of where the rain comes from as it falls heavily into puddles that are already full.

The image of a horizontal plateau, like Kelly's dancing perhaps, has a sense of balance to it that offers no gradient, and therefore no pull towards the next step. However, balance is a form of stillness that is only achieved through constant responsive movement, and the experience of being in these plateaued temporal states, although peaceful, was one of great intensity rather than effortless flow. It was more resonant of the twenty-four hour pumps that are required for the flat, calm of the reclaimed Fens to be maintained and the complex and intense effort needed to remain balanced, concealed or otherwise, within both dancers' movement. For as Peters writes, when we are facing imminent death there is an "intensification of internal time consciousness" where the retention of the past and future into the present produce a "complex (and singular) knot of loss, gain, regret and hope."

Peters' image of intensified temporal compression before death, of time being drawn in rather than flowing out, as the Deleuzian image of the interval suggests, feels closer to my experience of this time. This drawing in is present in the state of Kairos, the "supreme moment," which Mendes in her description of immanent death articulates as "[e]verything that you are, you must be it now." ${ }_{51}$ I suggest that both screendances evoke this sense of singular effort, of bringing everything to one moment, not least through showing the whole body of the dancer onscreen for the majority of the work, a choice that is relatively unusual in contemporary screendance. In Walk, we see the woman's entire body small and overtly heroic against the wide landscape.52 In Singin' in the Rain we see Kelly bring his whole body to a life-affirming moment of joy, and as his whole body smiles it is hard for me not to smile back.

However, screendance, like film - with their ability to be shot and re-shot-can offer "a distorted sense of effort" and continuity edits can cut out the "dead" time that must be endured in its entirety during the lived time of dying. 53 As Peters goes on to note, the temporal intensity of the time of dying is "only practicable in the short term" and the difficulty in life of course is that Chronos and Kairos must co-exist.54 Looking back I wonder about a less heroic version of the film in which I stop my walk to answer emails and get some washing done. During the time of my mother's dying we all longed for 
chronological certainty because we needed to know how long we needed to be supreme for?

(Not going anywhere)

For Bergson, time, in the sense of pure duration as opposed to spatialized time, "is change or it is nothing at all." ${ }_{55}$ If all is change then this raises the question of what if anything can be relied upon or carried beyond the present moment, a question that becomes more pressing in the time of dying. This question also forms the basis of what philosopher Daniel W. Smith identifies as the two key trajectories of contemporary philosophy that I began with, that of transcendence and immanence.56 A significant difference between Deleuze's interval in film and Mendes' articulation of a sense of time moving forwards and backwards in the time of dying, as Lomax is quick to assert, is that Deleuze rejects any notion of eternity for "when you invoke something transcendent you arrest movement." ${ }_{77}$ And yet there was a sense of 'forever' in the moments near to my mother's death that seemed to transcend time but not at the expense of us being in time together. We were in life but we were 'still' and time passed without leading anywhere. I wonder now whether the sense of transcendence I experienced here emerged, not from being outside of the present moment, but rather precisely from the in-timeness of a shared sense of time with another. Time shared in this time before death seemed to create a pool of time that we could rest in.

Peters argues that the fear of the effect of their immanent loss, on the one left behind, "compels the dying to consolidate their lives." 58 Hence the person who is dying often tries to retain the future and present within the present time of dying in order to create a "substantiality that both assuages and intensifies fear, as memory and loss, presence and absence respectively." 59 He calls this temporal summing up a "structure of consolidation" for the one that remains.60 Now, when I watch Walk and Singin' in the Rain, I sense something permanent, that moves through time with me and I can rely on. A structure of consolidation, perhaps, which is both moving and still. This is partially to do with the layers of memories that each film accumulates with each viewing, for although each film remains bound to their time of production, I (and the way I see) continue to move forward in time. This is true of all films however. What is particular to screendance though, and the specific examples I discuss here, is that they allow me to return not simply to movement but to dance, as an already consolidated moment of time.

Rosenberg writes that "screendance is predicated on the erasure of live performance's linearity and temporality." ${ }_{11}$ However, from a phenomenological perspective, arguably dance is a form of movement that, even as it emerges within it, already exists beyond a simple temporal linearity. For example, Horton Fraleigh writes that 
[w] hen I consider the unrepeatability of my life in relation to the near repeatability of a dance I have learned ... I see how my dance marks time. It marks time because it leaves a mark, a momentary mark, mar and wound. My dance marks time and signs it with my being.62

In this Horton Fraleigh indicates that dance, as a form of movement that can be returned to, has the capacity to remain both in and through time. Horton Fraleigh's description is reminiscent of Mark Johnson's phenomenological notion of bodily 'schema,' which he describes as ways of being or physical patterns of experience that are both long known and immediately experienced, both moving and still.63 Movements that are performed in the present but offer something that goes beyond that moment, drawing the past and future into the present.

I see examples of Johnson's movement schema in the symmetry and clarity of Kelly's patterns of movements that begin, peak and end in ways that feel both immediate and long known. Kelly's dance resembles a classical ballet with its sights, as Horton Fraleigh writes, "set beyond everyday existence and painful realities" but this is combined with an emphasis on the ground, on presence, and on noise. 64 His dance is both still and moving, performed by and yet transcending the transient body with its irregularities, and unplanned movement, just as love conquers the rain. The act of walking also embodies this dual temporality as each step brings the past with it and informs the next. Walking offers a space of interstices; a point of falling between past and future as the weight shifts forwards and simultaneously remains in the center. As I walked to the front of the church and along the field, I was both there, in every other step I had taken before this and also taking my place in a line reaching into the future. I watched my daughter watching me walk to the front of the church and much later I thought of schema forming and repeating and things moving without changing.

If, in dying, we bring the past and future into the present to give a consolidated whole to the other then this consolidation, perhaps, is not simply a "snapshot of a multiplicity" as Bergson would have it.65 It is not a reduction of time to space or of movement to stillness. It is a process that offers a sense of the movement, or life, of that person that remains after they have gone just as much screendance offers a consolidation of movement, movement schema perhaps, rather than aiming "to record moments arbitrarily stolen from the performance." ${ }_{66}$ The temporality of moving stillness is true of any dance perhaps, but screendance, unlike live dance, holds up the body in time, rather than creating a still picture of a body in a time, for us to experience again. In this sense screendance can be said to offer a structure of consolidation, like that that can occur in the time of dying, for it holds still a moment of moving time that can go beyond the time of its showing. 


\section{Biography}

Anna Macdonald is a moving image artist and scholar from the UK. She specialises in working directly with the public, finding ways to intensify and articulate people's experiences in ways that can be understood by others. Influenced by Mark Johnson's (2008) notion of bodily 'schema,' she is interested in using film to expose the emotional and conceptual resonance of simple actions such as, moving from 'here to there', 'unfolding' or 'getting slower'. Anna's work has been shown at galleries and festivals such as Athens Video dance project, Muestra Movimiento Audiovisual, Mexico, Home, Manchester, Art Currents, New York, Somerset House, London, Lightmoves, Ireland, Dascamdans, Belgium, Miden Festival, Greece, and VideodanzaBA, Argentina, and was nominated for the International Video Dance awards in Barcelona. Her work was selected as a flagship project for AHRC funded research into socially engaged art and she has published several articles about the body, time, and film.

Email:a.macdonald@mmu.ac.uk Website: http://annamacdonaldart.co.uk

\section{Notes}

1) Sherril Dodds, Dance on Screen, 33

2 Sebastián Melo and Nicolás Salazar Sutil, "Exposed to Time," 144.

${ }_{3}$ Claudia Kappenberg, "An Interdisciplinary Reading," 187.

${ }_{4}$ Erin Brannigan, Dancefilm, 26.

5 Laura Mulvey, Death 24x a Second; Mary Ann Doane, The Emergence of Cinematic Time. ${ }_{6}$ Peggy Phelan, "Trisha Brown's Orfeo," Sandra Horton Fraleigh, Dance and the Lived Body.

7 I have looked elsewhere at the idea of a moving stillness concerning the temporality of grief in an article called "Things that start slowly."

8 Eivind Røssaak, Between Stillness and Motion, 14.

9 Alphonso Lingis, speaking at Risk and Regulation: Arts and Medical Humanities Conference, Dartington Hall, Falmouth, June 2015.

10 Justin Remes, Motion(less) Pictures, 11.

11 Wavelength involves a static camera shot of a loft room where the camera continuously zooms forwards over 45 minutes.

12 Walk, Macdonald.

${ }_{13}$ Smith and Dean, Practice-led Research, 6.

${ }_{14}$ Singin' in the Rain, Donen and Kelly 
15 Inma Alvarez, "Time as a strand of the dance medium," 10.

${ }_{16}$ Gilles Deleuze, Cinema 1, and Cinema 2.

17 Gary Peters, "Time to Die," 224.

18 Deleuze, Cinema 1, 155.

19 See Brannigan, Dancefilm; Marisa Hayes, "Brief thoughts," and Kappenberg, "An Interdisciplinary Reading."

20 Anna Mendes, "The Time that Remains," 166.

${ }_{21}$ Peters, 224.

22 Lingis, The Community, 178-179.

23 Yve Lomax, "Thinking Stillness," 55.

${ }_{24}$ Caroline Garland, Understanding Trauma, 25.

25 Mendes, 166.

26 Robert Mackay, The Medium of Contingency, 1.

27 Lomax, "Thinking Stillness," 56.

28 Hayes, "Brief thoughts," n.p.

29 Mulvey, Death 24x a Second, 69.

зо Amy Herzog, "Images of Thought and Acts of Creation," 4.

31 Melo and Sutil, 161.

32 There is a Place, McPherson.

${ }_{33}$ Pearlman, Cutting Rhythms, 52.

${ }_{34}$ Peters, 5.

35 Jacob Potempski, "Revisiting Michael Snow's Wavelength," 10.

$36 \mathrm{I} \mathrm{am}$ aware here of the resonance this has with Heidegger's subject as it "looks ahead to its own death" (Brent Adkins, Death and Desire, 6).

37 Phelan, 17.

38 Anna Macdonald, "Holding and Curation," 53.

${ }_{39}$ David Loy, "Saving Time," 275.

40 Lingis, "Bodies that Touch Us," 164.

41 lbid.

42 Thomas Carl Wall, "The Time-Image," 2.

${ }_{43}$ Hayes, n.p.

44 Lomax, 30.

45 Mendes, 166.

46 Lingis, "Bodies that Touch Us," 166.

47 Doane, The Emergence of Cinematic Time, 140.

48 Mendes, 165.

49 Lomax, 60.

${ }_{50}$ Peters, 10.

51 Mendes, 166.

52 Michele Aaron notes "the spectre of heroism, grandeur or ineffability" that often accompanies films about dying. Death and the Moving Image, 158.

${ }_{53}$ Dodds, 34. 
${ }_{54}$ Peters, 14.

${ }_{55}$ Richard Rushton, Cinema After Deleuze, 5.

${ }_{56}$ Daniel Smith, "Deleuze and Derrida," 123.

57 Deleuze quoted in Lomax 55.

${ }_{58}$ Peters, 17.

$59 \mathrm{lbid}$.

60 Idem, 13.

${ }_{61}$ Rosenberg, Inscribing the Ephemeral Image, 28.

62 Horton Fraleigh, Dancing Identity, 146.

63 Johnson, The Meaning of the Body.

${ }_{64}$ Horton Fraleigh, Dance and the Lived Body, xxxv.

${ }_{65}$ Melo and Sutil, 152.

66 Idem, 159.

\section{References}

Aaron, Michele. Death and the Moving Image: Ideology, Iconography and I. Edinburgh: Edinburgh University Press, 2015.

Adkins, Brent. Death and Desire in Hegel, Heidegger and Deleuze. Edinburgh: Edinburgh University Press, 2007.

Alvarez, Inma. "Time as a strand of the dance medium." Proceedings of the IV Mediterranean Congress of Aesthetics, Art and Time (22-25 Jun 2008), Irbid: Yarmouk University (2009): 1-15.

Brannigan, Erin. Dancefilm: Choreography and the Moving Image. New York: Oxford University Press, 2011. http://dx.doi.org/10.1093/acprof:oso/9780195367232.001.0001

Deleuze, Gilles. Cinema 1: The Movement Image. Trans. Barbara Habberjam and Hugh Tomlinson. Minneapolis: University of Minnesota Press, 1986.

Deleuze, Gilles. Cinema 2: The Time Image. Trans. Robert Galeta and Hugh Tomlinson. Minneapolis: University of Minnesota Press, 1989.

Doane, Mary Ann. The Emergence of Cinematic Time: Modernity, Contingency, the Archive. Cambridge: Harvard University Press, 2002.

Dodds, Sherril. Dance on Screen: Genres and Media from Hollywood to Experimental Art. London: Palgrave, 2001. http://dx.doi.org/10.1057/9780230509580 
Garland, Caroline. Understanding Trauma: A Psychoanalytical Approach. London: H Karnac Books, 2002.

Hayes, Marisa. "Brief thoughts on the Art of the Animated GIF." Screendance Studies: Art in Motion. Posted 17th April 2016.

https://screendancestudies.wordpress.com/2016/04/08/brief-thoughts-on-the-art-ofthe-animated-gif/

Herzog, Amy. "Images of Thought and Acts of Creation: Deleuze, Bergson, and the Question of Cinema." Invisible Culture: An electronic Journal for Visual Studies 3 (2000): 119. http://www.rochester.edu/in_visible_culture/issue3/herzog.htm

Horton Fraleigh, Sondra. Dance and the Lived Body: A Descriptive Aesthetics. Pittsburgh: University of Pittsburgh Press, 1987.

----. Dancing Identity: Metaphysics in Motion. Pittsburgh: University of Pittsburgh Press, 2007.

Johnson, Mark. The Meaning of the Body: Aesthetics of Human Understanding. Chicago: University of Chicago Press, 2007.

Kappenberg, Claudia. "An Interdisciplinary Reading of the Film Entr'Acte." In Douglas Rosenberg (Ed.) The Oxford Handbook of Screendance Studies. New York: Oxford University Press. 2016. 187-204.

Lingis, Alphonso. "Bodies that Touch Us." Thesis Eleven 36.1 (1993): 159-167. http://dx.doi.org/10.1177/072551369303600111

----. The Community of Those Who Have Nothing in Common. Bloomington and Indianapolis: Indiana University Press, 1994.

Lomax, Yve. "Thinking Stillness." Stillness and Time: Photography and the Moving Image. Eds. David Green and Joanna Lowry. Brighton: Photoworks and Photoforum, 2006. 5563.

Loy, David. "Saving time: a Buddhist perspective on the end." Timespace: Geographies of Temporality. Eds. John May and Nigel Thrift. London: Routledge, 2001. 262-280.

Macdonald, Anna. "Things that start slowly." Body, Space, \& Technology Journal 11:2 (2013): 1-14. http://people.brunel.ac.uk/bst/vol1102/annamacdonald/home.html

Macdonald, Anna. "Editing I will not hope." Choreographic Practices Journal 4:2 (2013): 189-203. http://dx.doi.org/10.1386/chor.4.2.189_1

Macdonald, Anna. "Holding and Curation." Repertório: Teatro \& Dança 27 (2017): 49-58. https://portalseer.ufba.br/index.php/revteatro/article/view/20611/13297 
Mackay, Robert. The Medium of Contingency. London: Urbanomic and Ridinghouse, 2011.

Melo, Sebastián and Nicolás Salazar Sutil. "Exposed to Time: Cross-Histories of Human Motion Visualisation from Chrono- to Dynamophotography." In Douglas Rosenberg (Ed.) The Oxford Handbook of Screendance Studies. New York: Oxford University Press. 2016. 143-165.

Mendes, Anna. "The Time that Remains: Self-identity and temporality in cancer and other life-threatening illnesses and in Messianic experience." Palliative and Supportive Care 12 (2014): 165-168. https://doi.org/10.1017/S1478951512000922

Mulvey, Laura. Death 24x a Second: Stillness and the Moving Image. London: Reaktion Books, 2006.

Pearlman, Karen. Cutting Rhythms: Shaping the Film Edit. Burlington, MA: Focal Press, 2009.

Peters, Gary. "Time to Die: The Temporality of Death and the Philosophy of Singularity." In Andrew Fagan (Ed.) Making Sense of Dying and Death Vol 1. Amsterdam: Rodopi Press, 2004.

Phelan, Peggy. "Trisha Brown's Orfeo: Two Takes on Double Endings." In André Lepecki (Ed.) Of the Presence of the Body: Essays on Dance and Performance Theory. Middleton: Wesleyan University Press, 2004. 13-28.

Potemski, Jacob. "Revisiting Michael Snow's Wavelength, after Deleuze's Time-Image." Film and Media Studies 6 (2013): 7-17.

Remes, Justin. Motion(less) Picture: The Cinema of Stasis. New York: Columbia University Press, 2015.

Rosenberg, Douglas. Inscribing the Ephemeral Image. New York: Oxford University Press, 2012.

Røssaak, Eivind. Between Stillness and Motion: Film, Photography, Algorithms. Amsterdam: Amsterdam University Press, 2011.

Rushton, Richard. Cinema After Deleuze. London: Continuum, 2012.

Singin' in the Rain. Dir. Stanley Donen and Gene Kelly. 1952. Film.

Smith, Hazel and Roger Dean. Practice-led Research, Research-led Practice in the Creative Arts. Edinburgh: Edinburgh University Press, 2009. 
Smith, Daniel. "Deleuze and Derrida, Immanence and Transcendence: Two Directions in Recent French Thought." Contemporary Philosophy 11 (2007): 123-130.

There is a Place. Dir. Katrina McPherson. 2011. Film.

Walk. Dir. Anna Macdonald. https://vimeo.com/155039926 2016. Film.

Wall, Thomas Carl. "The Time-Image: Deleuze, Cinema, and Perhaps Language." FilmPhilosophy Journal 8:23 (2004) http://www.film-philosophy.com/vol8-2004/n23wall.

Wavelength. Dir. Michael Snow. 1967. Film.

West-Pavlov, Russell. Temporalities. London: Routledge, 2013. 


\title{
Intimate Encounters: Screendance and Surveillance
}

\author{
John White, University of Edinburgh
}

\begin{abstract}
This article explores some ways in which screendance might invite a greater or deeper degree of kinesthetic empathy than is traditionally possible with live performance. In particular, the use of the close-up and the creation of editing rhythms are two strategies that extend screendance viewers' kinesthetic empathy into a more intimate relationship with the dance(rs). Furthermore, this article analyzes Katrina McPherson's screendance The Truth as a case study in which this intimate viewing relationship is characterized by a kind of voyeurism shared with the act of viewing surveillance. I draw on some surveillance theory and artist Jill Magid's piece Evidence Locker in order to explore the surveillance aspects of The Truth.
\end{abstract}

Keywords: screendance, surveillance, kinesthetic empathy, voyeurism

In this writing I argue that the use of surveillance-style footage in Katrina McPherson's screendance The Truth reveals how a certain voyeurism characterizes viewing patterns of screendance more generally. Specifically, I argue that screendance's camera and editing techniques bring viewers into a more intimate spectator relationship than is possible when viewing live performance and that these techniques simultaneously position viewers as voyeurs. The camera in screendance makes possible for viewers a space of intimacy in which, like with surveillance and surveillance-style footage, it conveys intimate information about the dance(rs) through images that appeal to the viewers' imaginations. Intimacy as I mean it here operates on two levels: the (sense of) proximity between spectator and dance( $r$ ) often enabled by the camera, and the deeper empathic relationship that I focus on in this article.

My use of the term "intimacy" is largely tied up with the much-theorized concept of kinesthetic empathy, which describes how spectators viewing human movements do not simply watch but also feel them in their bodies and minds. 1 In Susan Leigh Foster's words, "The viewer, watching a dance, is literally dancing along." 2 While kinesthetic empathy has been analyzed extensively in dance and film, there are fewer instances of critical or scholarly work devoted to understanding kinesthetic empathy in dance that is made for the camera.3 I will look at how the camera extends notions of kinesthetic empathy as it pertains to live dance by virtue of the camera's ability to bring viewers into the space of the dance(rs), to focus viewers' attention on specific body parts and sounds, and to encourage a potentially deep empathic connection between viewer 
and performer that is inflected with the voyeuristic dimensions of contemporary surveillance. I choose the word intimacy because these forms of relating, by way of the camera, to the bodies in screendance go beyond kinesthetic empathy. As I will discuss later, kinesthetic empathy more typically refers to an affective, embodied response, particularly with regards to live performance. Intimacy as I mean it refers to a range of responses that are more cognitive and abstract, but nonetheless oftentimes embodied.

First, I will summarize some of screendance's techniques-about which McPherson and other scholars have written-to establish the intimate form of spectatorial access that is made possible in screendance by the movement of the camera and its proximity to dancers' bodies, as well as by editing rhythms.4 Second, I will look at three scenes in The Truth to demonstrate how the surveillance-style footage interspersed throughout the work reveals the ways in which screendance more generally acts as its own form of surveillance that hooks viewers by offering voyeuristic glimpses of closeup details of the dance(rs). Last, I will discuss the artwork Evidence Locker by Jill Magid to show how surveillance space can enact and even encourage an emotional connection between the viewer and the viewed. It is this sense of connection that, on top of the physical intimacy enabled by the camera, takes viewers of much screendance work, not just of The Truth, into the realm of emotional intimacy with the performers. In my experience of watching screendance it is this intimacy via the closeup camera that makes the act of viewing much screendance work so compelling. Drawing on the work of Dee Reynolds and Matthew Reason, screendance scholar Karen Wood writes that "kinesthetic response may be the foundation to spectators' motivations for watching dance and the pleasure gained from the experience." 5 I would extend this statement further to propose that the intimate kinesthetic response heightened by the camera may be the foundation to some spectators' motivations for watching screendance.

\section{The Choreographed Camera}

In this section I focus on how the choreographed camera as a mediating mechanism between viewer and performer complicates and extends notions of kinesthetic empathy as they have been theorized in relation to watching live dance.6 McPherson has written extensively about how she and other screendance practitioners manipulate the capabilities of the camera as a means of drawing viewers into their work.7 Two methods that I will look at here in relation to The Truth are the ability of the close-up to bring viewers into the dancers' kinesthetic spaces and the careful creation of editing rhythms that permit viewers themselves to feel both the dancers' movements and the screendance creators' responses to those same movements.

Foster, in tracing the origins of kinesthetic empathy as a term, writes that empathy "has been variously conceptualized in relation to physical experience." 8 Indeed, 
Reynolds writes that kinesthetic empathy is best understood in terms of affect rather than emotion. 9 She describes affect as embodied, as "a stage where emotions are still in the process of forming," and as "that point at which the body is activated, 'excited,' in the process of responding." 10 She further distinguishes affect and historical concepts of empathy that emphasized dynamism and inner movement from the cognitive dimensions of emotion.11 Both Foster and Reynolds, however, analyze kinesthetic empathy exclusively in relation to live performance. For example, Reynolds writes about how, as viewers, we can often be "uncertain where to focus our gaze" when watching dance.12 Do we follow an individual or the movements of the overall group of dancers?

With screendance's (sometimes very liberal) use of the close-up, options for where viewers focus their gaze within the larger dance-and on the dancers' bodies-are narrowed significantly. For example, in one scene of The Truth the camera pans slowly down a dancer's suspended arm as she lets the force of gravity move it in slow circles. In another scene, the camera zeroes in on the slight shaking of a tensed, outstretched hand-a tiny, not even necessarily choreographed movement detail that would not be as readily visible to a spectator in a conventional theater. According to Marcia $\mathrm{B}$. Siegel, early versions of televised dance recordings typically used wide, static shots as a means of "simulating the audience's view of dance in the theater" (she writes that close-ups were seen as "treacherous").13 However, McPherson argues that the strength of screendance lies in harnessing the capabilities of the camera, such as using it to get up close. Specifically, McPherson has explained how the choreographed camera can "enter the dancers' kinespheres - the personal space around them that moves with them as they dance-focusing on a detail of movement and allowing an intimacy that would be unattainable in a live performance context" (my emphasis). 14 In this scenario, the dancer and the camera act as "mutual performers," a relationship in which the mediums of dance and film do not serve or impede but rather complement one another. 15

In her book Dancefilm: Choreography and the Moving Image, Erin Brannigan devotes an entire chapter to the close-up. Brannigan looks to the writings of Béla Balázs and Gilles Deleuze to show the ways in which the close-up in cinema has been theorized largely in relation to the face. According to Deleuze, "it is the face, with its relative immobility and its receptive organs, which brings to light ... movements of expression while they remain most frequently buried in the rest of the body." ${ }_{16}$ But Brannigan argues that "[d]ance involves a bodily expressivity that attributes to the body what is usually given to the face: expression, intensity, feeling," 17 and she points to the work of postmodern choreographer Trisha Brown for an example of the "non-hierarchical dancing body" 18 that choreographically gives equal weight and importance to all body parts and all kinds of movement. 
McPherson and editor Simon Fildes give equal visual weight and importance to various body parts in The Truth. McPherson's directing and Fildes' editing do not preference any single area of-or approach to-the dancers' bodies. In fact, the dancers' faces are often cropped out of the frames entirely. Instead, The Truth shows an interest in the "smaller detailed movements of the body and its parts," such as the aforementioned shaking hand, that Brannigan terms "decentralized microchoreographies." ${ }_{19}$ By frequently showing the moving bodies in The Truth as torsos, legs, etc. isolated from the other body parts that initiate or carry a corresponding aspect of the movement, McPherson and Fildes focus viewers' attention on the ways in which specific physical sites commence, continue, or complete micro-movements of the choreography. They draw viewers in close to the expressive qualities of an encircling arm, a swiveling pelvis, or a sharp intake of breath. The Truth invites viewers to attribute to a close-up shot of a shaking hand what they might usually project onto the face: an expression of strain, a feeling of nervousness. By such strategies, screendance and its intervention of the camera encourage a more affective and close form of kinesthetic empathy with individual dancers. Though she does not write particularly about the close-up, Wood agrees that "[w]atching film can allow the spectator to look more closely at the movement, permitting a more detailed and intimate gaze at the action on the screen and therefore engaging with emotional expression." 20

It is not just strategies during recording that can deepen viewers' kinesthetic empathy with the screendance, but also rhythms and textures achieved during the editing process. McPherson includes a chapter in her instructional book Making Video Dance on "The Choreography of the Edit," or post-production strategies that continue and compound the effects of the choreographed camera. McPherson suggests that individuals making screendance cut from one clip to another before the movement is completed so that "the viewer will finish off the movement in their mind's eye." 21 Relatedly, Foster writes of Ivar Hagendoorn's argument that viewers of a live dance performance "do not simply decide where or what to watch, but instead, create versions of the dance as it unfolds in time before them." 22 Viewers "think up the movement and decide how and where the dancer should move next," like the choreographer before them has done.23 The fact that McPherson suggests specifically exploiting this tendency in viewers and inviting them to imaginatively complete the depicted movement, rather than showing them its completion, as a technique of screendance demonstrates an intention to strategically engage and intrigue viewers by appealing to more cognitive responses.

Screendance theoretician Karen Pearlman writes how editors of all films, not just dance films, have an embodied reaction to the material they edit. In addition to kinesthetic empathy-which she describes as "feeling with movement" (original emphasis) - she uses in her analysis the term "corporeal imagination," by which "the 
body ... imagines in relation to its own experience, drawing on remembered sensations to recognize feeling in movement." 24 According to Pearlman, when looking at filmed material, editors do not just notice when a performer blinks or breathes but also imitate it. The editor "[draws] on their own experiences of the rhythms of, for example, blinking" and in this way "uses their ... kinesthetic empathy to relay the external rhythms, which they perceive in the developing edits, through their internal rhythms, to create the rhythm of the film" (original emphasis).25 Wood, though she does not draw on Pearlman, writes that for viewers in turn "[e]mbodied engagement and kinesthetic response is therefore affected by ... participation in a rhythm external to that of our own body, which in this case is the rhythm of a film." 26

Screendance practitioners engage viewers in an embodied response to their work that is made that much more powerful by the fact that the work is imbued with its creators' own embodied responses. Pearlman writes that kinesthetic empathy happens for viewers of films as well as for viewers of live performance, but "[t]he difference is that, in cinema, the actor's breath rhythms have passed through the hands, or perhaps the lungs, of the editor." 27 The same goes for The Truth - its dancers' breaths and movements and the bodies of McPherson and Fildes. It is easy to imagine that, rather than randomly ordering the clips that make up The Truth or editing it in a manner that maintains its original continuity, McPherson and Fildes instead edited the screendance by playing off of their own kinesthetic associations with various potential sequences of clips in order to ensure a greater likelihood that viewers feel kinesthetic empathy with the resulting work.

In The Truth McPherson often repeats the same clip several times, even back-to-back with itself. While such repetition can produce a wide variety of responses in viewers, such as even causing them to lose interest, it is possible that the repetition produces or strengthens kinesthetic empathy for viewers. McPherson and Fildes also overlay clips with sound that is different from the clips' original sync sound so that, for example, the sound of a particularly compelling exhalation may coincide with a release in a dancer's movement, thereby (artificially) heightening the drama of the mo(ve)ment. Coupled with the camera's ability to bring the viewer right up into the movement and the breath, these editing strategies have the potential to draw in the viewer more powerfully than in live choreography typically seen from further away. Pearlman's proposition that viewers' empathic responses to a screendance may be conditioned, even to some degree prescribed, by the empathic responses of the work's editors complicates Foster and Reynolds' concepts of kinesthetic empathy.28 Whereas with Reynolds' kinesthetic empathy viewers of live dance have an affective response in which "the body is ... in the process of responding" and "emotions are still in the process of forming," 29 viewers of screendance, by way of the editors' alreadyplayed-out kinesthetic responses to the material, may in the moment of watching engage on a deeper emotional level. Such instantaneous responses are difficult to 
assess or measure; however, in my own experience of watching screendance I have felt my sense of amusement, sympathy, or joy in response to a movement or my sense of connection to, even desire for, a dancer heightened by camera techniques.

\section{A Voyeur's Window}

The Truth intersperses dance scenes with surveillance-style footage taken in a public station. Seen side-by-side with the surveillance-style footage, the dance scenes function effectively as a kind of surveillance through which viewers voyeuristically observe the dance(rs). I have drawn my understanding of voyeurism largely from scholar Clay Calvert's concept of "mediated voyeurism" that he argues dominates contemporary culture and that he defines (in short) as "the consumption of revealing images of and information about others' apparently real and unguarded lives ... frequently at the expense of privacy and discourse" (my emphasis).30 In The Truth, viewers consume revealing images of and information about performers, not unsuspecting people going about their everyday lives. However, the screendance manipulates the aesthetics of surveillance as a means of setting up viewers to feel as though they are watching unsuspecting, anonymous people. It is for this reason that I will here apply surveillance theory to a work that does not make use of actual surveillance but nonetheless positions viewers to relate to its subjects within surveillance space.

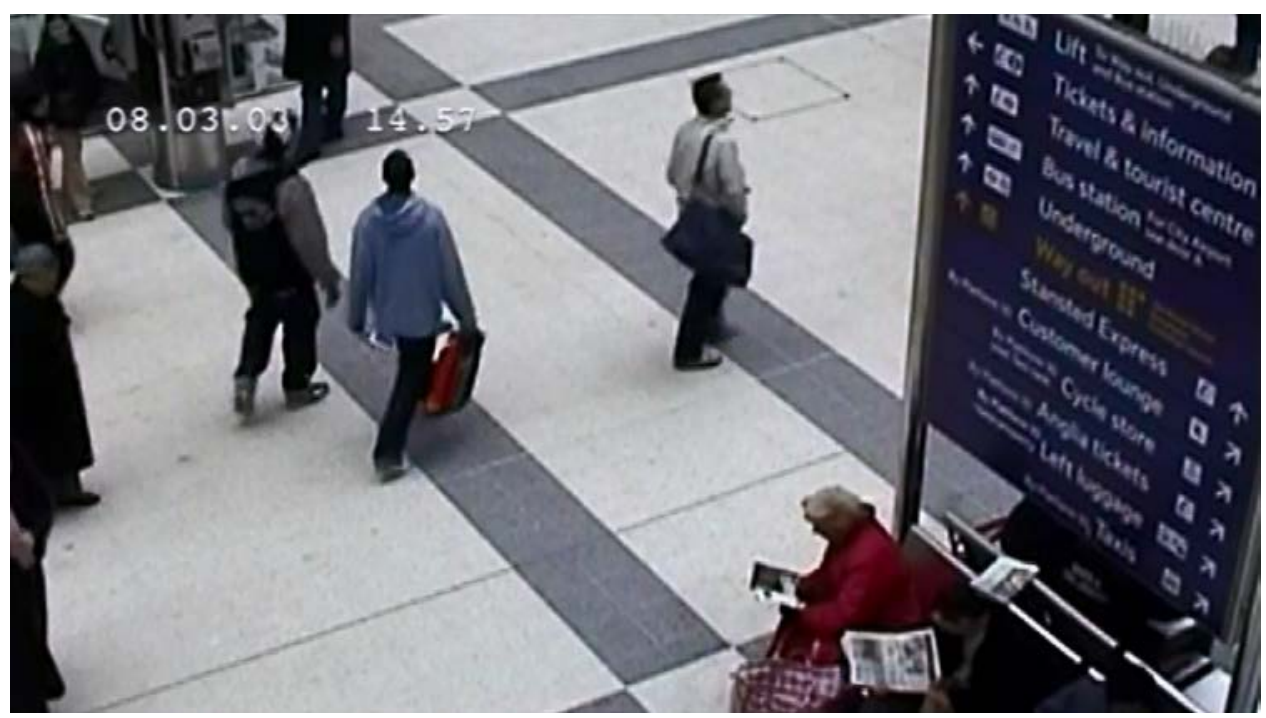

Screenshot. The Truth 
The project was framed from its outset as an investigation into how, according to Fildes, the truth of a situation is dependent on the context in which someone is given visual information, or how the truth of any situation is nebulous, changing, and subjective. 31 The screendance opens with a first clip of surveillance-style footage. The camera is positioned above the station crowd and is stationary. The footage is grainy and is time- and date-stamped in the top left corner.

There is no sound from the station. After anonymous members of the crowd are surveilled for a while, the camera singles out the work's four performers-Karin FisherPotisk, Kate Gowar, Matthew Morris, and Robert Tannion-walking through the station. One minute into the work, the footage changes from a frozen, zoomed-in shot of one of the men (Tannion) after he has placed a coffee cup on the ground to higherquality, non-surveillance-style video of him with the same clothing repeating the action. This time he carries out the action in a closed-off, white-walled room where he is alone.

The surveillance aspect of The Truth was envisioned specifically with CCTV (closedcircuit television) in mind. Robert Knifton writes that there is a greater proportion of surveillance cameras to population in the UK than anywhere else in the world and that the UK accounts for one-fifth of the global CCTV market.32 Statements like David Lyon's that "to participate in modern society is to be under electronic surveillance" ${ }_{33}$ are therefore important to a project conceived and sited in the UK. Surveillance is so widespread that John McGrath has argued that it is "turning the whole of life into a public performance," that it "puts life on show." 34

As viewers of The Truth come to know the people in the initial zoomed-in, frozen shots as dancers, subsequent surveillance footage thereby suggests not only that their movements in the station are choreographed but also that the movements and behavior in which we all engage in public, surveilled space is, whether or not we are conscious of it, choreographed by those who are watching. This no longer includes just bystanders whose gaze we may think we feel on us but, more importantly, city planners, governmental bodies, and intelligence agencies. In Knifton's words, "CCTV is a key aspect in the ... re-imaging of our cities since it allows those with social control to define what is ordinary behavior and to spatially express this normativity through the asymmetry of power the cameras give them." ${ }_{35}$ Using the city of Liverpool as a case study, Knifton gives surveillance in the criminalization of the homeless and skateboarders as examples of this "spatial cleansing" and "defining [of] acceptable bodily conduct in public." 36

In Hard Core, her seminal study of pornography, Linda Williams writes that cinema normalized so-called perversions like fetishism and voyeurism as "technological and social 'ways of seeing." 37 She writes that, "[a]s a result, viewers gradually came to expect that seeing human bodies in motion in the better way afforded by cinema [as 
opposed to the naked eye] would include these perverse pleasures as a matter of course." ${ }_{38}$ Relatedly, Maciej Ożóg writes that surveillance is so prevalent today that "voyeurism and exhibitionism are not only justified ... but they also become desirable and normal, not to say necessary forms of behavior in the mass media society." ${ }_{9}$ While neither of these quotes deals directly with screendance, they speak to the degree to which voyeurism is so often encoded in many peoples' relationships to images of moving bodies (sometimes problematically). The mere reproducibility and familiarity of the style of surveillance footage that permit the station scenes in The Truth to be read as such show how commonly the visuals of surveillance and voyeurism proliferate in our day-to-day lives, whether it be in the form of peeking into celebrities' lives via reality television, watching police footage on the news, or seeing one's self appear on the CCTV screen in a gas station or corner store. While this makes the pseudo-surveillance images in The Truth not unusual in and of themselves, the fact that the images are constructed to appear as surveillance affects how the work is perceived. Specifically, the 'surveillance' in The Truth engenders a voyeuristic intimacy between viewers and dance(rs) that characterizes the act of viewing the whole work, not just the surveillance-style scenes.

An important aspect of this voyeuristic intimacy in The Truth has to do with the work's blurring of private and public space. Lyon writes that "today [privacy] is tightly tied to avoiding surveillance." 40 Whenever The Truth switches to non-surveillance recordings, the higher quality, rhythmic editing, and movement capabilities of the choreographed camera that differentiate it from the surveillance camera and create a sense of spectatorial intimacy are compounded by the spatial move from the Liverpool Street Station to the more private-seeming rooms in which the dancers dance. Not only do the white-walled spaces (in their emptiness and closed-off seclusion) suggest the viewer is receiving a degree of exclusive access, but so does the choreography performed in those spaces. No longer being observed in the very public station, the dancers move more freely and uninhibited. They also move in ways that retroactively detail their relationships as observed in the station. A surveillance-style scene shows one of the women (Fisher-Potisk) walking together and acting familiarly with one of the men (Morris) as though he is a travel partner or friend. Then, in the scene that follows (the first in which all four dancers dance together), the two hold each other closely. 


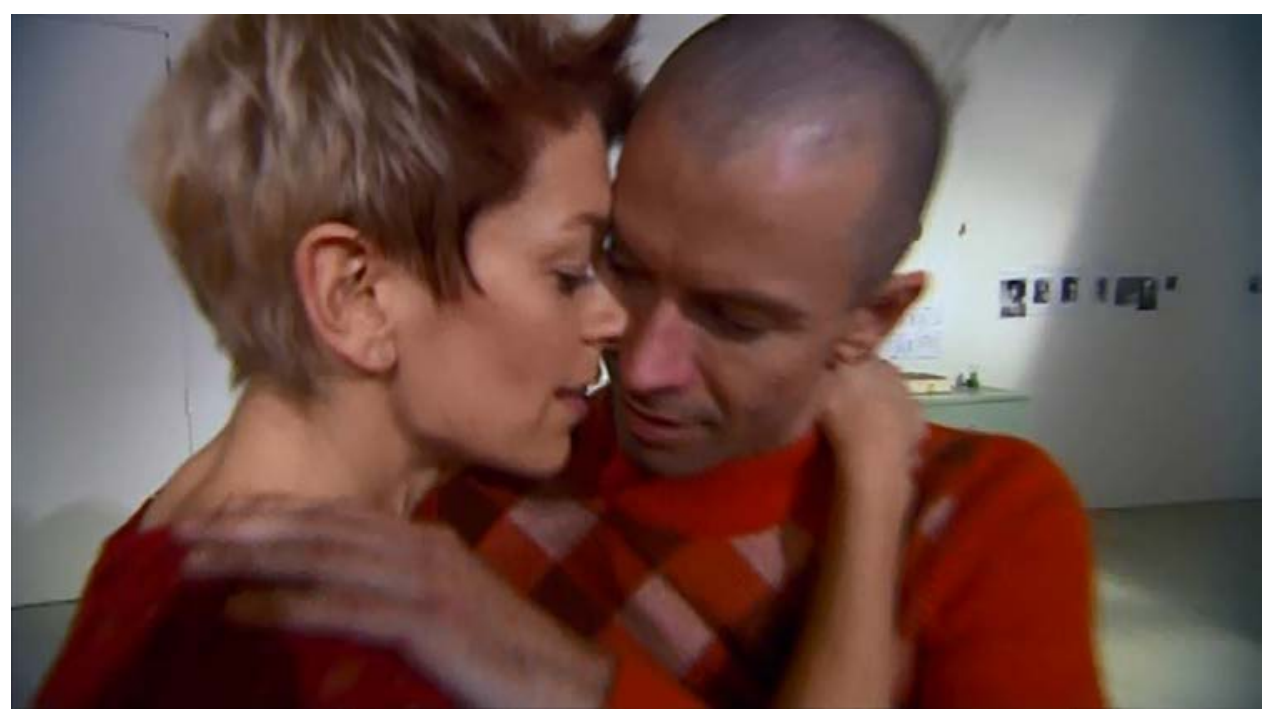

Screenshot. Karin Fisher-Potisk and Matthew Morris performing in The Truth

The embrace marks a move towards increased physical intimacy between the performers, and I notice while watching that I in turn feel closer to them. Whereas Morris and Fisher-Potisk laugh and share a parting hug in the station, they now reveal a perhaps more amorous dimension to their relationship. Later in the work FisherPotisk takes off her shirt so that she is in just a bra, and the man with whom she dances (now Tannion) takes off his trousers. They hold each other closely, as do the other two dancers (who have also taken off their trousers). This is another suggestion that the space is a private one, one in which couples can feel more open to express human intimacy. 41

Though these quiet moments between men and women align in a very traditional, heteronormative sense with Lyon's statement that "the private has usually been associated with the domestic," 42 they represent a set of behaviors (public displays of affection) that many people today increasingly feel free to carry out in very much nonprivate places.43 More importantly, the white-walled spaces featured in the nonsurveillance-style video are actually public. The scenes were filmed in an extension of Victoria Miro Gallery in London and a factory-turned-artists'-space in Dalston, a district in northeast London.44 They are locations that are heavily surveilled or are indicative of, in the case of the former, institutions that monitor people visiting their exhibitions and, in the case of the latter, workplaces that record the comings and goings of visitors.

The 'non-surveillance' scenes are sited in buildings that (even to viewers unaware of the real identities of the locations) suggest by their white walls their moneyed, highsecurity status. Therefore, although transitions from surveillance-style footage to nonsurveillance-style footage indicate a move from public to privatized space, the whole screendance constitutes a kind of surveillance. Early in the work, the initial station 
images and the subsequent video of Tannion dancing alone in a room are seen playing on a small, blueish screen behind Morris as he dances in the scene that follows.

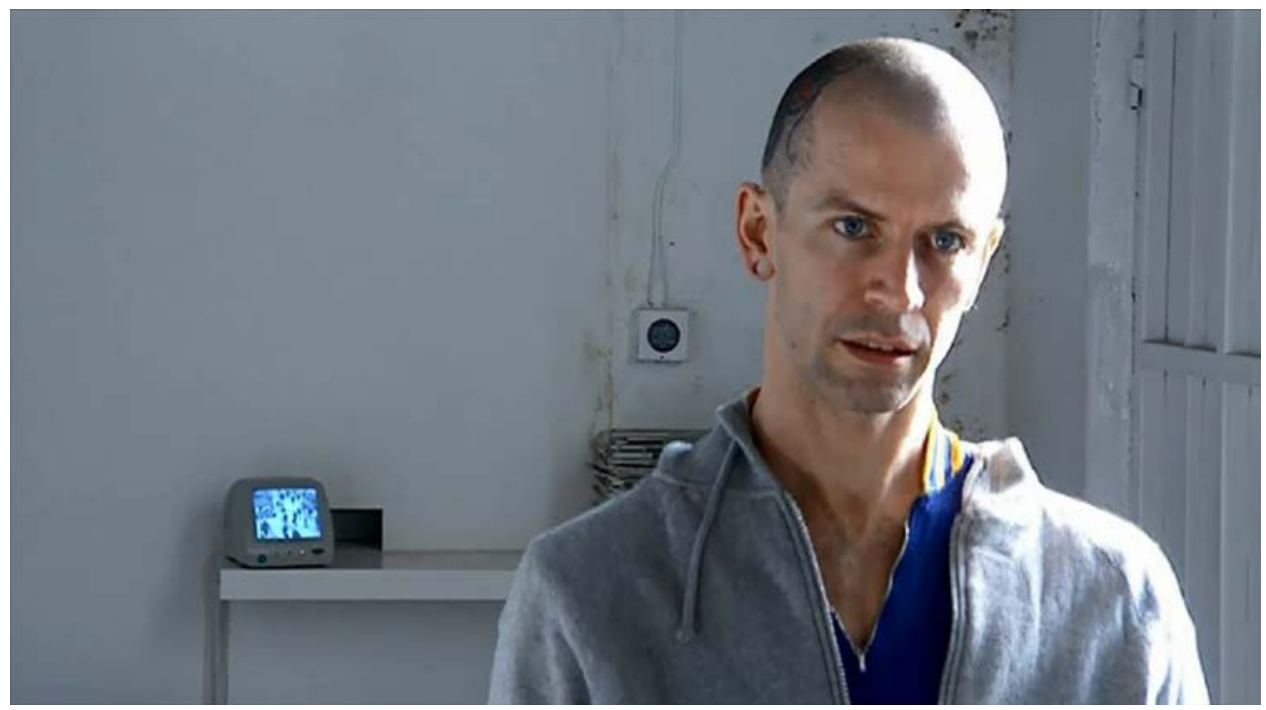

Screenshot. Matthew Morris performing in The Truth

This video-within-the-video enables "viewing through to other times and spaces," 45 but it also shows the viewer that the surveillance- and non-surveillance-style video are ultimately more or less the same. They both function as records of what McPherson and company did in the spaces they received permission to use, and they both allow viewers to watch closely the work's protagonists.

The non-surveillance-style images are more successful as observational material in that they transmit more information about the people they track than does the station footage. According to McGrath, "the surveillance camera displays the limits of its relation to the real place it is recording" in terms of, among other things, its typically low image quality and lack of sound. 46 However, McPherson's choreographed camera takes viewers who have just seen fuzzy, confusing surveillance-style video of the subjects of The Truth immediately into those subjects' intimate kinesthetic space to know their bodies, their movement styles, their sounds, and the way they look at and respond to each other in a manner that is not possible with the surveillance technology the work imitates. When McPherson repeats several times a close-up clip of Morris and Fisher-Potisk holding each other and swaying, she not only conditions viewers' kinesthetic responses to the clip but also invites viewers to detail their evolving sense of the relationship between the two dancers and, in turn, their relationship to the dancers. Each time that I have watched The Truth, I have felt reeled in by the increasingly intimate information I was fed until I ultimately felt unable to look away, even as I wondered if I should be watching something that felt quite private. 
It is apt, then, that Jeffrey Bush and Peter Z. Grossman have called the screen in screendance, much like in surveillance, "a one-way mirror, a voyeur's window." 47 The Truth foregrounds the ways in which screendance gives us a window into the intimate details of others' bodies and lives-even details that may initially seem as uneventful as the micro-details (e.g. the shaking hand) that I discussed in the previous section. McPherson and Fildes seem to have edited The Truth to create patterns, rhythms, and textures that invite us to investigate these details and our responses to them within a kind of mediated voyeurism.

\section{Intimate Choreographies}

Foster expresses skepticism about the possibility of empathetic connection in the "culture of surveillance." 48 In reference to a 2006 piece by Philadelphia's Headlong Dance Theater titled Cell, in which participants were led by a dispatcher (via a cell phone) through various interactions all around Philadelphia, Foster writes that the technology used imposes a sort of distancing that ultimately lends the impression that "the piece is being impersonally managed." 49 Jill Magid's 2004 work Evidence Locker speaks to the contrary, that surveillance space can actually engender a deep emotional intimacy across the screen that subverts the technology's detached, uneven power structure. Evidence Locker is a fitting companion piece to The Truth's manipulation of surveillance technology and Cell's participatory dimensions.

Magid lived for 31 days in Liverpool creating a commissioned work for the Liverpool Biennial. At the time, Liverpool had, according to Magid, the largest CCTV surveillance system in the world.50 Magid spent her time in the city writing and submitting daily Subject Access Request Forms detailing her activities and appearance so that footage of her would legally have to be kept in an evidence locker for each of the 31 days, which is the amount of time after which all un-requested surveillance recordings cascade off the system. At the end of her project, the footage was made available to her, and she has since, in turn, made it available online to the public for perpetuity. 51 She chose to fill out the daily forms, which she has made available alongside the footage, as though they were love letters addressed to her Observer:

Dear Observer,

I don't want to introduce you to everyone. I don't want to share you. I

separate you and you separate me.52

Her letters highlight the voyeuristic dimensions of surveillance-for example, on day two: "There are no curtains and I can imagine it's not so difficult to look into this room from the outside. I know you are not supposed to do that, but I bet you sometimes do it anyway." 53 Although the letters received no official written response, the officers manning the CCTV control room became increasingly invested in the poetics of the relationship Magid was setting up, especially in the case of one officer who, as told in Magid's final letter, gives her a ride on his motorcycle out beyond the range of the 
city's surveillance on her last day. That Magid then opened the footage and her letters up to outsiders underscores her interest in both voyeurism and exhibitionism in that she, in turn, invites the public at large to live vicariously through the intrigue of the story and the searching cameras.

Beyond voyeurism, though, Evidence Locker makes visible the intimate choreographies that observers create for those they observe, or even vice-versa. In the climax, so to speak, of the piece on day 24, Magid closes her eyes while on a busy public walkway, and an officer in the control room directs her movement via a phone and earpiece-in a manner not unlike Cell-as he watches her and moves and focuses the cameras in relation to her.

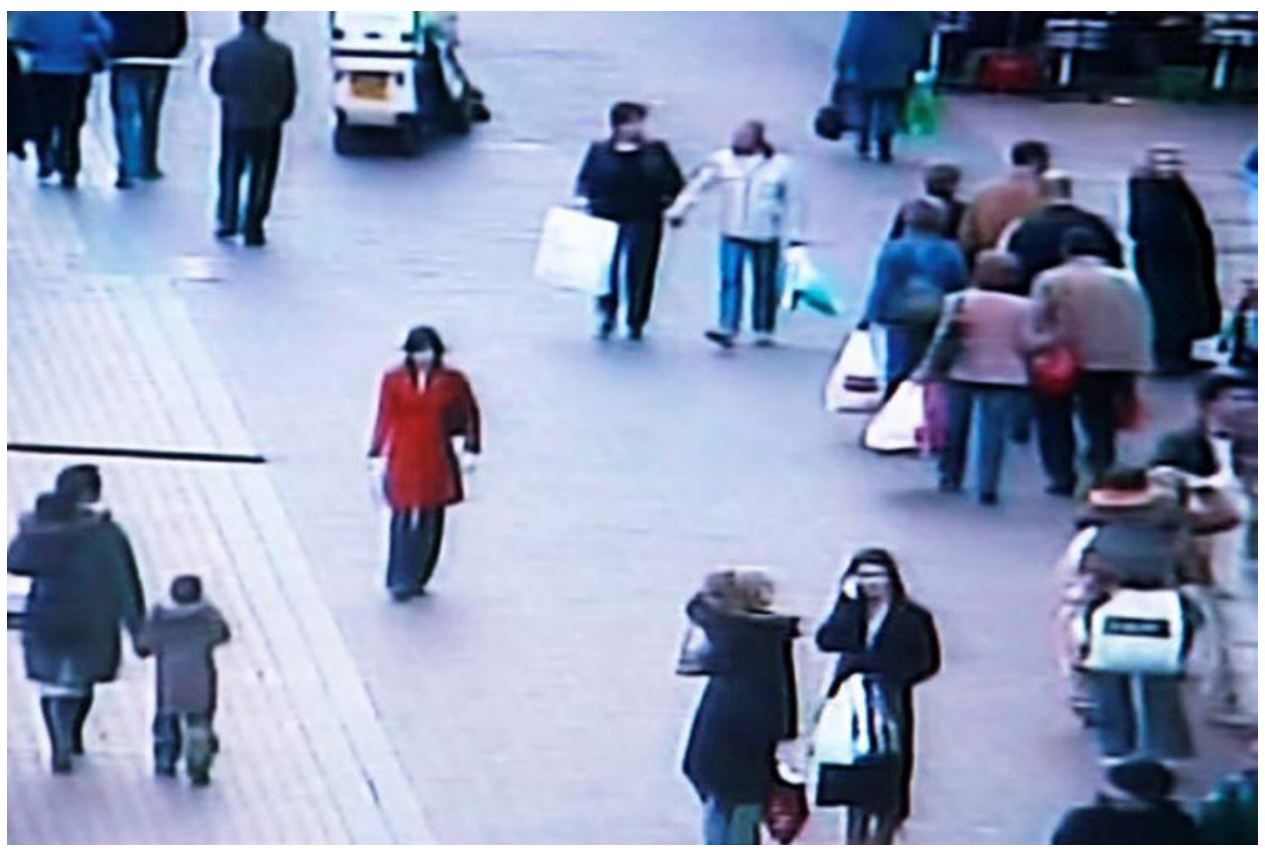

Screenshot. Jill Magid performing in Evidence Locker

In the accompanying Subject Access Request Form for the day Magid writes, "I imagined myself as you saw me and let my hands drop to my sides. I felt your approach. You stopped speaking. I could feel when my face filled your window ... And we rested like that, for maybe a minute." ${ }_{54}$ On the other side of the interaction, as Knifton writes, "the observer performs the role of jealous lover" in that the surveillance controllers went beyond a willingness to partake in Magid's game and began to devote time to looking for her, helping her, and speaking to her both on and off the clock. 55 Towards the end of the project Magid concludes, "I did not critique your system; I made love to it. You blushed." ${ }_{56}$

Evidence Locker perfectly exemplifies McGrath's statement that "the multiple desires and identifications that arise within surveillance space can sometimes coalesce into feelings of love." 57 If we accept that "the surveillance matrix creates not simply a 
parade of representations, but a lived space in which we experience our bodies and their relationships differently from previously," he argues, then "we inevitably accept that the emotions and needs intrinsic to human life will likewise be reconfigured in this new space." 58 Though I do not mean to suggest that viewers of The Truth necessarily fall in love with any of its performers, the use of pseudo-surveillance in the screendance foregrounds the reconfiguring of human emotions and needs that takes place when viewers are given the sort of intimate spectator-voyeur position that The Truth specifically and the choreographed camera more generally can provide.

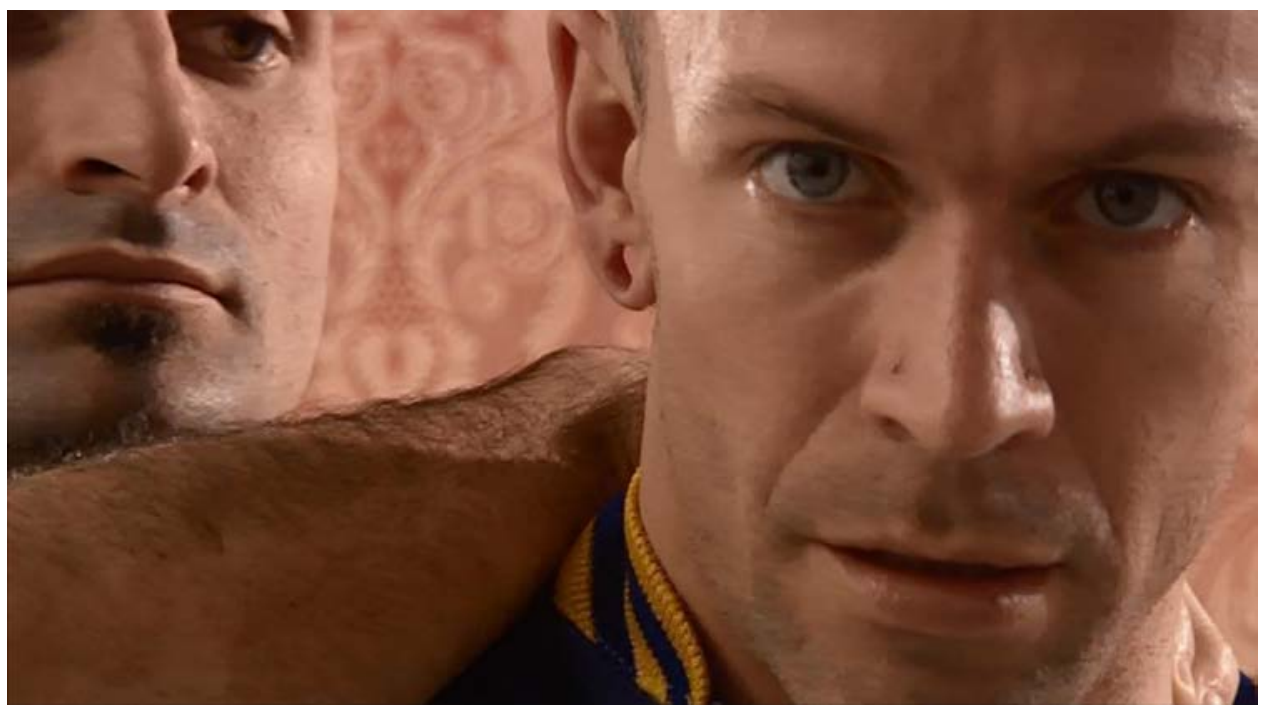

Screenshot. Matthew Morris and Robert Tannion performing in The Truth

The associations between the dancers that evolve over the course of The Truth involve the viewer in a triangulated relationship with the dancers, mediated by the camera, that does not differ that much from the love affair in Evidence Locker. Of course, viewers of screendance works do not usually have the contact or control that the officers had with or over Magid. However, screendance is nevertheless crafted in a manner that prioritizes viewers' sensations and experience and that draws them affectively and emotionally into the movements and relationships. Among other methods, viewers are drawn in through the use of the close-up and through editing rhythms that play off of the editors' own kinesthetic responses to the movements and relationships. These methods can also produce embodied responses in viewers. With The Truth, this might most readily occur the several times that dancers purposefully and significantly lock eyes with the camera, sometimes for as long as four or five seconds amidst movement and editing that is otherwise rapidly changing. Under the performers' close-up, direct, and prolonged (and oftentimes repeated) gazes, the viewer-voyeur feels caught, considered, connected, and maybe even blushes. 


\section{Biography}

John White is an art historian, dancer, and writer. He received a BA in History of Art and Architecture from Brown University, where he was a member of Brown's modern dance repertory company. He also received an MSc in Modern and Contemporary Art: History, Curating, and Criticism from the University of Edinburgh. He has worked at the Chinati Foundation in Marfa, Texas and currently lives and dances in New York City.

Email:jhn.e.wht@gmail.com

\section{Notes}

1 For a thorough and comprehensive history of the origins of "kinesthetic empathy" as a term, see Susan Leigh Foster, Choreographing Empathy. I also found the very wideranging topics covered in Dee Reynolds and Matthew Reason's Kinesthetic Empathy in Creative and Cultural Practices to provide invaluable context, as well as Karen Wood's "Kinesthetic Empathy" and Katrina McPherson's Making Video Dance.

2 Foster, 123.

3 Wood writes in 2016 that "[t]here is ... no research to date in dance or film studies on the kinesthetic experience of watching screendance." Wood, "Kinesthetic Empathy," 247. In the article she studies audiences' kinesthetic and emotional responses to screendance and how filmic techniques like synchronicity between movement and music, defamiliarization, and narrative structures influence those responses. Wood published similar research on audiences' kinesthetic and empathetic responses to screendance in Wood, "Audience as Community."

4 In particular I rely on McPherson's instructional book Making Video Dance, as well as Erin Brannigan's Dancefilm and Karen Pearlman's Cutting Rhythms.

${ }_{5}$ Wood, "Kinesthetic Empathy," 251.

6 I take the term "choreographed camera" from McPherson, Making Video Dance, 24.

7 See "Dance and the Camera" in Idem, 22-40.

${ }_{8}$ Foster, 10.

${ }_{9}$ Reynolds, "Kinesthetic Empathy," 124.

$10 \mathrm{lbid}$.

11 ldem, 127.

12 Idem, 132.

${ }_{13}$ Siegel, "Visible Secrets," 31.

14 McPherson, Making Video Dance, 24.

15 McPherson, "A Passion for Screendance," 49.

16 Deleuze, cited in Brannigan, 48.

17 Brannigan, 45. 
18 Idem, 51.

19 Idem, 44.

20 Wood, "Kinesthetic Empathy," 247.

21 McPherson, Making Video Dance, 189.

22 Foster discussing Hagendoorn, 167.

23 Ibid.

${ }_{24}$ Pearlman, 11.

25 Idem, 17.

${ }_{26}$ Wood, "Kinesthetic Empathy," 253.

${ }_{27}$ Pearlman, 17.

${ }_{28}$ For a thorough analysis of embodied responses to genre film, see Sarah Friedland, "The Meaning of the Moves."

${ }_{29}$ Reynolds, 124.

${ }_{30}$ Clay Calvert, Voyeur Nation, 2.

31 John White, discussion with Simon Fildes.

32 Robert Knifton, "You'll Never Walk Alone," 83.

33 David Lyon, The Electronic Eye, 4.

34 John McGrath, Loving Big Brother, 5.

35 Knifton, 88.

36 Idem, 88-89.

37 Linda Williams, Hard Core, 46.

38 Ibid.

39 Maciej Ożóg, "Surveilling the Surveillance Society," 97.

40 Lyon, 180.

${ }_{41}$ For a related exploration of "reading sexualized voyeurism and exhibitionism which deploys a 'surveillance aesthetic' as cultural critique, even as emancipatory action," see Bell, "Surveillance is Sexy."

42 Lyon, 182.

43 Foster writes, "Increasingly, individuals, jacked into their globally dispersed contacts, ignore the rituals and protocols that have defined public space. They do not partake in the protocols of civil exchange that defined eighteenth century comportment, nor do they observe the strong opposition between public and domestic spaces that dominated the nineteenth century. Instead, they rely on technologies of surveillance that monitor public behavior to provide the common ground on which they move." Foster, 189.

44 For a detailed account of the planning and execution of filming The Truth see McPherson, Making Video Dance, 225-246.

${ }_{45}$ White, discussion with McPherson.

${ }_{46}$ McGrath, 78.

47 Jeffrey Bush and Peter Z. Grossman, "Videodance," 13.

48 Foster, 195.

49 Ibid. 
${ }_{50}$ For Magid's own words on the project see Embedded - Jill Magid.

51 The process for viewing the footage and receiving emailed copies of the forms/letters is detailed at Magid, Evidence Locker. The forms/letters are also available in book form, see Magid, One Cycle of Memory in the City of L.

52 Magid, from emailed copy of letter \#17.

53 Magid, from emailed copy of letter \#2.

54 Magid, from emailed copy of letter \#24.

55 Knifton, 91.

56 Magid, from emailed copy of letter \#30.

57 McGrath, 209.

58 Idem, 210.

\section{References}

Bell, David. "Surveillance is Sexy." Surveillance and Society 6.3 (2009): 203-212.

Brannigan, Erin. Dancefilm: Choreography and the Moving Image. New York: Oxford University Press, 2011. http://dx.doi.org/10.1093/acprof:oso/9780195367232.001.0001

Bush, Jeffrey and Peter Z. Grossman. "Videodance." Dance Scope (Spring/Summer 1975): 11-17.

Calvert, Clay. Voyeur Nation: Media, Privacy and Peering in Modern Culture. Boulder, Colo.: Westview Press, 2000.

Cell. Headlong Dance Theater. Philadelphia: 2006. Performance.

Deleuze, Gilles. Cinema 1: The Movement Image. Translated by Hugh Tomlinson and Barbara Habberjam. Minneapolis: University of Minnesota Press, 1986.

"Embedded - Jill Magid" (2011). YouTube.

https://www.youtube.com/watch?v=MQE2zW8yUWI

Evidence Locker. Dir. Jill Magid. Liverpool: 2004. Performance, digital video.

Foster, Susan Leigh. Choreographing Empathy: Kinesthesia in Performance. New York: Routledge, 2010.

Friedland, Sarah. "The Meaning of the Moves: Gestural Mythologies and the Generic Film." International Journal of Screendance 6 (2016): 39-56.

http://dx.doi.org/10.18061/ijsd.v6i0.4940 
Knifton, Robert. "You'll Never Walk Alone: CCTV in Two Liverpool Art Projects." In Outi Remes and Pam Skelton (Eds.) Conspiracy Dwellings: Surveillance in Contemporary Art. Newcastle: Cambridge Scholars, 2010. 83-94.

Lyon, David. The Electronic Eye: The Rise of Surveillance Society. Cambridge: Polity Press, 1994.

Magid, Jill. Evidence Locker. http://evidencelocker.net/story.php.

----. One Cycle of Memory in the City of L. Self-published, 2004.

McGrath, John E. Loving Big Brother: Performance, Privacy and Surveillance Space. London: Routledge, 2004.

McPherson, Katrina. "A Passion for Screen Dance." Dance Theatre Journal 13.4 (1997): 48-50.

----. Making Video Dance: A step-by-step guide to creating dance for the screen. London: Routledge, 2006.

Ożóg, Maciej. "Surveilling the Surveillance Society: The Case of Rafael LozanoHemmer's Installations." In Outi Remes and Pam Skelton (Eds.) Conspiracy Dwellings: Surveillance in Contemporary Art. Newcastle: Cambridge Scholars, 2010. 95-112.

Pearlman, Karen. Cutting Rhythms: Shaping the Film Edit. Amsterdam: Focal Press/Elsevier, 2009.

Reynolds, Dee. "Kinesthetic Empathy and the Dance's Body: From Emotion to Affect." In Dee Reynolds and Matthew Reason (Eds.) Kinesthetic Empathy in Creative and Cultural Practices. London: Intellect, 2012. 121-136.

Reynolds, Dee and Matthew Reason (Eds.) Kinesthetic Empathy in Creative and Cultural Practices. London: Intellect, 2012.

Siegel, Marcia B. "Visible Secrets." In Gay Morris (Ed.) Moving Words: Re-Writing Dance. New York: Routledge, 1996. 29-42.

The Truth. Dir. Katrina McPherson. Chor. Paulo Ribeiro and Fin Walker. Prod. Goat. 2003. Film.

White, John. Discussion with Katrina McPherson, independent artist. July 29, 2015.

White, John. Discussion with Simon Fildes, independent artist. June 26, 2015.

Williams, Linda. Hard Core: Power, Pleasure, and the "Frenzy of the Visible." Los Angeles: University of California Press, 1989. 
Wood, Karen. "Audience as Community: Corporeal Knowledge and Empathetic Viewing." International Journal of Screendance 5 (2015): 29-42.

https://doi.org/10.18061/ijsd.v5i0.4518

----. "Kinesthetic Empathy: Conditions for Viewing." In Douglas Rosenberg (Ed.) The Oxford Handbook of Screendance Studies. New York: Oxford University Press, 2016. 245261. 


\title{
Movements of Media in Yvonne Rainer's Hand Movie (1966) and Richard Serra's Hand Catching Lead (1968)
}

Kyle Bukhari, Sarah Lawrence College

\begin{abstract}
This article focuses on two experimental films from the 1960s: Yvonne Rainer's Hand Movie (1966) and Richard Serra's Hand Catching Lead (1968). It scrutinizes the way both works exhibit a hybridized and indeterminate approach to artistic media. It offers an empirical reading of the films' movement and contextualizes them historically to move on to a theory of medium informed by Deleuze, Levinson, and Rajewsky. How does Rainer's move from the time-based media of dance and choreography, and Serra's move from the object arts of painting and sculpture, into the medium of film, advance our understanding of what is at stake aesthetically when boundaries of media are dissolved, transited, or displaced? Dance aesthetics requires that we show how movement gets translated into medium. I propose that the movement of media creates a displacement that is parallel to the displacement from the empirical to the theoretical in this article, where displacement becomes a form of reflection and critique.
\end{abstract}

Keywords: Yvonne Rainer, Richard Serra, experimental film, medium, hybridity

This article focuses on two experimental films from the 1960s: Yvonne Rainer's Hand Movie (1966) and Richard Serra's Hand Catching Lead (1968). I In particular, it scrutinizes and schematizes the way both works exhibit an indeterminate and hybridized approach to artistic media that brings the status of their respective aesthetic identities into question. Both films have been categorized within minimalist, 2 post-minimalist, 3 and post-modernist 4 aesthetics-classifications that themselves have sparked substantial debate. Each film has a similar ontological premise: a hand engaged in an activity, captured within the medium of film.5 This is particularly salient considering each film is a product of an artist that hails from a distinctly different disciplinary background. Rainer, a pivotal figure in American dance and founding member of the Judson Dance Theatre, redefined what could be considered dance to include everyday movements, working with objects, and task-oriented choreographies. She went on to generate an extensive oeuvre of films, poetry, and writing before returning to choreography in the 1990s. The American artist Serra, now known as a sculptor of large-scale works in rectilinear or torqued, undulating steel, was a multidisciplinary artist in the mid-1960s with an MFA in painting from Yale. His mixed media pieces 
purposely defied categorization, 6 incorporating rubber, neon tubing, lead, film and video, and even live animals as material.7

Rainer and Serra's arguably transgressive approach to the rules and conventions of their respective artistic media was not unusual for the post-minimalist artists whose work was often based in the investigative overlap between the object and temporal arts, a method that moved beyond modernist formal constraints and foregrounded materials and process. Art historian Benjamin Buchloh has suggested that within this interchange between media, the temporality embedded within process, gleaned from the performing arts, was repurposed and synthesized with the material nature of the plastic arts, giving way to new media hybridity.9 This rethinking of traditional conceptions of medium, what art historian Rosalind Krauss has defined as determined by: "specialized roles, methods of production, and conventional materials" arguably made performance, film, and video some of the most appropriate media to realize these new priorities.10 Krauss' definition of medium exemplifies how art and technology operate in tandem, and the way they have been theorized philosophically, from Walter Benjamin 11 to Marshall McLuhan. ${ }_{12}$ The availability of a new technological medium, in this case a hand-held Super 8 camera, simultaneously modified artistic production and destabilized entrenched aesthetic categories, absorbing the former into the new medium in one fell swoop, yet still bearing vestigial traces of the previous form embedded within, an idea that has been explored in depth by J. David Bolter and Richard A. Grusin with their notion of remediation, a concept that captures the particular paradoxes of media's immediacy and invisibility in our digital age.13

The questions that guide this article hinge on the idea of movement of and between media. I initially consider how an artist with a background and training in a more 'traditional' medium 14 such as dance, painting, or sculpture, branches out to test the waters of a secondary or even tertiary medium. I then examine how viewers perceive these works in their compliance or divergence with then-established conventions of medium specificity. How, for example, does Rainer's move from the time-based media of dance and choreography, and Serra's move from the object arts, i.e. painting and sculpture, into the medium of film, advance our understanding of what is at stake aesthetically when boundaries of media are dissolved, transited, or displaced? Is it only through the dissolution of medial boundaries that the identity of an individual medium becomes distinct? What does it mean to speak of a resulting hybridity? Is hybridity a static category composed of equal, heterogeneous parts, or is it rather a synthetic identity that is in a state of dynamic flux? Finally, how does knowledge of art and dance historical developments inform perception, and allow for aesthetic classification of component, or constituent media, of the artistic work or production we witness?

Divided into three sections, this article is structured by the organizing theme of movement, and progresses from the empirical towards ever-increasing levels of 
theoretical abstraction. Starting with brief descriptions of Rainer's Hand Movie and Serra's Hand Catching Lead, a nascent ontology that formally links the films comes into focus. I then deploy philosopher Gilles Deleuze's cinematic theory of the "movementimage" to support my claim that movement, and its very idea, are over-determining factors of both films.15 Where Deleuze's "theory of frame" provides a technical methodology to make visible previously unseen differences between the films, his notion of "out of field" (hors-champs) provides the possibility for an imaginative movement of the mind outside of what is optically perceptible on the screen, a move that I propose renders Rainer and Serra's obscured bodies not absent, but starkly present.

As mentioned above, the composition of the films and the experimental approach taken by the artists would tend to move the discussion towards notions of hybridity. Philosopher Jerrold Levinson's concept of "Gedanken" or "thought hybrids" helps support the movement thesis that conceptually underpins this project. 16 In my reading of Levinson, I posit that the directional movement toward the constituent media of a hybrid results in an aesthetic indeterminacy of hybrid forms. Within this indeterminacy, a conceptual dynamism becomes discernible, and I suggest that this aesthetic hybridity is itself the result of the movement of the media forms themselves, a process augmented by how we choose, consciously or not, to perceive them as hybridized works of art.

Terminology is not to be underestimated. The use of words like intermedial, intramedial, and transmedial, drawn from intermedial studies, show from a linguistic perspective how abstract movement implied in language can open a space or gap between concepts of media.17 Within this space, a theory of displacement can gain traction. This is key to my movement thesis, since it makes visible what is at stake when media can be seen not only as in motion, or hybridized, but ultimately in a state of perpetual displacement. A theory of displacement also points to the way the arts, as marginalized or commodified social practices, can be seen as displaced within society-stripped of their political power, or instrumentalized for commercial purposes. This is a larger, more complex issue that can only be gestured to here.

\section{Manual Ontologies}

Rainer filmed the $8 \mathrm{~mm}$ black and white film entitled Hand Movie (1966) with fellow Judson artist William Davis while confined to a hospital bed, recovering from surgery.18 It was her first film, and the first of a set that would become known as 5 Easy Pieces. Critically, it is one of the few film artifacts of her early work. For Rainer, these films were seen as experiments rather than finished art works; she now refers to them humorously as her "early boring short films." 19 This is despite their status as a rare visual record from a key period of artistic production that includes canonical works such as Parts of Some Sextets (1965), the penning of her infamous "No Manifesto" 
(1965), 20 the eponymous Trio A (1966), and The Mind as a Muscle (1968) in which Hand Movie was screened as well. 21

A brief analysis of Hand Movie proves fruitful for apprehending its structure, temporal unfolding, and subtle articulations that subvert the semiotic potentiality of gesture.22 Considered choreographically, the movements in Hand Movie tend to begin neutrally and escalate in complexity, before returning again to a flat 'start' position of the hand. Rainer deliberately shows the hand from all sides-suggesting a sculptural, threedimensional perspective. A single digit is often isolated from its relation to the rest of the hand; two fingers might interlock, allowing a new freedom for the other digits. At times the movement is barely perceptible: a gentle splaying of the palm and fingers, or slow curling and uncurling. Most striking in Rainer's articulation of her fingers is that she makes her digits appear as if they are autonomous units, no longer under the coordinating jurisdiction of the hand-and this gets messy-as they then appear to be involved with the task of untangling themselves-an action not normally associated with the everyday use of the hand.

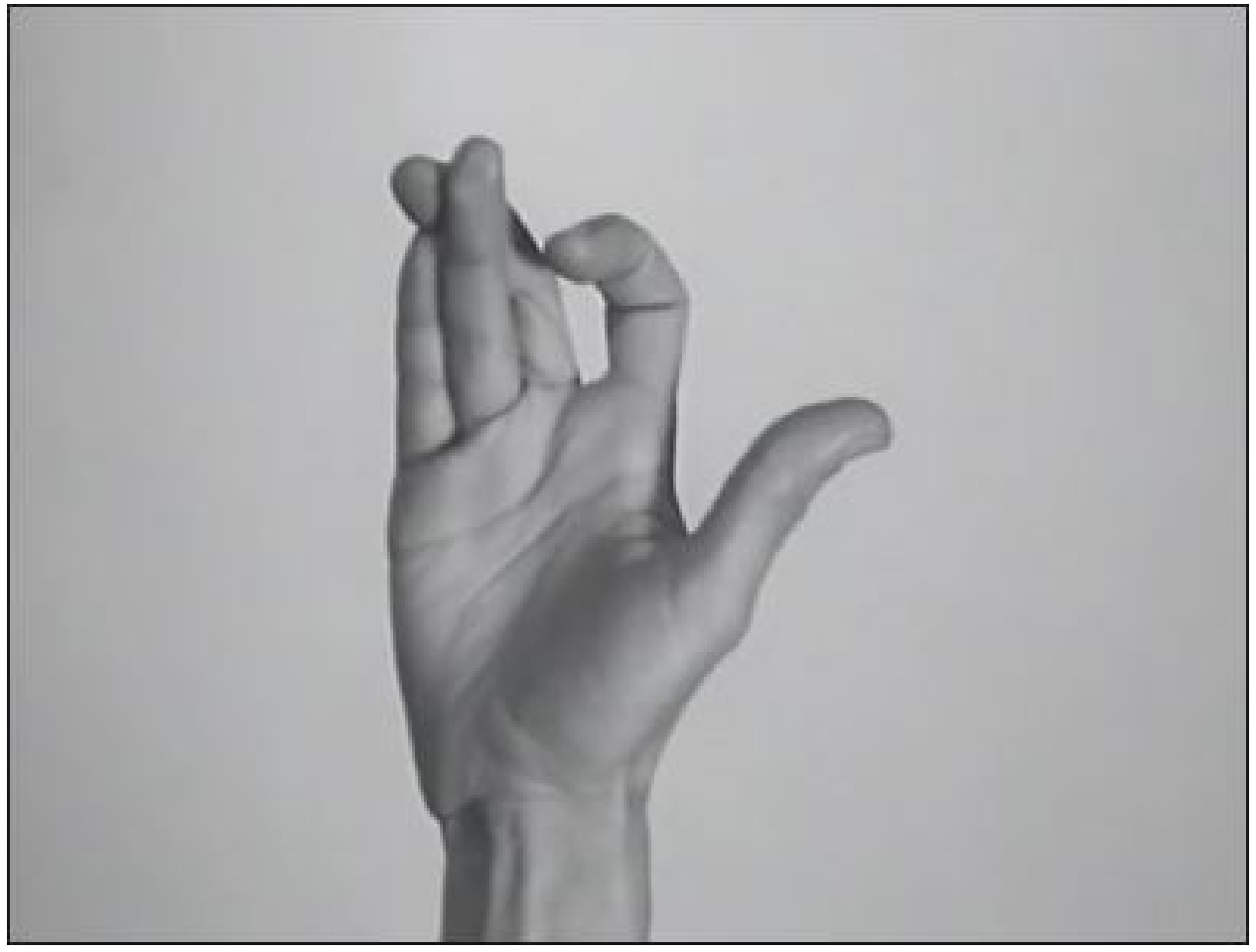

Yvonne Rainer's Hand Movie (1966). Camera: William Davis. Permission courtesy of the artist.

The hand, as Rainer reminded me in a recent email exchange, is that of a young woman, and she was surprised I had not remarked on the fact.23 Rainer was thirty-two at the time of the filming, and her comment raises issues of gender, age, and the historiography of living artists. Certainly it illuminates the gap between her original experience and intention in making the film and what historians and theorists 
retrospectively read into the work, or what she has called "writers' long-winded attempts to make anything more of the films," with the present text apparently included in that category. This gets at an important aspect of much of the work that was generated by the Judson Dance Theater, namely a focus on experimentation over archiving, where the short-lived nature of the live art form was pushed to the extreme.24

In terms of gender, it could be said that only through a comparison of the Rainer and Serra films does the gender binary become distinctly visible. Rainer scholar Carrie Lambert-Beatty has written that the hand in Hand Movie is not immediately identifiable as either male or female," 25 and when observed in isolation this might hold. But when a viewer considers the exploratory, gently probing and sensate movements of Rainer's hand, and contrasts them with the forceful grasping of falling pieces of lead in Serra's Hand Catching Lead, what Douglas Crimp has described as a "powerful male wrestling art from stuff," 26 a gender performance becomes effectively readable. This is nevertheless framed by Rainer's special status as one of the few women who has established a place for herself within the male-dominated canon of minimalism.27

One of the key ideas associated with Rainer's work of the period is the notion of the materiality of the body-the body as a material to work with, just as if it were plywood or steel. In her own words, Rainer questioned "how to use the performer as a medium rather than persona." 28 This approach can be seen as a development of choreographer Merce Cunningham's depersonalization of the performer, but which also signaled a rethinking of the body as the site of medium itself, an embodiment of the artist's materials. This specific notion of medium gains traction if we take on Lambert-Beatty's proposal that Rainer's hand in the film enacts an "avoidance of all ... kinds of signification." 29 The hand exhibits a semiotic opacity; the movements never crystallize into readable gestures - the fist never solidifies into a symbol of defiant power, the fingers never form a peace or victory symbol. The hand, Lambert-Beatty proposes, is reduced to a state of non-signification. I suggest this lack of transparency and readability calls attention to the very materiality of the hand; it represents nothing other than its physical, manual self. It can even be seen as exemplary of what Rainer described in the 1968 program for the Mind is a Muscle as the "unenhanced physicality" of the body.30

Where Rainer's Hand Movie unfolds along a temporal continuum of ever-changing movements, Serra's Hand Catching Lead is a three-minute exercise in reflex, repetition, and rhythm - a task-based experiment in which he attempts, and frequently fails, to catch falling pieces of lead. The 1968 film, like Rainer's Hand Movie from two years earlier, was Serra's first. He followed it with four more films that featured hands: Hand Lead Fulcrum (1968), Hands Scraping (1968), 31 Hands Tied (1968), and Frame (1969).32 Serra's move to film, synchronous with his written Verb List (1967-8), cinematically 
documents his shift from working with rubber in works like Scatter Pieces (1967), to lead with works like Slow Roll: For Philip Glass (1968), and his subsequent prop pieces. For Serra, this period was richly informed by the work happening at the Judson Church, particularly that of Rainer. Art historian Hal Foster has suggested that Serra's exposure to Judson led to the desymbolizing and desubjectivizing of his work, removing its representational function, and objectification, and taking the artist's hand out of the equation-an irony that both Rainer and Serra play with in their foregrounding of the hand as cinematic subject.3s Speaking of the Judson influence, Serra recalls that "dance and performance clarified a lot of what I wanted to do-I would go to Yvonne's performances and come home with more ideas how to proceed with than I found in the art world ... we were all into process at the time. It didn't matter whether you were a sculptor or a filmmaker or a musician." 34 This statement gets at the impulses that one artistic medium can give another, and characterizes a movement that results in the rethinking of medium-specific conventions, the prevailing ethos of the time. But it also raises interesting questions about the way the live arts can act as a catalyzing environment for the visual arts, as has been shown in twentieth century from the art-laden productions of Diaghilev's Ballets Russes to Merce Cunningham and John Cage's collaborations with Robert Rauschenberg and Jasper Johns. The deeper issue here points to the limits of influence within the classical aesthetic hierarchy of the arts, where historically the live arts have been crucial to the aesthetic development of the plastic arts, but have not always been acknowledged as such. 35

The movement in Hand Catching Lead remains the same from start to finish, yet Serra's failure to catch the lead provides an indeterminate aspect to an otherwise predictable exercise. The result: a movement system composed of a human hand and multiple lead objects. Notably, composer Philip Glass collaborated with Serra on Hands Scraping Lead, and Serra dedicated the sculptural work Slow Roll: For Philip Glass to the composer as well. This points to the potential of a musical reading of the film, where the repetitive continuous actions without climax can be seen as exemplifying certain tendencies within so-called 'minimalist' music, further illustrating the porosity of borders between media. 


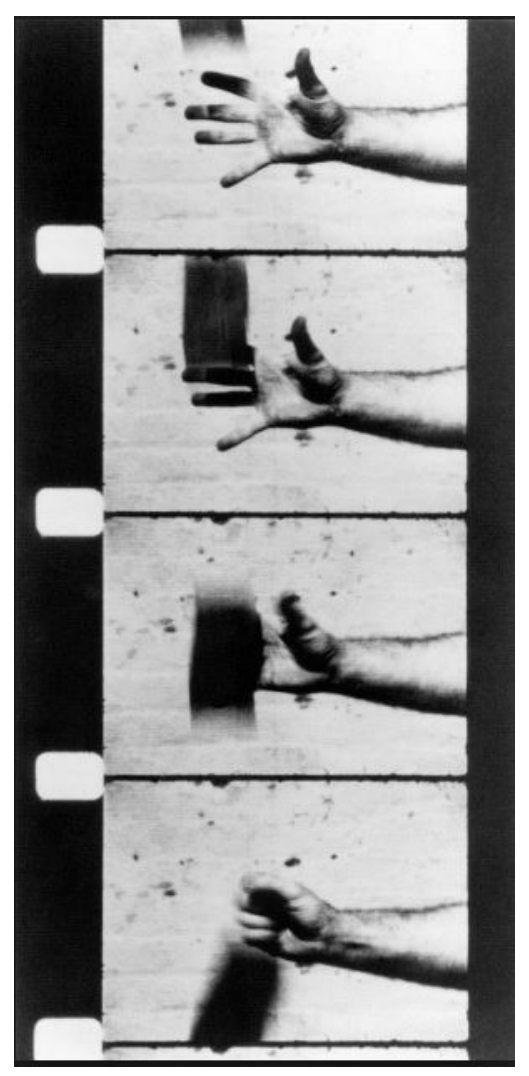

Richard Serra's Hand Catching Lead (1968). Permission courtesy of the artist.

Two movements structure the film. The first is the grasping action of Serra's hand as he attempts to catch the falling lead. The second is the piece of falling lead itself. The intersection of these two movements forms a dynamic horizontal and vertical axis. The tensing and releasing movements of the tendons in Serra's wrist make visible, at an intimate level, the minute process of the manual labor of the artist's body at work. The physicality of Serra's hand is noteworthy as it is enacted in a completely functional way. This appears to be a different strategy than that of Rainer, who on one level can be seen enacting a pure exploration of manual articulation as a relation of the bodyas-medium to itself, whereas the relationship of Serra's hand with the lead is a performative and process-oriented embodiment of the relationship of the artist with his materials.

Serra recalls seeing Rainer's Hand Movie, and her other early films at the Anthology Film Archives in New York. Along with seeing Andy Warhol's Chelsea Girls (1966), the films allowed Serra to "entertain" the prospect making his own films. Where Warhol's "detachment" made the medium appear accessible, Serra recollects he "felt a very direct relationship" with Rainer's films." 36 This detail is central to the discussion of movement between aesthetic categories and identities, as it was seeing the work of Rainer, an experimental choreographer, working in film for the first time, coupled with seeing Warhol's film, the work of an established visual artist, that inspired Serra to 
enact a media transgression himself, a jump from the realm of the object arts sculpture and painting to that of film. I suggest that this creative act also constitutes a movement between media, where artists working in diverse media act as catalyst for each other.37

\section{The Movement Image and Out of Field}

Gilles Deleuze wrote in 1986 that great filmmakers could be compared "not merely with painters, architects and musicians but also with thinkers," 38 placing film on par with philosophy as a knowledge-producing endeavor, and elevating it above its aesthetic relations. One idea he introduces is the "false movement" of the cinema, which is the way individual frames of a film run together sequentially to produce a seamless moving image. 39 Through this fictitious illusion of movement, a result of the aggregation of the individual images passing in a high-speed progression, what he terms a "movement-image" becomes possible. Like photo flip books, the movement is not associated with the single still images, but rather with the moving image they create by their viewing in rapid succession, mirroring the phenomenon of kinetic perception itself. What is interesting about his proposal is the way it draws attention to how movement is perceived in reality, where the condition of movement already structures our perception of it thoroughly. Deleuze draws the conclusion that film actually mirrors thought processes and perception, and the projected celluloid strip may be an approximate, material realization, of the way the mind apprehends the phenomenological world. I would like to propose that both Rainer and Serra's films are robust examples with which to engage this philosophical position-in different ways, and on their own terms. For our purposes, Deleuze's "movement-image" helps separate the levels of movement at work in the films: the event of the original hand movements performed for film, the illusion of Deleuze's "movement-image" generated by the individual images, and the actual physical movement of the filmstrip that a series of white spots on the celluloid make visible. 40 


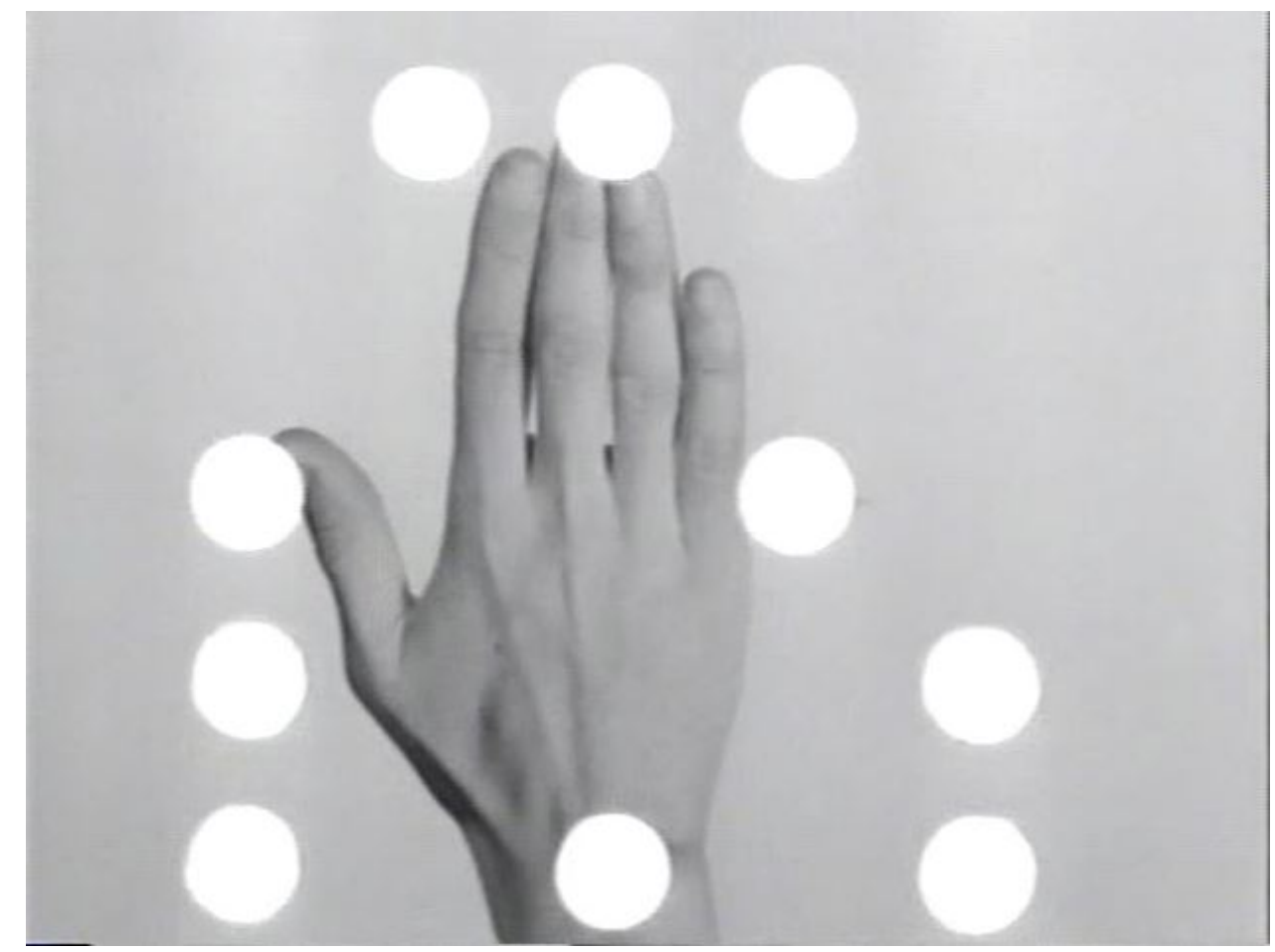

Yvonne Rainer's Hand Movie (1966). Camera: William Davis. Permission courtesy of the artist.

Two other aspects of movement analysis Deleuze introduces are his "theory of frame" and "out of field" (hors-champs). Using these theories allows me to suggest these films are fundamentally different instantiations of the way movement is captured within the rectangular edges of the frame. Yet where Deleuze tells us that the boundary of the screen image constitutes a closed system, and that what is transpiring within its borders can be thought of as an "information system rather than a linguistic one," I propose that in the case of these two films, the hand, with its gestural potential, resists reduction to the informative and instead inhabits a space of articulation and functionality. ${ }_{41}$ Nevertheless, the frame does provide information with its composition of static rectilinear lines and diagonals, within which the moving image stabilizes and balances itself. Deleuze suggests that what is inside the frame can be thought of in two ways: either as 1) a "dynamic-physical" information system that in reality extends beyond the frame, or 2) a "geometric" information system, in that its movements do not go beyond the frame, rather they emanate from it.42 The difference between these two perspectives posits movement as either pre-existing the frame dynamically and physically, or originating from the screen geometrically. The question is this: what can Deleuze's frameworks of analysis reveal about these works' underlying structures of movement?

The durational aspect and minimalist approach in both films can make Deleuze's theory of frame clearly visible, while simultaneously differentiating their cinematic ontology, allowing for a robust interpretation of the way movement functions in the 
works. And if we apply Deleuze's proposal, we do get some interesting results: Rainer's Hand Movie appears to fall into Deleuze's "geometric" concept of frame. Why? The upright position of the hand creates a stable vertical line, and although Rainer's wrist is cropped along the bottom edge, the movement is generally generated from the hand, which, apart from the few times she moves it laterally across the frame, is predominantly centered in the screen. Hence the hand movement is centrifugal and centripetal, directed both outwards and inwards. Considered as such, it appears that the movement in Hand Movie originates from the screen as opposed to prefiguring it-making it "geometric" in nature.

On the contrary, Hand Catching Lead can act as an illustration of Deleuze's "dynamicphysical" theory of frame. Although the action of Serra's grasping hand (and forearm) is centered in the setting, it nevertheless indicates a dynamic system of movement taking place outside the borders of what is visible. The falling pieces of lead point to an unseen source or origin. The fluctuation of movement in Serra's arm, as he grasps the falling pieces, suggests a whole-body effort is at work to achieve the framed effect, and in this sense the work appears to be "dynamic-physical" in nature.

With this theory of frame it is possible to see that although these two films can initially be seen as optically similar, they are actually very different instantiations of filmed movement. This is important as it not only complicates the artists' relationships with the conventions of their respective media, but it also reveals how these works are exemplary in their embodiment of the interdisciplinary nature of the works of the period, specifically the way the object arts borrowed aspects from the temporal arts, and vice versa.

Deleuze expands his theory of the frame with the notion of the "out of field," which posits that an image is only a subset of what exists outside of the borders of the shot. Herein lies another conceptual movement. The "out of field" necessitates a viewer's mental shift outside the frame, and then back into it. As both films feature a cropped image of the hand that excludes the rest of the body, the theory is particularly pertinent to this analysis. By considering what exists in the "out of field," it is possible to include the dynamics of what is not seen with the interpretation of what takes place within the frame.

That Rainer's and Serra's bodies are unseen is not, therefore, a negation of them. Rather, this absence can become in Deleuzian terms "perfectly present." 43 So considered, Rainer's immobile body recovering from surgery, the hospital bed and room, along with her Judson colleague William Davis filming the scene, all become components in the analysis and interpretation of the film. In this sense Rainer's hand becomes a synecdoche, the part that reflects the whole of the entire hospital scene. Considering the "out of field" in Hand Catching Lead is equally productive. The physical system arranged by Serra, with the dropping the pieces of lead must have been an 
exhilarating choreography of movement, object, and rhythmic components. Where Rainer's "out of field" is static due to incapacitation, Serra's "out of field" is kinetic and dynamic, again suggesting a reversal of medium between the more static nature of the object arts and the physically kinetic nature of the performative arts. Applying Deleuze's formalist analytical concepts to Rainer and Serra's films reveals unseen movements hidden within their structure that allows for a novel rethinking of their aesthetic identity. I now turn to Jerrold Levinson's account of hybrid art forms, which offers a precise and historically contextualized way of thinking about the interaction and synthesis of artistic media such as can be seen in Hand Movie and Hand Catching Lead.

\section{Aesthetic Hybridity, Historical Context, and Indeterminacy}

Levinson suggests that art forms are considered 'hybrid' when they can be decomposed conceptually into two or more distinct artistic activities or ostensible media.44 This definition gains traction with the works under consideration. He additionally proposes the need to understand the historical context - not the structural or material composition - to determine if a work is hybrid. Levinson explains: "hybrid status is primarily a historical thing as is...being a biological hybrid. An art form is a hybrid one in virtue of its development and origin, in virtue of its emergence out of a field of previously existing artistic activities and concerns." 45 I agree that the historical aspect is key in identifying both Hand Movie and Hand Catching Lead as hybrid forms, cases where the artists have combined their respective artistic media with the new medium of film. In order to understand what Rainer is doing with her hand as an instance of the dance medium, and what Serra is doing as occurring within the plastic arts, it is necessary to have followed the historical development of their respective media, and how they chose to respond to its conventions at that particular moment in time. For Rainer, it was a concern with the materiality of the body and functional, selfcontained movements that resisted phrasing, transitions, or overt theatricality. For Serra it was a concern with the way materials interacted with the process of artmaking, and how this became visible in residual forms that purposely defied mediumspecific definitions.46

Even for works that are not hybrids, a knowledge of the history and theory of the practice is often needed to identify if something is art at all, let alone a hybrid.47 Think of Marcel Duchamp's Fountain (1917) or Andy Warhol's Brillo Boxes (1964) as optically indiscernible from their non-art counterparts. It is only through acculturation and knowledge that a viewer of these works is able to see past their potentially misleading forms to understand how they each signified a revolution in the history of representation.48

As if to offer a counter-model of analysis, Levinson suggests another more flexible lens with which to look at works of art as ahistorical hybrids, that is as if they were a 
combination of certain media, which he calls "Gedanken" (thought) hybrids.49 This ahistorical model is significant, as I propose it implies both direction and choice for the viewer in the identification process, supporting my thesis that conceptually speaking, hybrid media can be seen as in a particular kind of movement not only in their production but also in their mode of reception. Levinson provides three main models for classifying various types of ahistorical hybridity: the juxtapositional, the synthetic, and the transformational. Levinson proposes a silent movie as an example. This is apt, since both Hand Movie and Hand Catching Lead at least initially possess aspects of the silent movie form. Where Levinson determines that a silent movie is composed of photography and theatre, I suggest that Hand Movie can be seen as being made up of photography and dance-but is it not also potentially sculptural? Or performance art? Hand Catching Lead is an equally complex combination, of photography for sure, but what are the additional constituent media? Painting? Sculpture? Hal Foster has referred to this film as a "sculptural film" but Serra has resisted this categorization by arguing that even when aesthetic languages can be shared by artists working in diverse media, the "basic assumptions of film" as a two-dimensional illusionistic "plane" has no sculptural potential whatsoever, and any attempt to speak about his work (by Foster) in that way is "nonsense." 50

For Levinson, the question is if a silent movie is a synthetic or transformational hybrid. He concludes that it is synthetic; for in order for it to be transformational, an entirely new medium needs to have arisen out of the combination. This is where it gets interesting and somewhat tricky; the understanding of the silent movie's hybridity can move in either direction of its constituent media, and Levinson then argues that the silent movie can be seen either as a "kinetic photograph" or a "non-bodily theatre." 51 Thus considered, Rainer's Hand Movie is also synthetic, as its hybrid identity can move either in the direction of dance, as a dance film, or in the direction of an experimental film that features the hand of a dancer. Hand Catching Lead is equally synthetic, moving between the object and performance arts even in light of Serra's comments above on Foster's proposal of "sculptural film." In both cases, a new medium has not arisen out of these hybrids. Yet the option for the viewer to move directionally toward different constituent media elucidates one of my key claims concerning the movement of media, and how within hybrid forms, an indeterminacy exists that asks that different media be considered as constituent, a request of the viewer that brings the aesthetic components of a hybrid into a dynamic state of flux.

An interpretive question then ensues: what kind of meaning arises from an artwork whose aesthetic identity is in flux due to the indeterminate status of its medium? I propose that an indeterminate media identity destabilizes and makes us question the very means through which the content is received, and therefore by which it might be recognized. This moment of indecision when confronted with the task of aesthetic classification is crucial for three reasons: 1) It firstly calls attention to the way our 
concepts for artistic media are both socially constructed and historically conditioned-in this case, the medium of film (shot on Super 8 and $16 \mathrm{~mm}$ cameras) frames both Rainer and Serra's projects as being of their particular historical and technological moment, while interrogating their status in relation to the plastic and performing arts. 2) It gives agency to the viewer, which allows them to activate their own knowledge of the history and theory of the arts, and make their assessment of what artistic media are at play. And 3) it gets at the protean aspect of an art work as a form of representation that is full of aesthetic potential, and can arguably be perceived as many works of art at once when considered in the iterations brought about by the indeterminacy of the hybrid form.

By acknowledging the inherent potential within hybridity and creatively choosing to receive the same content through different artistic channels, I suggest new meanings arise from a work that initially appeared to bound by a single aesthetic concept, i.e. experimental film. In the case of Hand Movie, and Hand Catching Lead, film, performance art, sculpture, painting, and dance, can all be considered as constituent media. I suggest the meaning of the work multiplies to the degree that each medium involved adds its own particular history and conventions to the reading. Additionally, Rainer and Serra's films can be read and theorized fully from the various disciplinary perspectives such as art history, dance studies, and film studies. This leads me to propose that the aesthetic and disciplinary confluence actually allows the works themselves to move simultaneously within multiple artistic discourses. This highlights a heretofore unseen way in which there is a discursive movement at work in relation to the hybridized aspects of these films. I now want to move the discussion away from ideas of hybridity and indeterminacy within Rainer and Serra's works, and towards another theoretical terrain, one that looks at artworks in terms of their intermediality. I focus particularly on how language from intermedial studies can enrich the discussion and bring it toward a final stage of theoretical abstraction. Although there is some conceptual overlap with Levinson's proposals, using the intermedial as a framework for Hand Movie and Hand Catching Lead provides an analytical approach that supports my movement thesis by allowing for a spatialized conception of the way artistic media dynamically interrelate.

\section{Intermedial Turns}

The prefixes inter-, intra-, and trans- are remarkably kinetic, especially when coupled with the word medial, (i.e. intermedial, intramedial, and transmedial). These terms, drawn from intermedial studies, allow for a further development of my movement thesis, namely that an examination of the movement implied in the words themselves opens up a dynamic theoretical space around, across, and between media. This is a theoretical jump. Nevertheless, I want to forward the idea that by mentally opening up this abstract space, a theory of displacement can enter the discussion. I suggest that this notion can make another strata of movement visible in Rainer and Serra's films 
such that the configuration of the media of dance, film, painting, sculpture, and performance art are can be seen as in a state of continuous displacement. First, some historical background on the critical study of intermediality 52 undertaken within the German academy since the 1990s will help to situate my argument.53 At the tail end of a long-standing tradition of interart studies 54 is what has come to be known as the "intermedial turn." 55 Irina Rajewsky provides a brief contextualization of this turn. She has proposed that intermedial studies offers new ways of thinking about both the "medial border crossings and hybridization" and "materiality" that has been evidenced within current artistic production. 56

Rajewsky describes two current debates within intermedial studies useful to the present discussion. The first debate is epistemic, that is, based in the knowledge of art media and how we can recognize them as such by mentally cross-referencing intermedial artifacts under analysis. For example, how is a performance of a minimalist work like Hand Movie related to dance, or Hand Catching Lead to painting or sculpture? Like Levinson's historical context, an external referent is needed to make such an identification. The second debate is both epistemic and ontological as it deals with the knowledge of the artistic forms as well as their structural differences. At issue is whether it is only through the relationship between various media that an individual medium is made visible. 57 In this sense, the fact that Hand Movie is framed within the medium of film makes the gestural and performative elements of the hand, and the history (and disavowal) of theatrical dance that it arguably embodies that much more apparent, while simultaneously calling attention to the film medium as starkly different from that of Rainer's choreographic experiment for the camera.

Looking at the terminology used by scholars in intermedial studies shows close similarities to Levinson's hybrid forms, but also productively expands the vocabulary. Rajewsky offers a technical breakdown of intermediality into discrete parts that include transmediality, remediation, and the plurimedial.58 Where intermediality deals with the crossing of borders between media, transmediality is the way a "certain motif, aesthetic, or discourse" can appear across diverse media.59 The plurimedial model can be seen as analogue to Levinson's juxtapositional model, in the sense that the media involved remain true to their original form. Remediation can be seen as comparable to Levinson's transformational model when a whole new medium is created. Adding to these terms are proposals such as intramedial transposition, illustrated with the example of an adaptation from stage to screen.

Considering Hand Catching Lead within an intermedial framework, I propose that it is both inter- and intramedial, that is, medially between and inside sculpture, performance, and film. Taking the intermedial perspective, Serra grasps the material of sculpture, the lead, but does not create a static sculptural object. The process aspect is revealed in a repetitive and performative sequence. Film is the container for the activity, but rather than encompassing the constituent media completely, it points to 
them from a space in between. I would also add that it gestures towards the objectoriented conventions of 1960s dance due to the influence of Rainer's film and performance work. On the other hand, as an intramedial work, I suggest that Hand Catching Lead takes place completely within the medium of film, as well as fully within the sculptural tendencies of repetition of the period directly preceding the making of the film, 60 and hence is fully "inside" of these media. As has been previously established, I am making a case that discerns the heretofore unseen movements of and between media, not only optically and physically, but also theoretically. By applying the inter and intramedial models to Hand Catching Lead, I further assert that the constituent media of the film can begin to be conceptualized in spatial terms, and within this space it becomes possible to envision new configurations and constellations of media in movement.

At this point the language of the intermedial has established a more specific structural framework with which to consider the movement between, within, or across media. I want to push this idea further and propose that due to this spatialziation of media in movement, a theoretical space or gap between the individual media becomes apparent. I have addressed the potential meaning of an artwork that has an indeterminate aesthetic status by arguing that it calls attention to the various media of which it is composed as forms of representation. I have not yet addressed the issue of what is implied in this space or gap between media. Perhaps the space is a space of non-representation from which representation draws its content, or the edges of its abstract form. Or, it is a space of pure potential and possibility that preexists medial formations before they cohere as social and aesthetic constructs.

Philosopher Lydia Goehr has suggested a theory of displacement that can gain traction here. The theory supposes that it is not a dissolving of distinctions between media that is the issue with hybridity or intermediality, or in her case between music and film. Rather it can be seen as an act of medial displacement, where in the new configuration a fluid yet tenuous relationship between the original media remains.61 She further suggests that the potential meaning generated by this displacement has social implications. The dissolution of aesthetic boundaries, where former differences between traditional media have been erased is a reflection of a society and culture where all distinctions have been eroded, and where art itself has been displaced.62 The notion of displacement that takes place in the conceptual space of media brings a new dynamic to the discussion, as this becomes a theoretical space of risk where moving across, through or between its interstices can be aesthetically dangerous and socially emancipatory, opening new perspectives by displacing the old ones.

To return to Hand Movie, I propose that it is possible to perceive just such a medial displacement at work. Rainer has displaced the dancer with a hospital patient (herself) the body with the hand, and dance with a choreographic experiment. The move into the two-dimensional realm of film displaces the live performance of gesture and 
replaces ephemerality with persistence. In Hand Catching Lead, Serra, the sculptor, has been replaced by a performer, the sculptural object by the process of its making, and the three-dimensional sculptural object has been collapsed, displaced by the twodimensional image of film. In both cases, a series of displacements has been enacted on the practical level that not only has theoretical ramifications, but that also illustrates how the tension between the displacing and displaced forms remains in a delicate yet taut relation.

\section{Conclusion}

The final question now is this: how does the arrival at a theory of displacement reflect back on the trajectory that the discussion has taken? Dance aesthetics requires that we show how movement gets translated into concepts, and in this article in particular, into medium. I propose that the movement to medium creates a displacement that is parallel to the displacement from the empirical to the theoretical that has been undertaken in this article, where the act of displacement becomes a form of reflection and critique. I set out to argue that movement is as an overarching thematic of the films, dynamically structuring the various analyses, viewpoints, proposals, and theories gathered together. What has been revealed in this process is that movement is also the underlying force of the conceptual framework that has been developed along the way. That is, there are two clear lines of movement generated thought that travel along parallel and at times overlapping empirical and theoretical tracks. From Deleuze's cinematic ontology that analyzed the original movements and actions by Rainer and Serra, to the movement of the film strip itself, and the notion that movement is a cinematic illusion, I began to question the assumptions of where movement might lie hidden in plain sight in the films, a necessary foundation upon which more abstract thinking would be possible later.63 What became clear in the first section of this article is that when movement is analyzed both empirically and ontologically, a level of detail becomes visible that reveals the underlying kinetics of the films themselves as embodiments of the interdisciplinary ethos of their period. I also suggest that it can change the very way movement is perceived and understood in daily life.

The discussion of hybridity brought a new element of synthesis into the conversation. Levinson's proposal to ground the analysis of a hybrid within a historical context not only allowed me to make the connection of Rainer's hand movements to dance and the choreographic, and Serra's catching pieces of lead to the art of painting and sculpture, it also provided the idea that an external referent is necessary to identify the component media of a hybrid. This gets at another aspect of movement that travels along the path between the object of analysis and its history. By identifying indeterminacy as an effect of hybridity, I proposed that to cognitively move toward the constituent media of a hybrid, its' identity is destabilized. What is novel here is the way that the cognitive, or mental movement involved in thinking about the constituitive 
media of a hybrid begins to get at their abstract form. The language of the intermedial provided the next crucial intellectual step; to begin to see how aesthetic media in abstraction can be seen as if in movement themselves, which also had a spatialzing effect on the concepts. Once the media are in movement, the negative space between and around them comes into stark contrast, and that ultimately provides a field where a theory of displacement can come into play. As an original critical and reflective perspective, a previously unseen dimension of medial form and content in Rainer and Serra's aesthetic displacements is revealed, one that transits between the space of the practical, the social, and the theoretical-a place where media behaves and moves in strange ways, and artists experiment with their bodies, materials, and aesthetic alterity, while always maintaining a tenuous and fragile dialectical relation to what they know, and who they were before.

\section{Biography}

Kyle Bukhari studied Anthropology \& Aesthetics at Columbia University, and Dance Studies at the University of Roehampton, London where he was the 2013-14 US-UK Fulbright Fellow in Dance. He has danced with the Joffrey Ballet, New York, and the Zurich Ballet, Switzerland and was a winner of the Best German Dance Solo (1998). In 2013 Kyle choreographed and performed at the Whitney Museum, New York with anthropologist Michael Taussig and currently collaborates with New York choreographers Jodi Melnick and Yanira Castro. He has presented his research in the philosophy of dance at Columbia University, University of Ghent, Belgium, University of Groningen, Holland, Video Art Festival Camaguey, Cuba, and the Center for Ballet and the Arts at NYU. Kyle is on the faculty at Sarah Lawrence College, New York.

\section{Email:kbukhari@sarahlawrence.edu}

\section{Notes}

1 See also Douglas Rosenberg's "Introduction" in The Oxford Handbook of Screendance, 9-10. Rosenberg places these films in relation to suggest they are exemplars of expanded cinema and media "boundary crossing" with the screen as the site of transgression.

${ }_{2}$ Carrie Lambert-Beatty, "Other Solutions," 49.

з Benjamin Buchloh, "Process Sculpture and Film," 5. 
4 Douglas Crimp, "Sculpture Exceeded," 71.

5 Yvonne Rainer's Hand Movie is from a set titled 5 Easy Pieces, and is the only one to feature her hand. Serra's hand or hands appear in five of his films of the period.

${ }_{6}$ Hal Foster, "To Support," 8.

7 Richard Serra created works featuring live animals in Live Animal Habitat (1965-66) at the Galeria La Salita, Rome, 1966 while on a Fulbright fellowship.

${ }_{8}$ Buchloh, 5 .

9 lbid.

10 Art historian Rosalind Krauss provides another perspective on how medium has been conceived within the discourse of art history, namely in terms of genre and material support ("Two Moments from the Post-Medium Condition," 56). I understand this as a combination of both the actual physical materials used (Krauss uses the word 'substance'), such as oil and canvas for painting, cast bronze or metal for sculpture, combined with the conventions and tradition of a plastic arts practice. Yet for Krauss, this is a reductive and outmoded way of thinking about medium; she opts for the idea of 'technical support,' as it reflects the complexity of the new technologies being utilized by artists that often make it difficult to determine what material support is actually in place (Ibid.). Krauss has additionally suggested that we are now in a paradigm of the 'post-medium,' particularly with the rise of installation art.

11 Walter Benjamin, "The Work of Art," 19.

12 Marshall McLuhan, "The Medium is the Message," 7.

13 J. David Bolter and Richard Grusin, Remediation, 4.

14 Rainer studied modern dance with Martha Graham, Merce Cunningham, and Anna Halprin, African dance with Louise Gilkes, and ballet with Nina Strogonava, among others. Serra received his MFA in painting in 1964 from Yale.

${ }_{15}$ Gilles Deleuze, The Movement Image, 12.

16 Jerrold Levinson, "Hybrid Art Forms," 5.

17 Irina Rajewsky, "Intermediality, Intertextuality, and Remediation," 44.

18 Lambert-Beatty, 310, endnote 46.

${ }_{19}$ Rainer in email to author.

20 Rainer has written that the "No Manifesto ... was never meant to be a prescriptive for all time ... but rather ... [to] clear the air at a particular cultural and historical moment ..." Feelings are Facts, 264.

${ }_{21}$ Hand Movie was also screened as part of Rose Fractions (1969) at the Billy Rose Theatre in New York, only to be infamously replaced after opening night with a pornographic film.

22 Lambert-Beatty, 173.

23 Rainer in email to author.

24 Others who were not part of Judson, such as Twyla Tharp, documented their work of the period extensively. 25 Lambert-Beatty, 173.

${ }_{26}$ Crimp, 71. 
27 Anna Chave, "Minimalism and Biography," 149. Chave's discussion of the gendered lines along which Minimalism has been discursively formed is apt for the discussion of gender and subjectivity within Rainer and Serra's works.

${ }_{28}$ Rainer quoted in Lambert-Beatty, 167.

29 Idem. 173.

30 Rainer "Statement" from The Mind Is a Muscle program, Anderson Theater, New York (April 1968); reprinted in Work, 1961-73, 71.

${ }_{31}$ Hands Scraping (1968) was notably made in collaboration with the composer Philip Glass. See Annette Michelson, "The Films of Richard Serra," 72.

32 Also within this vein of hand iconography is the color film Color Aid (1970-71) featuring Serra's dirtied fingers and colored cards.

${ }_{33}$ Foster, 8.

34 Idem, 16, note 6. See also Serra in McShine "A Conversation About Work with Richard Serra," 25-26.

35 In Rosalind Krauss' Passages in Modern Sculpture, Serra's Hand Catching Lead opens the final chapter with no mention of Rainer's influence on Serra, although Krauss does hesitantly mention Rainer's insistence on "the parallels between the sensibility of the new dance and that of minimalist sculpture" in an earlier chapter. Krauss, 243, 236.

${ }_{36}$ Serra quoted in Michelson, 68 and 74.

37 Movement between media aside, it is the shared iconography of the hand in Rainer and Serra's films that is noteworthy, particularly as this type of hand-focused image, cropped tightly within a frame, is not without precursors in film. Jean Cocteau's surrealist masterpiece The Blood of a Poet (1930) featuring the speaking hand of the tormented artist can be seen as prefiguring both Rainer and Serra's films.

38 Deleuze, 1.

39 Idem, 2.

40 We could also include the movement of the Super 8 Camera machinery, as well as the movement of the film projectors that were used to screen the films before they were ultimately digitized.

41 Idem, 12.

42 Idem, 13.

43 Idem, 16.

44 Levinson, 5.

45 Idem, 6.

${ }_{46}$ Foster, 7.

47 See Arthur Danto, "The Art World."

48 Idem, 8.

49 Levinson, 6.

50 Serra quoted in Michelson, 73. Even when Krauss refers to Serra at the time as a "young sculptor" (Passages in Modern Sculpture, 243), I would also venture in light of Serra's comments that referring to Hand Catching Lead as a sculptural film is a retroactive projection of Serra's later artistic identity as a sculptor on to his 
experimental and mixed media works of his earlier period of production where his artistic identity was consciously protean.

51 Levinson, 11.

52 Sabine Huschka proposes a "movement specific intermediality" ("Media-Bodies," 61) as a way of thinking about William Forsythe's performance installations that is of interest but beyond the scope of the current work here. She offers a concept of intermediality that is focused on the body of the performer and audience as sites of image and linguistic production, and sensory experience of space.

53 The disciplinary questions and problems within the field of intermedial studies are not new. The intermedial debate can as be seen as analogous to the debate in literary theory emerging out of Mikhail Bakhtin's dialogism and Julia Kristeva's intertextuality. 54 Rajewsky, 44.

55 Werner Wolf, "(Inter)mediality and the Study of Literature," 2.

56 Rajewsky, 44. Rajewsky's case study is German choreographer Sasha Walz's Körper (2000).

57 Rajewsky, 48.

58 Idem, 5.

59 lbid.

60 Krauss, 244.

61 Lydia Goehr, "Three Blind Mice," 208.

62 Idem, 231.

63 This first step was also an aesthetic set up that can be traced to my interest in the philosopher Arthur Danto's theory of indiscernibility in relation to Rainer's pedestrian dance works and how things that appear to be optically and ontologically indiscernible can actually have a deeply divergent identity. Where Danto's theories are suitable for the often static nature of the object arts, Deleuze's theories are highly kinetic and more suitable for the time-based arts.

\section{References}

Benjamin, Walter. "The Work of Art in the Age of its Technological Reproducibility: Second Version." In Michael W. Jennings, Brigid Doherty, and Thomas Y. Levin (Eds.), Edmund Jephcottet (Trans.) The Work of Art in the Age of Its Technological Reproducibility, and Other Writings on Media. Cambridge: Harvard University Press, 2008: 19-55.

The Blood of a Poet. Dir. Jean Cocteau. 1930. Film. YouTube.

https://www.youtube.com/watch?v=RomiXOYTqKI 
Bolter, J. David and Richard A. Grusin. Remediation: Understanding New Media. Cambridge: MIT Press, 1999.

Buchloh, Benjamin H.D. "Process Sculpture and Film in the Work of Richard Serra." In Hal Foster and Gordon Hughs (Eds.) Richard Serra, OCTOBER files. Cambridge: MIT Press, 2000 [1978]. 1-20.

Bukhari, Kyle. "Embodiment of the Ordinary in Yvonne Rainer's We Shall Run (1965)." Unpublished essay. 2013.

Burt, Ramsay. Judson Dance Theatre: Performative Traces. New York: Routledge, 2006.

Chave, Anna C. "Minimalism and Biography." The Art Bulletin 82.1 (2000): 149-163. https://doi.org/10.2307/3051368

Crimp, Douglas. "Sculpture Exceeded." October 18 (Autumn 1981): 67-78.

Danto, Arthur. "The Artworld." The Journal of Philosophy 61.19 (1964): 571-84.

https://doi.org/10.2307/2022937

Deleuze, Gilles. Cinema 1: The Movement Image. Trans. Hugh Tomlinson and Barbara Habberjam. Minneapolis: University of Minneapolis Press, 1986.

Foster, Hal. "To Support." In David Frankel (Ed.) Richard Serra: Early Work. New York: David Zwirner, 2013.

Four Pieces by Morris. Dir. Babette Mangolte. Chor. Robert Morris. 1993.

http://www.babettemangolte.org/film1993.html

Goehr, Lydia. "Three Blind Mice: Goodman, McLuhan, and Adorno on the Art of Music and Listening in the Age of Global Transmission." New German Critique 35.2/104 (Summer 2008): 1-31.

----. Elective Affinities. New York: Columbia University Press, 2008.

Hand Catching Lead. Dir. Richard Serra. 1968. Film. YouTube

https://www.youtube.com/watch?v=_NBSuQLVpK4

Hand Movie. Dir. Yvonne Rainer. 1966. Film. YouTube https://www.youtube.com/watch?v=CuArqL7r1WQ

Huschka, Sabine. "Media-Bodies: Choreography as Intermedial Thinking Through in the Work of William Forsythe." Dance Research Journal 42.1 (Summer 2010): 61-72. https://doi.org/10.1017/S0149767700000838

Krauss, Rosalind. Passages in Modern Sculpture. Cambridge: MIT Press, 1998 [1977]. 
----. A Voyage on the North Sea-Art in the Age of the Post-Medium Condition. New York: Thames and Hudson, 1999.

----. "Two Moments from the Post-Medium Condition." October 116 (Spring 2006): 5562.

Lambert-Beatty, Carrie. "Moving Still: Mediating Yvonne Rainer's 'Trio A."' October 89 (Summer 1999): 87-112.

----. "Other Solutions." Art Journal 63.3 (Autumn 2004): 48-61.

https://doi.org/10.1080/00043249.2004.10791134

----. Being Watched: Yvonne Rainer and the 1960s. Cambridge: MIT Press, 2008.

Levinson, Jerrold. "Hybrid Art Forms." Journal of Aesthetic Education 18.4 (Winter 1984): 5-13. https://doi.org/10.2307/3332623

Lovatt, Anna. "Ideas in Transmission: LeWitt's Wall Drawings and the Question of Medium." Tate Papers 14 (2010). http://www.tate.org.uk/research/publications/tatepapers/ideas-transmission-lewitts-wall-drawings-and-question-medium

McLuhan, Marshall. "The Medium is the Message." Understanding Media: The Extensions of Man. Cambridge: MIT Press, 1994 [1964]: 7-21.

McShine, Kynaston. Richard Serra Sculpture: Forty Years. New York: Museum of Modern Art, 2007: 25-6.

Michelson, Annette. "The Films of Richard Serra: An Interview." In Hal Foster and Gordon Hughs (Eds.) Richard Serra, OCTOBER files. Cambridge: MIT Press, 2000 [1979]. 21-57.

Morris, Robert. "Notes on Dance." In Mariellen R. Sanford (Ed.) Happenings and Other Acts. London and New York: Routledge, 1995. 168-172.

Phelan, Peggy. "Yvonne Rainer: From Dance to Film." A Woman Who: Essays, Interviews, Scripts. Baltimore: John Hopkins University Press, 1999. 3-17.

Rainer, Yvonne. "Some Retrospective Notes on a Dance for 10 People and 12 Mattresses Called 'Parts of Some Sextets,' Performed at the Wadsworth Atheneum, Hartford, Connecticut, and Judson Memorial Church, New York, in March, 1965." The Tulane Drama Review 10.2 (Winter 1965): 168-178. https://doi.org/10.2307/1125242

----. Work 1961-73. Halifax: Nova Scotia School of Art and Design Press, 1974.

----. Feelings are Facts, A Life. Cambridge: MIT Press, 2006. 
----. Personal conversation with author at Dia Beacon, New York. May 13, 2012.

----. "Re: Article on Hand Movie." E-mail to author. October 14, 2016.

Rajewsky, Irina O. "Intermediality, Intertextuality, and Remediation: A Literary

Perspective on Intermediality." Intermédialités 6 (Autumn 2005): 43-64.

https://doi.org/10.7202/1005505ar

Rosenberg, Douglas. "Introduction." The Oxford Handbook of Screendance Studies. New York: Oxford University Press, 2016. 9-10.

https://doi.org/10.1093/oxfordhb/9780199981601.013.37

Wolf, Werner. "(Inter)mediality and the Study of Literature." CLC Web. Comparative Literature and Culture 13.3 (2011): 1-9. https://doi.org/10.7771/1481-4374.1789 


\title{
Anarchitextures: Intermedial Encounters On The Screen
}

Ariadne Mikou, University of Roehampton

\begin{abstract}
In this article I draw on architectural and choreographic ways of thinking to discuss how filmed material is transformed through projection and active and mobile spectatorship. Shifting my attention from what is projected to where it is projected, I expand the discourse beyond the single flat cinematic screen. I do this by concentrating on how the projected surface (its placement in space and its assembly with multiple screens) creates social encounters. This study accepts Rosenberg's definition of the screen as "a receptor of an otherwise ephemeral image and which reifies that image in the process of receiving it." ${ }_{1}$ Anarchitextures 2 is a screen-based performance project through which I explored Eisensteinian montage to include a spatial and ambulatory practice. The project speaks to choreographic environments and events that use the screen as a socially engaged practice, and also poses some questions regarding the boundaries that appear to shape the screendance field.
\end{abstract}

Keywords: practice-as-research, intermediality, event-spaces, Tschumi, expanded choreography, haptic materiality, Bruno, montage in space, Eisenstein

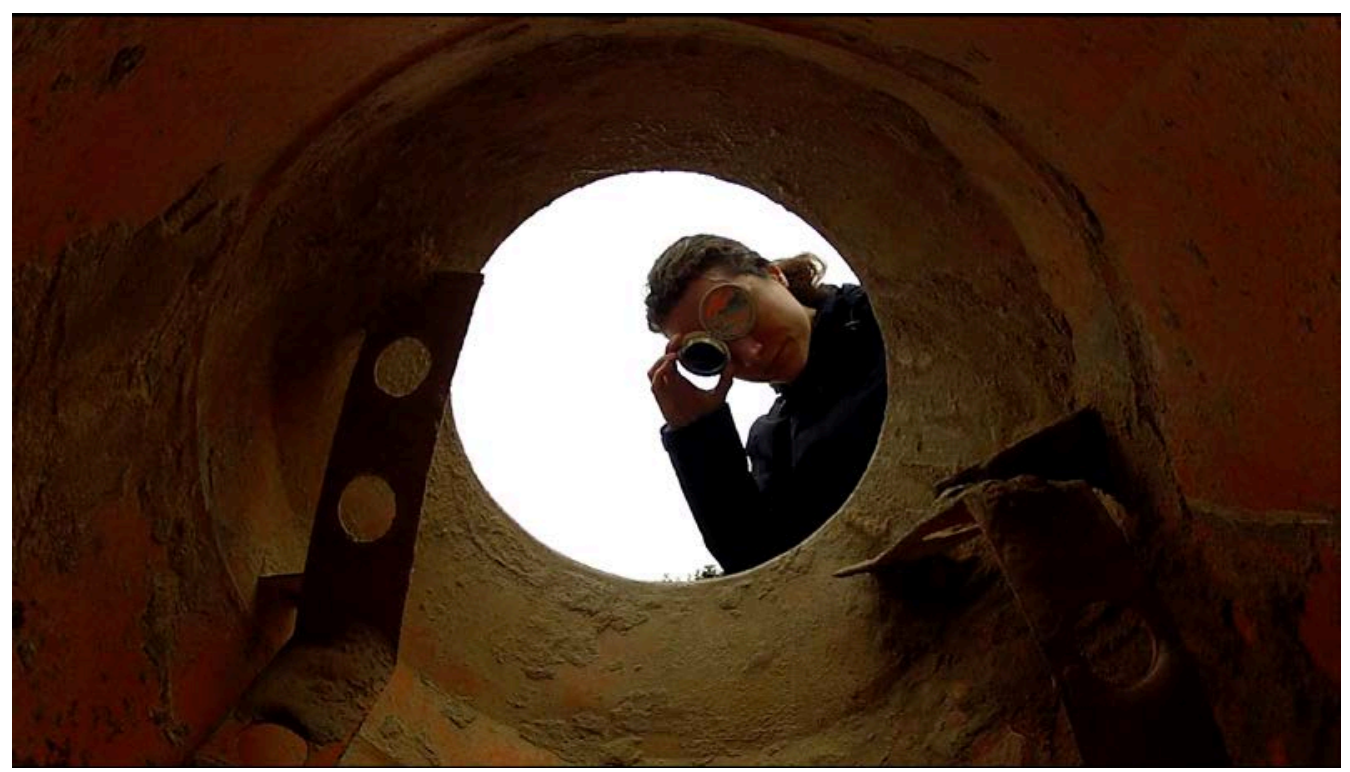

Still image by one of the several clips projected during Anarchitextures. Credit: Author. Link to video: https://vimeo.com/170866405 
Lights at a low intensity inside Michaelis Building, a black box theatre located in South West London. Around 100 rectangular cardboard boxes painted with blackboard paint and covered with a thin layer of cement form vertical walls on the top of a large architectural diagram designed by white tape on the black floor of the stage. It is a copy of the architectural plan of Robin Hood Gardens Estate, a twin social house in East London that is currently in a state of impending demolition. Moving images of a performer that have been recorded while she was moving around the two weathered buildings of the Estate, are projected on the light and able-to-be-divided walls of the set design. Gradually throughout the day, the audience enters the environment and begins to displace the boxes, allowing the space to transition from detailed clarity to chaos. Because of the displacement of the cubes, the projected image fragments, folds, gains three-dimensionality, or disappears from the textured cubes to appear differently on other non-reflective surfaces of the surrounding space. Throughout the alteration of the environment the white taped lines of the traced buildings remain intact while the pre-constructed environment evolves into a demolished landscape. In the backdrop, a repetitive clip depicts the continuous circular motion of a concrete mixer. The clip suggests an exit from the darkness of the theatre to the natural light of the sky, but the incoming light remains overshadowed by a pair of eyes, which look from the opening of the womb-like concrete machine into the world of theatre.

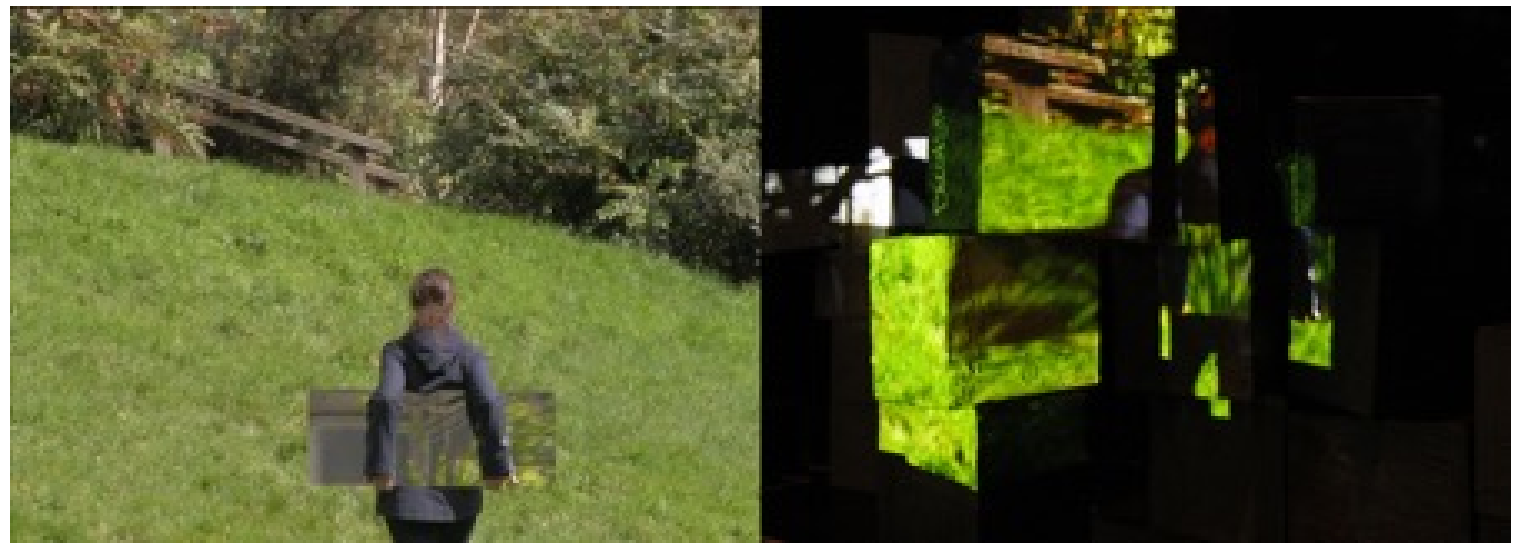

Sculpting the Image. Fillm still (left) and photo of the same still during Anarchitextures (right). Credit: Author

Anarchitextures 3 is a screen-based and intermedial 4 choreographic environment and event. It is influenced by Diapolyekran and other scenographic and technological experiments of Czech set designer Josef Svoboda whose moving-image constructions integrate filmic projections. Anarchitextures shares with the screen-based performances of Svoboda the way film and stage share the same space, but remain distinct.5 Svoboda's alterable architectures for the stage derive from modularitymobile compartments able to join in various combinations to form transformable 
spaces.6 The alteration of Svoboda's environments is based on mechanically conceived apparatuses, but the presentation and evolution of Anarchitextures depends on interaction and the authority that the spectator is given to transport and reposition the cardboard boxes; each of which carries the potential to be a screen under the projected light across the floor of the stage.

Svoboda's experimentations focused on "the relationship between the live and the filmic and the projected and the architectonic" 7 and I will similarly attempt to share my thoughts from three perspectives: the architectural, the choreographic, and the screenic:

- Architecture, entering the discourse on performative and temporal architecture, 8 is characterized by "action, interaction, temporality and adaptation" 9 and it appears as an ephemeral environment.

- Choreography opens a dialogue with the expanded notion of choreography, 10 which reconsiders movement beyond the mere arrangement of agile bodies in motion.

- Screenic refers to "the transformation of the filmic raw material during its processing by projection and, ... to the fact that what occurs on the screen is part of a more general phenomenon involving theatre space and spectatorship." 11 The anarchitextural filmic material has been projected into cardboard boxes covered with concrete-the architectural and predominant material of the streets and cities; the spaces of concentrated polyphony and diversity where political and social actions and conflicts may take place.

I have used the projected image and the screen to unite architecture and choreography into a choreographic environment and event placed inside a theatrical context. The black box theatre became a visual and participatory environment free from the conventions of visual art and conformed more to the rules of the dance world. 


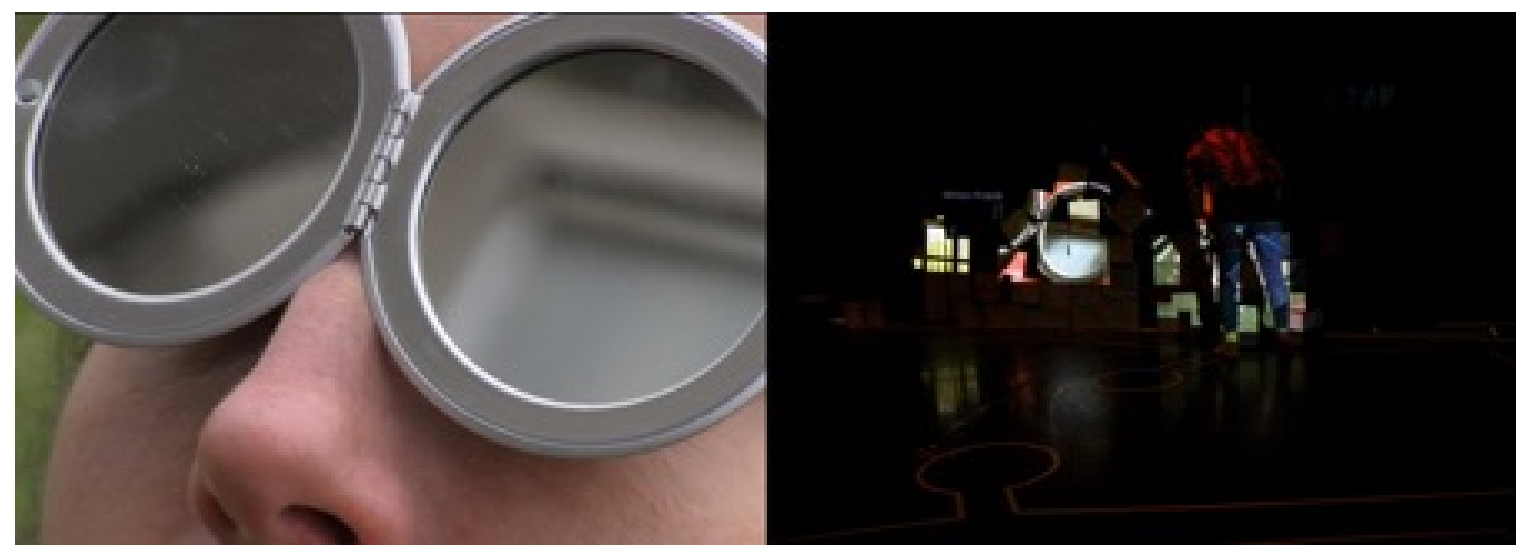

Building in process. Fillm still (left) and photo of the same still during Anarchitextures (right) Credit: Author

\section{Architectural Inputs}

The artist Alan Kaprow first used the word environment to frame his large multimedia works and distinguish them from installation art. The latter still nowadays refers to "the type of art into which the viewer physically enters, and which is often described as 'theatrical', 'immersive', or 'experiential'."12 Although both environment and installation share a dependence on sensually triggered viewership ${ }_{13}$ and an affinity with the site where they happen for a short life-span, Kaprow proposes that installation means, "very simply and literally, that somebody is taking something already fabricated or made, generally, and installing it." 14 Commenting on its distinction from installation-based art, he identifies the main characteristic of environment as that of "surround." 15 An environment, usually of room-size, is a "threedimensional work of art, often of temporary nature, which the viewer can enter." 16 For example, Rachael Whiteread's Embankment, 17 a massive sculpture of a large number of polyethylene white boxes stacked in piles, could be considered an installation of objects, but its monumental scale can also turn it into an environment.

The act of surrounding is key to my understanding of architecture and also connects architecture and environment. I perceive architecture as a structure bigger than my body in which I have the possibility to enter and feel protected by. Architect Bernard Tschumi writes: "Architecture is defined by the actions it witnesses as much as by the enclosure of its walls," 18 and architect Kate Macintosh presents the protective shelter as the fundamental element of architecture.19 In Anarchitextures, the limits of the ephemeral environment were manifest through the construction of walls made by cardboard boxes (covered in a thin layer of concrete) placed along the white-taped outline of the architectural plan of Robin Hood Gardens Estate. Anarchitextures was an attempt to create an ephemeral architectural environment, transformed into an event space by the intruding and interacting audience. 
Between 1981 and 1983, Tschumi defined architecture as the space of events, which is described as "both the space and what happens in it." 20 This concept makes architecture an experiential and live art performed by the "building and the people, the walls and the bodies." 21 An architect, similar to a film or theatre director, is the one who sets conditions22 and architecture is a stage to be performed on by actors of everyday life; a stage-set in which "radical choreographic ideas of space from dance and film could substitute for the power structure of plans, sections, and elevations." 23 The opportunity for pedestrian performances on the architectural and urban stage renders the space alive and transformable through the interaction of the user with architecture. Similarly, the theatrical stage where Anarchitextures took place is a space-or an architectural condition as Tschumi suggests-designed according to theatrical codes of spectatorship and conventions of staging that I adapted to the participatory project of Anarchitextures. The action of the audience to dislocate the cubes inside the ephemeral anarchitextural space, by attempting to recompose the configurations of the cardboard boxes, gradually unfixed the artwork-as-product and handed more artistic agency to the audience. The participatory actions to cross, transform, and appropriate the theatrical stage helped to turn both the anarchitextural environment and the surrounding black box theatre into event-spaces. Anarchitextures gradually evolved into an anarchic environment that slowly lost its pre-planned and pre-choreographed order through the actualization of the event, a social encounter that invites active and participatory spectatorship.

\section{Expanding the Notion of Choreography}

Choreography in an expanded view has been defined as the ability of an organism, a mechanism, a body, and a system to produce movement.24 Choreography as the disappearance of the subject which experiences dancing movement and the visibility of "the experience of movement itself, without the subject" 25 disconnects choreography from its direct association with the human bodies and turns attention into the ways movement is organized in space. In the Artificial Nature Series, Danish choreographer Mette Ingvartsen directly explores non-human choreography and performance. The Artificial Nature Project is a choreography for materials activated by human and non-human performers and Evaporated Landscapes is an artificial landscape in evolution made by ephemeral materials. Anarchitextures is in dialogue with these practices that approach broader concepts of mobility, evolution, spatial transition, and transformation as choreographic; it is not only an environment for moving inside or looking at, but also a transitioning space under the manipulation of the spectator. Movable screens, fabricated from boxes and arranged on the theatrical stage by the visitors, contributed to the continuous transformation of the ephemeral environment. The transformation of the anarchitextural landscape in time can be considered as movement, which occurs in the performative structure of Anarchitextures as a whole, and helps us to experience choreography as time. 
Besides the concept of spatial transformation perceived as movement, the moving and transported boxes-as-screens may also be converted into performers. The handfabricated screens have been anthropomorphized and architecture-morphized, as a result of the light projected onto them. Giuliana Bruno, researcher on the intersection between architecture, film, visual arts and media, refers to the transformative agent of projected light, and writes that "[t]he white film screen is like a blank wall on which the moving pictures of a life come to be inscribed. Etched on the surface, these experiential pictures, like film's own, change the very texture of the wall." 26 In Anarchitectures, cardboard boxes from a retail shop-"disconnected from utility and functionality through defamiliarization" 27 -were converted into individual or assembled screens that the projected light animates; the light changed their identity from pure and life-less geometric objects to screens carrying meaning and narrative. On the theatrical stage, the place where live performances usually occur, the movable boxes became the performers of the anarchitextural environment under the power of the projected light that philosopher Gilles Deleuze, speaking about the objective of the cinema in contrast to the theatre, refers to as the "luminous dust." 28

The construction of cubic sculptures can also be considered a choreographic task for visitors to alter the composition of the screens and, in turn, affect the appearance of the projected images. Under the active spectators, the moving images fragmented, got folded, or even disappeared. The input and responses of the active spectators to re-arrange the screenic configurations of the projected images transformed the choreographic environment into a choreographic event. Dance scholar Sophia Lycouris claims the use of choreographic environment 29 as an appropriate term to describe installation spaces that have emerged from choreographic thinking, and that require the audience to physically engage with them. Taking into account Kaprow's definition of surrounding environments and Tschumi's participatory character of event-spaces, I propose that the term choreographic event is more appropriate to describe environments which are, as Lycouris suggests, the outcome of a choreographic manifestation in space and the participants' active input. The choreographic event without the contribution of the mobile spectators and their response to the construction of screenic sculptures remains an intact and immersive choreographic environment. However, the identification of a choreographic outcome as event or environment is slippery and depends on the degree of audience participation and space activation that, in turn, define the degree of social engagement between choreographic work and spectator. Through this lens, a choreographic event is close to the notion of social choreography 30 which according to choreographer Ingvartsen is concerned with "the organisation of space, the organisation of a group in space and of its behavior." 31

I have defined the organisation and behaviour of the visitors inside the anarchitextural environment by the participatory and collaborative constructing and deconstructing 
of the anarchitextural environment and the quasi anarchic approach (in terms of lack of any specific choreographic instruction and control) of displacing, replacing, and repositioning the boxes-as-screens. In Anarchitextures, I juxtapose museums and galleries where projects' specifications, institutional conventions, and authorities usually encourage a fixed composition in space and prevent any haptic interaction with the exhibited work; I suggest to activate the sense of touch that is immanent in the social encounters with architecture and dance. Haptic, an experience activated by architecture, 32 refers to the ability to come into physical contact through the skin. 33 The surfaces of a building - such as the walls that surround us and the floor where we step with our feet-create a sensual effect 34 caused by the texture, density, and temperature of the architectural materials. The sense of touch activated through our skin and not only by our hands is also immanent in social dance, contact improvisation, or any type of partnering dance. According to choreographer Boris Charmatz, the co-instigator of La Musée de la Danse, dance is "permeable" 35 like the anarchitextural environment of this discourse. In Anarchitextures the audience manipulates the appearance and disappearance of the image, its fragmentation or completion. Touching, holding, and transporting the hand-fabricated screen to compose and recompose the projected images is part of building the haptic memory of the building-soon-to-be-demolished.

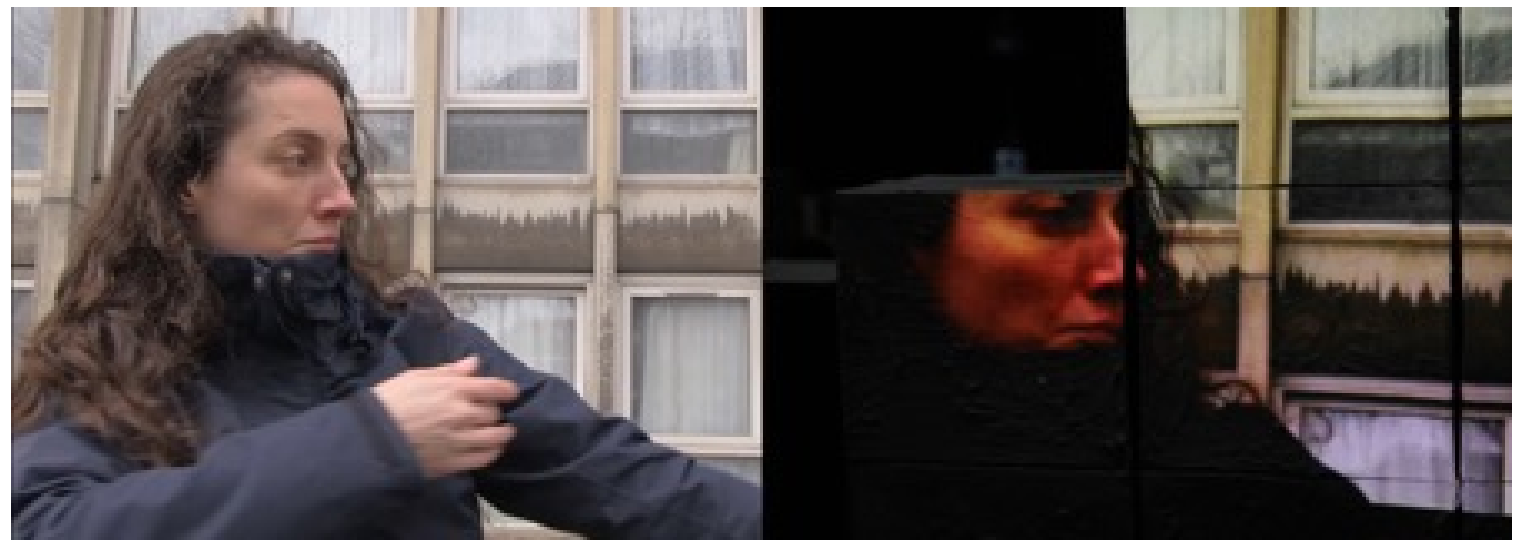

Katja Vaghi performing at the back side of the Eastern Block of Robin Hood Gardens Estate (left). Textured image during Anarchitextures (right). Credit: Author

\section{Screen Perspectives}

Haptic Screen Encounters

Screens-"a space of crossovers, in which the visual and the spatial arts come to be connected in textual materiality and surface tension," ${ }_{36}$-have been the focus of architects, film makers, and visual artists. For example, screens as architectural walls partition the internal spaces of the transparent Glass Pavilion (2006) in Toledo (OH) that is designed by the architectural group SANAA. Images that trace the family history of film director Chantal Akerman are projected on a tulle-as-screen that is part of her 
installation Walking Next to One's Shoelaces Inside an Empty Fridge, and Robert Irwin's installation Excursus: Homage to the Square "engages the forms of canvas, wall and screen in architectural inquiry." Irwin constructed rooms by scrim-walls where the color textures and hues of Joseph Albers' paintings are materialized in their surfaces through light. The viewers of the installation appear and disappear through the transparently fabricated walls and "like actors in a film, enter into a play of light and shadow, becoming shadows themselves." 37 In the above cases, screen is a wall, a surface, and a canvas which are all elements of architecture, film, and painting respectively. Therefore, screen is:

An object used to protect, obscure, or conceal, ... an architectural and sculptural apparatus used to separate or divide space in a process of exclusion or delimitation, ... a surface or a receptacle on which images are projected or displayed, ... a metaphorical term or a site of mediation involving a relationship between what is shown and what remains under cover.38

In the case of Anarchitextures, screens are modular units that were manipulated, assembled, and separated by the audience, and formed as walls with sculptural and volumetric depths. These assembled screens turned into three-dimensional surfaces expanding the depth, plasticity, and limits of a flat cinematic screen. The surfaces of the cardboard boxes had been painted with concrete that gave the projected image a textured layer and mostly concealed their mundane origins.

The concrete surface and canvas of the hand-fabricated screens offered to the moving image a skin, which helped to shift "our focus from the optic and toward a haptic materiality." 39 The surface of the screen, thus its outside, mediates between the projected image and the hand of the audience and "it is by way of such tangible, 'superficial' contact that we apprehend the art object and the space of art, turning contact into the communicative interface of a public intimacy." 40 Elisabeth Grosz, speaking about the operation of the outside, describes its ability to connect processes, events and series, creating a "plane of consistence or coexistence." 41 Therefore, I propose that the external cover-the skin of the fabricated screens-becomes the surface that connects visual and spatial arts through their disciplinary external membranes; the textured screen turns into a space for the exchange and coexistence of architecture as texture, film as surface, and dance as contact with another skin.

In the Skin of the Film Laura U. Marks, refers to the affect and synesthetic impact of viewing in all our senses, including the haptic, and defines haptic visuality as "the way vision itself can be tactile, as though one were touching a film with one's eyes." 42 Bruno's haptic materiality and Marks' haptic visuality refer to the difference between the skin of the screen and the skin of the moving image. Both perspectives play on the idea that the surface, the texture, and the medium on which the moving image is 
projected or screened matters, because it affects us differently. The mediation of the image by different surfaces is unique and every architectural texture and surface, such as the cinema screen or the brick, the metal, and the wood, absorbs the light of the moving image in different ways. In Anarchitextures, the texture of the building is not only depicted or represented on the screen, but it is sensed through the haptic encounter of the audience's hands with the dressed boxes-as-screens. Concrete, a very stable and strong architectural material when supported by steel, references the building of Robin Hood Gardens Estate. The concrete skin of the screen adds an additional layer of weathering - and the potential for a non-digital ruination-to the projected image. Therefore, the texture of the building merges with the skin of the moving image and the surface of screen; all of them reveal the passage of time.

Time is not only evident on the outer skin of architecture, but it is etched on the skins of the moving image and the screen-the surface that embodies "the relation of materiality to aesthetics, technology, and temporality." 43 By the end of the anarchitextural event, the concrete applied to the cardboard boxes has been almost pulverized, imprinting its grey dust on the floor and the skin of the hands of the audience. In this way, I think of Anarchitextures as an ephemeral gesture in space that gradually turns into rubble in the same way that derelict buildings fall under the power of excavating machines. Bruno, speaking about the essence of time imprinted on the screen, refers to Jane and Louise Wilson's A Free and Anonymous Monument an installation-archiving of the modern ruin of Victor Pasmore's Apollo Pavilion in the North East of England - that influenced me in the development of Anarchitextures. She writes that time is "impressed on other kinds of architecture-the translucent screens of moving-image installations. Pictures in motion write our modern history. They can be the living, moving testimony of the effects of duration. Moving images are modernity's ruins." 44 Bruno understands the screen of moving image to be a kind of architecture that captures the passing of time and I also propose that the texture and spatial arrangement of the boxes-as-screens contribute to an embodied archiving of the weathered buildings. The way that the anarchitextural screens were placed on the floor of the theatrical stage created free spaces for the mobile spectators to circulate among them as if inside the landscape of the Robin Hood Gardens Estate, and also able to touch the concrete texture of the building. Sporadically re-arranged pathways-among assembled screens formed into relief walls-were waiting to be crossed. 


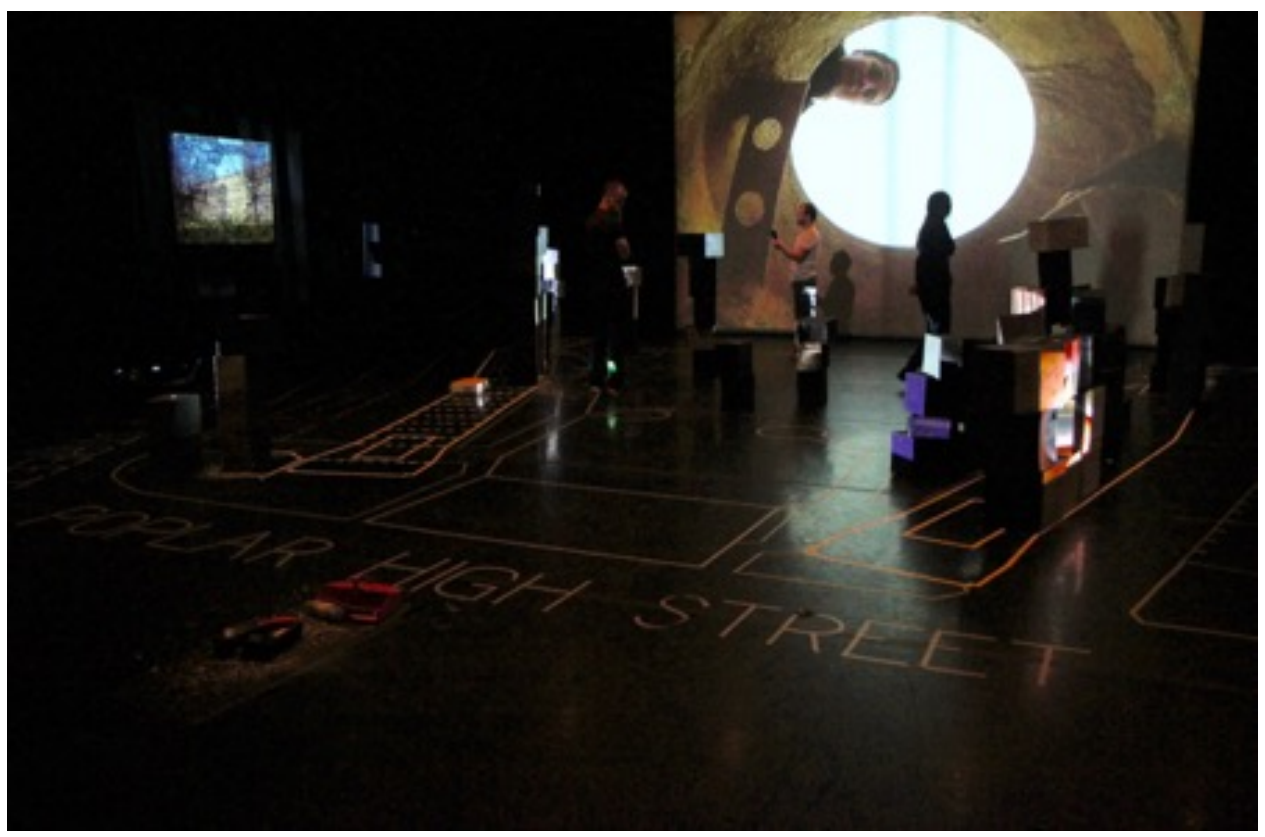

Diagram in space. Credit: Author

Walking as Montage. An active archive in process

In the field of architecture, the concept of path has been theorised by Le Corbusier, who called it promenade architecturale and defined it as the experience of walking through and in general circulating inside a building. The notion of path joins architecture and film "in a practice that engages seeing in relation to movement." 45 In contrast to Tschumi's approach to architecture as an opportunity for interaction through the notion of event-spaces, Le Corbusier gave to the experience of architecture an ocular attribute dependent on locomotion. He observed that architecture is "appreciated while on the move, with one's feet ...; while walking, moving from one place to another. ... A true architectural promenade [offers] constantly changing views, unexpected, at times surprising." 46 A promenade architecturale, otherwise a journey in space and time through a specific path, is what encourages mobile spectatorship and offers to architecture a dynamic conception which "overcomes the traditional notion of building as a still, tectonic construct." 47 As Bruno puts it, referring to the choreographed journey across the buildings of the Acropolis in Athens, "as we walk among (its) buildings, it is our legs that construct meaning." 48 Moving allows us to conceive the architectural space as a peripatetic and cinematographic practice. The elements of space are still, but our transportation among them creates memories and personal sequences of urban and architectural narratives.

Film director and theoretician Sergei Eisenstein stated that the mobile spectator on an architectural path "moved through a series of carefully disposed (architectural) 
phenomena which absorbed in order with his visual sense." 49 By the same token, Eisenstein identifies as path, and in particular the cinematic path, the mental ability of the mind to follow "a multiplicity of phenomena, far apart in time and space, gathered in a certain sequence into a single meaningful concept; and these diverse impressions pass in front of an immobile spectator." 50 This is the essence of Eisensteinian montage, which renders the screen the linking point of "various elements (fragments) of a phenomenon filmed in diverse dimensions, from diverse points of view and sides." 51 From this perspective, and as Eisenstein confirms, the cinematic technique of montage is inherited by the peripatetic experience of architecture, which provides to the spectator the possibility to create narratives of space in the imaginary screen of the mind. The cinematic path is a pre-defined and re-playable compression of space and time that unfolds in front of a static viewer, while the architectural path is a choreographed void that can always be revisited by a moving person. The speed, the pauses, and the order that the points of the path are linked to, may be composed in an improvisational and personal manner and in this way the architectural path is similar to the path as defined in dance.

Dancing is interwoven with the action of traversing immaterial space through a predefined or improvised path. In choreography, approached according to its etymology as "dance-writing," 52 the path is visualized as a drawn line usually found in dance notations and scores. For instance, from the first dance notations of RaoulAuger Feuillet to Yvonne Rainer's floor plans for Trio B, the flow of movement in space is indicated by a trace drawn on the paper. Path and trace are both imaginative forces for moving in space through time. Both are represented as a line, but they differ ontologically because one refers to the past and the other to the future. Trace is "any enduring mark left in or on a solid surface by a continuous movement." 53 Path is a soliciting of perambulation, a route-finding device through a mapped space. The poetic drawings of Anne Teresa De Keersmaeker on the sand during the violin phase of Fase, the bodily drawings of Trisha Brown (It's a Draw/Live Feed), and the digital visualisations of the trace in William Forsythe's choreographic objects (Improvisation Technologies, Synchronous Objects), witness dance's concern for the inscription, capture, materialisation, transformation, and interpretation of the trace and path into movement, and vice versa. In both architecture and dance, the trace as an archive of motion and transition can suggest a path that is waiting to be crossed again.

The triadic intersection of the path in architecture, film, and choreography distinguish the concept of montage in space inside a choreographic environment from montage for screen. While the latter requires a static receiver of moving-images, the mobile spectator in a choreographic environment is engaged in an active editing of space and is potentially involved in the production of an event-space; a dynamic transformation of space. During Anarchitextures the moving spectator is the editor who creates the montage of the moving images from Robin Hood Gardens Estate by walking in space, 
mentally and manually putting the pieces of the 'puzzle' together. The spectatorwanderer is the one who gains an understanding of the building (Robin Hood Gardens Estate) by navigating in space, moving, touching, and re-arranging its components. The wanderer constructs a non-linear narrative out of the architectural traces, the sculptural assemblies of cubes, the optional audio archives, and the textured images of the fragmentary and dramaturgically constructed anarchitextural environment. The mobile spectator, who experiences locomotive, ocular, and haptic senses, becomes an active participant who at the end enacts the work and builds an embodied and multisensory memory of architecture.

\section{Expanding the Screendance Field}

In this writing, I have sought to examine the transformation of space, the shared artistic authorship, the haptic interaction with the screens, and the navigation in space as the basic participatory aspects of the screen-based project Anarchitextures. As Anarchitextures was presented inside a theatrical context, I have attempted to rethink the limits between stage and auditorium and to propose the theatre as a revitalized public space for the dialogue between architecture, choreography, and moving-image through the creation of choreographic events-choreographed conditions that give permission to the audience to gradually transform the work and the space using the elements of the work. I have also written about the immersive and experiential character of architecture, the permeability of dance, the haptic visuality of film, and the way that they might be present together on the materiality, texture, and transportability of the modular screen. Spectatorship based on the haptic materiality of the screen and mobilized inside choreographic paths produces experiences associated with how we engage with architecture through haptic and ocular senses. Montage in space-an invitation towards the audience to apply basic tools of film editing, such as assembling and cutting for the production of social space-provided some views on challenging fixed and passive spectatorship. Assemblage and cut were applied to the sculptural compositions of the screens that in turn transformed the space and the composition of the moving-images.

Furthermore, I have suggested that the design of space, either of a building or an installation, and an environment, is deeply choreographic as it also concerns paths for moving journeys. For this last reason, I wish to propose that choreographic aspects of visual installations push such environments into the current discourse on expanding the definition of screendance. 54

Screendance is gradually expanding and striving to emancipate dance from its strict association with the trained body. For example, Harmony Bench's hyperdance "recuperates performance for the screen and positions the computer user not only as a viewer/spectator, but as a performer and even co-choreographer." 55 Claudia Kappenberg's Screendance Effort Graph maps the field of screendance "without 
prescribing aesthetic forms or limiting the range of possibilities." ${ }_{56}$ Anna Heighway's notion of radical screendance sheds light on screendances in the absence of the moving body and in the presence of anything "kinetically driven." 57 Such radicalities mirror the practices of expanded choreography and expanded cinema. I propose that we consider screen-based installations-deriving from choreographic thinking, providing choreographic experiences, and containing choreographic principles-to be expanded screendance; that visual installations, environments, and events could also be characterized as screendance installations, environments, and events.58

Screendance environments and events demand an active spectator. Thus, spectatorship is less concerned with seeing, but with engaging full body immersion, participation, and social interaction, which may not only be limited to the process of making screendance, but expanded into the way that screendance arrives to an audience. The way that space between and around viewers may be organized becomes important for screendance makers and curators as long as screendance curatorship is aligned with expanded choreographic practices. The fact that every surface can turn into a screen, and therefore every space can be transformed under the power of the projected light can enrich the possibilities of the screendance-asevent. Events turn attention to what happens in the spaces between bodies, and between bodies and architecture, and can pave the way for the display of screendance as an event with social parameters-as an expanded choreographic action that may transform and appropriate spaces and spectators' experiences.

\section{Biography}

Ariadne Mikou is an interdisciplinary dance artist, movement educator and emergent scholar from Greece. After graduating from the School of Architecture at Aristotle University of Thessaloniki (GR) she moved to USA in order to pursue a Master of Fine Arts in Dance from The Ohio State University with support from the State Scholarship Foundation of Greece. She is currently based in London where she is concluding her fully-funded practice-as-research $\mathrm{PhD}$ at the University of Roehampton having as focus the spatio-corporeal and social intersections of event-oriented artistic practices that include architecture, choreography and the moving-image. In parallel with curating exchanges between artists, her practice includes making and writing about works created for the screen, installations and mediated performances.

Email:alosidne@gmail.com

Website: www.amikou.com 


\section{Notes}

1 Douglas Rosenberg, Screendance, 16.

2 Anarchitextures was realized with the contribution of Katja Vaghi (video performance); Tom Medwell (camera); futuremellon/not yet art (production); Michael Toon (technical management); Chelsea Rolfe, Emily Sadler, Bruce Sharp, Jenny Whittaker (technical assistance).

3 The name Anarchitextures derives from the anagrammatic alteration of Anarchitecture, an art collective that was initially formed in 1973 by Gordon MattaClark and other artists in order to "think about the transitional, or transpositional, in architectural practice" (Pamela M. Lee, Objects to Be Destroyed,104). Matta-Clark has been well known for his violent interventions in pre-demolished buildings and his vanishing anarchitectural actions revealed the inside of architecture to the outside through cutting parts of derelict buildings. In a similar way, Anarchitextures bring the insides of the disciplines into view and exchange with each other. Other contemporary practices that mirror Matta-Clark's logic of cut is the work of Sara Oppenheimer whose sculptures cut or withdraw part of existing spaces.

4 Dominique Chateau and Jose Moure write in 2016 that "Intermediality is a key concept introduced by historians having realized that traces of other media are to be found in movies. It is also reversible: traces of movies are to be found in other media." Chateau and Moure, Screen, 21.

${ }_{5}$ See Chris Salter, Entangled. 152.

6 Idem, 50.

7 Idem, 153.

8 See Kolarevic and Malkawi, Peformative Architecture, and Salter.

${ }_{9}$ Salter, 84.

10 Expanded Choreography. Xavier Le Roy, Macba, 2012.

${ }_{11}$ Château \& Moure, 16.

${ }_{12}$ Claire Bishop, Installation Art, 6.

13 Ibid. Bishop writes that Installation art "presupposes an embodied viewer whose senses of touch, smell and sound are as heightened as their sense of vision."

${ }_{14}$ Alan Kaprow and John Held, An Interview with Alan Kaprow.

15 Ibid.

${ }_{16}$ Edward Lucie-Smith cited in Julie Reiss, From Margin to Center, 12.

17 Embankment was commissioned for Tate Modern's Turbine Hall.

18 Bernard Tschumi, quoted in Rachel Sara and Alice Sara, "Between Dance and Architecture," 62.

${ }_{19}$ Utopia London.

20 Tschumi, et al, "Performance/Architecture," 53.

21 Sara and Sara, 63.

${ }_{22}$ See Tschumi, "The Architecture of the Event."

${ }_{23}$ Salter, 85.

24 See Rudi Laermans, "'Dance in General."' 
25 Bojana Bauer, "The Makings of," 15.

${ }_{26}$ Giouliana Bruno, Atlas of Emotion, 105.

27 André Lepecki quoted in Erin Brannigan, "Dance and the Gallery," 14.

28 He writes that cinema "spreads an 'experimental night' or a white space over us; it works with 'dancing seeds' and a 'luminous dust'; it affects the visible with a fundamental disturbance, and the world with a suspension, which contradicts all natural perception." Gilles Deleuze, Cinema 2, 201.

${ }_{29}$ See Sophia Lycouris, "Choreographing Environments."

30 See Andrew Hewitt, Social Choreography, and Bojana Cvejic and Ana Vujanovic, TkH Journal Special Issue on Social Choreography.

31 Mette Ingvartsen, "Soft Choreography," 68.

32 Teachers of architectural design Kent Bloomer and Charles Moore refer to the haptic systems that allow to perceive architecture through our bodies. 1977. Architect and urban designer Steen Eiler Rasmussen describes the textural effects of architecture. 1964. Juhani Pallasmaa writes about how the eyes of the skin see architecture. 2005 Christian Norberg-Schulz examines the phenomenological encounters with architecture 1980.

33 Bruno, Atlas of Emotion, 6.

34 Architect Peter Zumthor writes about architecture that it is perceived as "a bodily mass, a membrane, a fabric, a kind of covering, cloth, velvet, silk, all around me ... A body that can touch me." Atmospheres, 23.

35 Jérôme Bel and Charmatz, "Jérôme Bel and Boris Charmatz," 236-7.

${ }_{36}$ Bruno, Surface, 7.

37 Idem, 74.

${ }_{38}$ Château \& Moure, 15.

39 Bruno, Surface, 3.

$40 \mathrm{lbid}$.

${ }_{41}$ Elizabeth Grosz writes: "[t]he interiority of (these) series is of less interest than the way they are capable of being aligned to connect, creating their plane of consistence or coexistence, which is made possible only through the operations of this outside." Space, Time and Perversion, 134.

42 Laura U. Marks, "The Skin and the Screen," 11.

43 lbid.

44 Bruno, Public Intimacy, 82.

45 Bruno, Atlas of Emotion, 58.

46 Le Corbusier quoted in ibid.

47 Idem, 57.

$48 \mathrm{Idem}, 56$. The buildings of Acropolis in Athens are also the case study of Eisenman's treatise Montage and Architecture (ca 1938).

${ }_{49}$ Sergei Eisenstein quoted in Micheal Dear, "Between Architecture and Film," 11.

50 Eisenstein, "Montage and Architecture," 116.

51 Eisenstein quoted in Yve Alain Bois and M. Glenny, "Introduction," 111. 
52 Susan Leigh Foster, "The word 'choreography' derives from two Greek words, choreia, the synthesis of dance, rhythm, and vocal harmony manifest in the Greek chorus; and graph, the act of writing." Choreographing Emphathy, 16.

53 Tim Ingold, Lines, 43.

54 See for example Harmony Bench, "Hyperdance"; Claudia Kappenberg, "Does Screendance need to look like dance?"; Rosenberg Screendance; Anna Heighway, "Understanding the 'Dance'"; Andrea Davidson, "Extending the Discourse of Screendance."

55 Bench, 89.

56 Kappenberg, 103.

${ }_{57}$ Heighway, 45.

${ }_{58}$ For instance, the screenic variations of the multi-channel installation Total Recall by Gretchen Bender is clearly based on rhythmic changes of visual images that could be considered equally choreographic. In her attempt to deconstruct the totality of television as a medium of consumerism, Bender uses synchronization and juxtaposition of moving images across different screens. In turn, this technique follows the paradigm of a rhythmic mosaic image on a single channel screen.

\section{References}

A Free and Anonymous Monument. Art. Jane \& Louise Wilson. London: Baltic Centre for Contemporary Art, 2003. Installation.

Anarchitextures. Dir. Ariadne Mikou. London: Michaelis Theatre, 2016. Installation.

Artificial Nature Series. Chor. Mette Ingvartsen. 2009-2012. Performance Series.

Bauer, Bojana. "The Makings of ... Production and Practice of the Self in Choreography: The Case of Vera Mantero and Guests." Performance Research. 13:1 (2008): 15-22.

https://doi.org/10.1080/13528160802465425

Bel, Jérôme and Boris Charmatz. "Jérôme Bel and Boris Charmatz: Emails 2009-2010." In Noémie Solomon (Ed.) Danse: An Anthology. Dijon, France: Les Presses du Réel, 2014: 241-250.

Bench, Harmony. "Hyperdance: Dance Onscreen, Dance Online. Exploring the Internet as a Site for Dance Performance." In Jessica Vokoun (Ed.) Screendance: The State of the Art Proceedings. Durham, NC: Duke University, 2006: 89-95.

Bishop, Claire. Installation Art. A Critical History. London: Tate Publishing, 2005. 
Bloomer, Kent. C. and Charles Moore. Body, Memory and Architecture. New Haven aand London: Yale University Press, 1977.

Bois, Yve Alain and M. Glenny. "Introduction." Assemblage. 10 (1989): 110-115.

Brannigan, Erin. "Dance and the Gallery: Curation as Revision." Dance Research Journal 47.1 (2015): 3-25. https://doi.org/10.1017/S0149767715000054

Bruno, Giuliana. Atlas of Emotion: Journeys in Art, Architecture, and Film. London and New York: Verso, 2002.

----. Public Intimacy. Architecture and the Visual Arts. Cambridge and London: The MIT Press, 2007.

----. Surface. Matters of Aesthetics, Materiality, and Media. Chicago: University of Chicago Press, 2014.

Chateau, Dominique. and Jose Moure. Screen. From Materiality to Spectatorship - A

Historical and Theoretical Reassessment. Amsterdam: Amsterdam University Press, 2016.

Cvejic, Bojana and Ana Vujanovic (Eds.) TkH Journal Special Issue on Social

Choreography 21 (2013). http://www.tkh-generator.net/portfolio/tkh-21-socialchoreography/

Davidson, Andrea. "Extending the Discourse of Screendance." In Doug Rosenberg (Ed.) The Oxford Handbook of Screendance Studies. New York: Oxford University Press, 2016: 389-419.

Dear, Michael. "Between Architecture and Film." Architecture and Film Architectural Design. 64.11/12 (1994): 9-15.

Deleuze, Gilles. Cinema 2: The Time-Image. Translated by Hugh Tomlinson and Robert Galeta. Minneapolis: University of Minnesota Press, 1989.

Eisenstein, Sergei Mikhailovich. "Montage and Architecture." Assemblage. 10 (ca 1938): 110-115.

Embankment. Rachael Whiteread. London: Tate Modern, 2005. Installation.

Excursus: Homage to the Square. Robert Irwin. New York: Dia Center for the Arts, 1998. Installation.

Fase. Chor. Anne Teresa De Keersmaeker. 2002. DVD.

Forsythe, William. "Choreographic Objects." 2008

http://www.williamforsythe.de/essay.html 
Foster, Susan. Choreographing Empathy: Kinesthesia in Performance. London:

Routledge. 2011

Glass Pavillion. Arch. SANAA. Toledo (OH). 2006. Building.

Grosz, Elizabeth. Space, Time and Perversion: Essays on the Politics of Bodies. New York and London: Routledge, 1995.

Heighway, Anna. "Understanding the 'Dance' In Radical Screendance." International Journal of Screendance 4 (2014): 44-62. https://doi.org/10.18061/ijsd.v4i0.4530

Hewitt, Andrew. Social Choreography: Ideology as Perfmance in Dance and Everyday Movement. Durham: Duke University Press, 2005.

https://doi.org/10.1215/9780822386582

Improvisation Technologies Dir. William Forsythe. 1994. CD-ROM.

Ingold, Tim. Lines: A Brief History. London: Routledge. 2007

Ingvartsen, Mette. "Soft Choreography." TkH Journal Special Issue on Social Choreography 21 (2013): 68. http://www.tkh-generator.net/portfolio/tkh-21-socialchoreography/

It's a Draw/Live Feed. Chor. Trisha Brown. Minneapolis: Walker Art Center, 2008.

Drawing \& Performance.

Kaprow, Alan and John Held. An Interview with Alan Kaprow. 1988.

http://www.ubu.com/papers/kaprow_held_interview.html

Kappenberg, Claudia "Does Screendance need to look like dance?" International Journal of Performance Arts and Digital Media. 5.2-3 (2009): 89-105.

Kolarevic, Branko and Ali. M. Malkawi. Peformative Architecture: Beyond Instrumentality. New York and London: Spon Press. 2005

Laboratoire du Geste. Expanded Choreography. Situations, Movements, Objects. http://www.laboratoiredugeste.com/spip.php?article583

Laermans, Rudi. "'Dance in General' or Choreographing the Public, Making Assemblages." Performance Research 13:1 (2008): 7-14.

https://doi.org/10.1080/13528160802465417

La Musée de la Danse. Dir. Boris Charmatz. Rennes: Centre Chorégraphique National de Rennes et de Bretagne. 
Lee, Pamela M. Objects to Be Destroyed. The Work of Gordon Matta-Clark. Cambridge \& London: The MIT Press. 2000.

Lycouris, Sophia. "Choreographing Environments: New Technologies and MovementRelated Artistic Work." In Jo Butterworth and Liesbeth Wildschut (Eds.) Contemporary Choreography. A Critical Reader. Abingdon: Routledge. 2009. 346-361.

Marks, Laura. U. "The Skin and the Screen - A Dialogue." In Dominque Chateau and Jose Moure (Eds.) Screens: From Materiality to Spectatorship - A Historical and Theoretical Reassessment. Amsterdam: Amsterdam University Press, 2016. 258-263.

Norberg-Schulz, Christian. Genious Loci: Towards a Phenomenology of Architecture. London: Academy Editions, 1980.

Pallasmaa, Juhani. The Eyes of the Skin: Architecture and the Senses. Chichester: Wiley Academy, 2005.

Rasmussen, Steen Eiler. Experiencing Architecture. (2nd ed.) Cambridge, MA: The MIT Press, 2000.

Reiss, Julie. H. From Margin to Center. The Spaces of Installation Art. Cambridge and London: The MIT Press, 1999.

Rosenberg, Douglas. Screendance: Inscribing the Ephemeral Image. New York and Oxford: Oxford University Press, 2012.

https://doi.org/10.1093/acprof:oso/9780199772612.001.0001

Sara, Rachel and Alice Sara. "Between Dance and Architecture." In V. Hunter (Ed.) Moving Sites. Investigating Site-Specific Dance Performance. New York: Routledge, 2015. 62-78.

Salter, Chris. Entangled. Technology and the Transformation of Performance. Cambridge and London: The MIT Press, 2010. https://doi.org/10.7551/mitpress/9780262195881.001.0001

Synchronous Objects. Dir. William Forsythe, Maria Palazzi, and Norah Zuniga Shaw. 2009. http://synchronousobjects.osu.edu/

Total Recall. Gretchen Bender. Liverpool: Tate, 2014 [1987]. Installation.

Tschumi, Bernard. "The Architecture of the Event." Architectural Design 61.1-2 (1992): 24-27.

----. Architecture \& Disjunction. Cambridge and London: The MIT Press, 1996. 
Tschumi, Bernard, Dorita Hannah, and Omar Khan. "Performance/Architecture: An Interview with Bernard Tschumi." Journal of Architectural Education 61.4 (2008): 52-58. https://doi.org/10.1111/j.1531-314X.2008.00187.x

Utopia London. Dir. Tom Cordell. 2010. DVD.

Walking Next to One's Shoelaces Inside an Empty Fridge. Chantal Akerman. Berlin: Jewish Museum Berlin, 2007. Installation.

Zumthor, Peter Atmospheres: Architectural Environments Surrounding Objects. Basel: Birkhauser, 2006. 



\section{PROVOCATIONS AND VIEWPOINTS}





\title{
Screendance Self/portraits
}

Hetty Blades, Coventry University

\begin{abstract}
Screendance works often comprise multiple authorial perspectives. The camera, staging, sound, choreography and context all contribute to the aesthetic and conceptual potential of the work. This provocation draws on Tamara Tomić-Vajagić's (2014) notion of the 'self-portrait effect' to discuss how a confluence of first and third person perspectives cultivates representations of selfhood in two screendance examples: Vis-er-al (2015) by Polly Hudson and 52 Portraits (2016) by Jonathan Burrows, Matteo Fargion, and Hugo Glendinning.
\end{abstract}

Keywords: self/portrait, screendance, selfhood

The construction and circulation of the self is one of the central features of contemporary culture. Selfies and social media provide ways for us to generate and circulate expressions of ourselves and others, extending the visual art traditions of portraiture and self-portraiture. As Tamara Tomić-Vajagić points out, dance has the potential to problematize the distinction between a portrait and self-portrait due to the interplay between the expression of the choreographer or director and the dancer (in cases where the two are distinct). 1 The aim of this provocation is to raise questions about the way that screendance might further complicate dance's muddling of portraits and self-portraits 2 through the layering of perspectives and the relationship between the body and the camera. I draw on two works: Vis-er-al (2015) by Polly Hudson and 52 Portraits (2016) by Jonathan Burrows, Matteo Fargion, and Hugo Glendinning.

In October 2015, Hudson convened three days of workshops, screenings and performances at Vivid Projects, a collaborative media arts space in Birmingham (UK) as part of their 9 Evenings series, a reference to Billy Klüver's 9 Evenings: Theatre \& Engineering, a collaborative project between artists and scientists in New York in 1966. Hudson's pieces, Vis-er-al (2015) and Making Lemonade (2013) were displayed as installations during the event. Making Lemonade was looped in different times on three screens that surrounded the audience. In another room, Vis-er-al was projected onto a large wall. Both are solo works, choreographed and performed by Hudson. As visitors arrived at the event they were invited to contribute to a "Yes Manifesto," a rethinking of Yvonne Rainer's famous "No Manifesto," 3 adding explanations of what dance might be and granting permissions for its potentiality. On the evening that I 
attended, dance artists Katye Coe and Charlie Morrissey were also part of the event, sharing their joint movement practice in one area of the space.

My next example followed a very different format. Each Monday throughout 2016, a danced vignette arrived in my email inbox, thanks to Burrows, Fargion, Glendinning, and 51 dance artists or partnerships. Each film contains a short 'portrait' of a dance artist or duo, during which they perform a sequence of movements alongside an offscreen vocal accompaniment. Each portrait is situated in the same black-box setting, on or around a chair and table. Each instance is idiosyncratic to the featured artist, yet maintains enough visual uniformity to be clearly part of the same work.

These two works complicate the distinction between portraits and self-portraits. As the title suggests, 52 Portraits is a portrait-like work, however, the work has selfportraiture within it, as each micro-work includes choreography generated by the featured artist. Vis-er-al, on the other hand, is a solo work, based on an autobiographical event. It could therefore be seen as a straightforward self-portrait, but challenges this notion due to the way that the work is edited collaboratively and features multiple viewpoints.

\section{Self/portraits}

The term 'portrait' tends to denote a visual image in which an artist has set out to represent a particular person or group. 4 However, a portrait is not simply a picture of another person. Cynthia Freeland suggests that portraits: must portray a recognizable subject; should reveal something about the inner life of the subject; and require that the person being depicted 'looks back' at, or poses for, the artist, allowing themselves to be viewed. 5 Broadly speaking, a 'self-portrait' is an image constructed of oneself by oneself. In this sense, it offers a 'first-person' rendering, in contrast to a portrait's 'third person' perspective.6 Many dance works pose generative questions when thought about in relation to the traditions of portraits and self-portraits. For instance, is a selfauthored work necessarily a self-portrait of the artist? Does the dancing body always reveal or express something of the inner life of the mover? Furthermore, some works problematize these two categories because the choreographer and dancer (in cases where they are different people) both contribute to the construction of meaning. An artist might choreograph a work about themselves, which is then performed by other dancers, or else she might make a work 'on' particular dancers, using their unique movement styles and material contributed by the dancers, thus both parties contribute to the expression of the work.

Tomić-Vajagić discusses ways that performance 'blends' first and third person perspectives.7 Writing initially about visual art, she suggests that "some self/portraits as sites of performance may produce interesting destabilizations of the work and imply equivocal meanings due to the amplified blending of the inside and outside points of view." 8 Tomić-Vajagić goes on to argue that dance performances have the 
potential to produce similarly "ambivalent self-presentations," 9 which she terms "self/portrait effects." 10

52 Portraits and Vis-er-al both generate self/portrait effects. For example, each of the micro-works in 52 Portraits is created through the combined contribution of the featured artist, Burrows, Fargion, and Glendinnig, meaning that the portrayal combines internal and external viewpoints. Vis-er-al also blends "inside and outside points of view." Hudson choreographed the movement, and worked with Matthew Beckett to film and edit the work. Furthermore, the camera-work means that the work fluctuates between direct comprehensible images of Hudson's face and body, and more abstract images. While self-portraits in the visual art tradition might also work with abstraction, the temporality of film means that it is possible to fluctuate between abstract and direct representations, blending representational views.

\section{Portraits}

52 Portraits is a year-long work, sent via email to subscribers in weekly installments and archived on the work's website. The entire series was also screened at Sadler's Wells in London (UK) in January 2017. Most of the featured artists are UK-based, although there are some European and American artists included. The series draws on practices outside of, or on the edge of, contemporary dance, and features artists at various stages of their career. The majority of the portraits are solos, although there are some duets, and one group piece (the final portrait, which is of the artistic team: Burrows, Matteo and Francesca Fargion, and Glendinning). The framing is very simple. The artists sit at, on, next to, or above, a table in a black box space. Off-screen Fargion and/or his daughter Francesca sings a song constructed of stories and anecdotes from the featured artists' lives. The artists perform a series of movements, which tend towards the gestural, inasmuch as they do not entail large, whole-body movements or travel in space. However, despite these commonalities, each installment is unique. The choices the artists make within the set frame of the work reveal aspects of their approach to movement. As dance critic Judith Mackrell writes of 52 Portraits, "It's often in the tiny variables, within each snapshot, that the most penetrating information is revealed." 11

The first portrait in the series is of Kwame Asafo-Adeji, Artistic Director of the contemporary hip-hop company Spoken Movement. Asafo-Adeji performs staccato, syncopated hand-gestures on the table in front of him. At times his movements extend into space, but they remain within a small kinesphere that does not reach beyond the table and chair. He starts with his head bowed low to the table. It rises suddenly as he grasps the space in front of him. His gaze follows his hands, only occasionally meeting the camera, giving the portrait an inward tone. While AsafoAdeji moves, Matteo Fargion sings, recounting stories from the artist's childhood, such as falling from a coconut tree at age five. Fargion describes Asafo-Adeji's early 
movement inspiration (Michael Jackson), and his mother's job as a midwife, explaining in the final line of the song that she will soon retire back to her house in Ghana.12

At one point Fargion sings, "Kwame says that when he dances it doesn't feel like he's there at all." ${ }_{13}$ This description of the artists' internal world parallels with his inward gaze. While his movement material is sharp, fast, and energetically present; the tone of Asafo-Adeji's focus tells a different story. He appears contemplative, absorbed. The lyrics highlight the potential of dancing to offer a place where the artist can disappear, demonstrating how the portrait offers a collision of his internal and external worlds. His body is present; but his sensation is of disappearance-a tension evident in the relationship between his hand gestures and gaze.

The portrait from Scottish dance artist Claire Cunningham also starts with the artist looking down at the table. Like Asafo-Adeji, and most of the other artists, she is seated behind the table, square to the camera. Piano music starts before she moves. She slowly lifts her hands, which have been resting on the table in front of her. The movements are small at first, her fingers move as if playing a piano. As the movement grows larger, Cunningham starts to rock, and we see that she is sitting on a pair of crutches. For those familiar with Cunningham's work this does not come as a surprise, yet the structure and framing of this opening draws attention to the crutches, through their initial invisibility. This time it is Francesca Fargion who sings. "Claire is concerned with the notion that disability is a valid and positive way of existence." 14 She goes on to describe Cunningham's feelings about dancing, as "like curiosity or like physics" and "quite mechanical." ${ }_{15}$ Cunningham's gestural movements start to grow larger; her hand and arm extending further across the table, to draw her body round to face the back of the set. She moves slowly; the momentum created by the interplay between her movement and the balance of her body on her crutches creates a gentle, lilting dynamic. As Cunningham explores different balances, new shapes are revealed through the configuration of her body and crutches. Simultaneously, Fargion describes how the artist never quite knows what will happen next, drawing attention to the unpredictability of the movement. Towards the end of the portrait Cunningham leaves her crutches, moves into a deep plié, and walks to the side of the table. To exit the space, Cunningham pushes herself from the edge of the table and stands next to it, as the crutches balance on the rear edge. As with Asafo-Adeji's portrait, the interplay between the text and the movement, and subsequent merging of internal experiences and external movement presents a different picture of the artists than would be evident in the movement alone. However, the text does not describe the movement directly, but at times, highlights certain facets of it.

My consideration of 52 Portraits relates to Tomić-Vajagić discussion of Rineke Dijkstra's time-based portraits of young people club dancing. Analyzing Dijkstra's 2009 video installation The Krazyhouse, Tomić-Vajagić explains how the work follows a set format, with each performance taking place in a studio against a white backdrop, but that the 
dancers selected their own music and were free to move however they pleased.16 Tomić-Vajagić suggests that some of the dancers generate the self/portrait effect through the self-expression evident in their movement.17 Additionally, the interplay between Dijkstra's setting, structure, and instruction, and the decisions of the dancers can generate a self/portrait effect, through the blending of first and third person perspectives, which produce a 'liminal' space between perspectives. 18

I suggest that consideration of the self/portrait effect can function as an analytic tool, drawing us into deeper interrogation of the layers of representation generated in (screen)dance. As Tomić-Vajagić points out, "Any depictions of people or performances arguably may involve a certain blending of the first- and third-person perspectives." ${ }_{19}$ However, she goes on to point out that there are certain works in which the blending of perspectives is 'amplified.' 20 I suggest 52 Portraits is a clear example of this amplification. The work uses a similar structural device to Dijkstra's portraits. In this case, Burrows, Fargion, and Glendinnig determine the sound, camera work, and staging. Burrows also offers movement structures. For example, in an email to contributing artists Igor and Moreno, published in the program for the live screening, 21 and available on the website, Burrrows explains how he offers artists the structure from a classical music form called La Folia (a triple meter tune played in a minor key, which Burrows describes as having a "looping structure" made up of four phrases).22 He also offers other structures, and artists can choose whether or not to work with them. As well as selecting a structure, the featured artist(s) generate(s) the movement content. Therefore, there is openness within the set parameters of the work, which cultivates an effect akin to Tomić-Vajagić's blending of internal and external perspectives.

Furthermore, ambiguity is generated by the multiple authorial contributions and subsequent dialogue between the text and the movement. Many of the portraits are accompanied by a song about the artist's experiences and beliefs. The text arises from interviews between Burrows and the artists.23 Parts of the responses are then selected by Burrows and made into a song by Fargion.24 The result is that the words of the artists are re-told through the song, demonstrating a blending of perspectives. Furthermore, the relationship between the movement and the sound is not transparent. As demonstrated in the descriptions of Asafo-Adeji' and Cunningham's portraits, at times the artists appear to be responding directly to the text, while other sections are more abstract. As viewers, we are left to wonder whose perspective formed the relationship between the movement and text. The question of when the artists' expression becomes Burrows' and vice versa reveals the 'liminal space' described by Tomić-Vajagić, 25 generating a self/portrait effect. 


\section{Vis-er-al}

Vis-er-al starts with a shot of Polly Hudsons's inverted body. Clothed in a white dress, her pelvis points upwards, her back is visible, but her head, shoulders and neck are hidden. She appears to be in a shoulder-stand, but is in fact filmed from above, with her head hanging over her legs. It is hard to tell this at first, partly due to her suspension in the weightless space of the black screen. With nothing to indicate a floor, ceiling or walls, the body floats. Her back and pelvis form an abstract, mushroom-like shape, which is not immediately recognizable as a body.

Alongside the minimal, electric sound-score by Darren Pickles, Hudson's body unfolds, her head lifting towards the camera. The film is shot on a FS700 camera and therefore the movement unfolds in in slow motion. The momentum of Hudson's long hair implies a sense of haste that does not match the speed of the film. Her hair fills the screen, but just before her face appears beneath it, the camera switches perspectives. This time the shot is very close to Hudson's chest. Her shoulders, clavicles, and the top of her breasts fill the screen, but her face remains out of view. Still in slow motion, we see her chest rise with an intake of breath and fall with an exhale. This is accompanied by a rhythmic, gong-like sound, which adds a sense of weight to her movement. The camera cuts again to her lips and nose before moving above her body. A zoomed-out perspective allows us to see her full body in a less abstract form: as she moves slowly with her arms out in front of her, the camera rotates around her body, generating a sense of momentum.

Those who experience this work at a screening are likely to read the accompanying program note that explains how the work arose from Hudson's experience of being in a car accident.26 The relationship between the camera, the movement, and the music generate a sense of foreboding or trauma. The short, fragmented shots, deepbreathing, and off-balance camera-work all contribute to a sense that Hudson is experiencing something upsetting. At 1 minute 10 seconds, Hudson's face is fully revealed. The camera then moves to a birds-eye view, maintaining the sense of momentum - perhaps arising from impact-and we see Hudson's body mid-flow. The movement of her hair indicates speed and velocity, despite the slowness of the footage. As the film continues, these moments are interspersed with stillness and close-up images of Hudson's hands, chest, and neck. A prolonged shot features water falling through her hands. It is not evident to the viewer where the water originates from, or its significance in Hudson's story. Its movement becomes part of an eclectic vocabulary of images, shot from multiple perspectives and generating ambiguous forms of expression.

This example does not offer the same relationship between set structure and openness as the previous example, but it can be said to extend the self/portrait effect seen with 52 Portraits above. The autobiographical nature of the work means it could 
be interpreted as a straightforward self-portrait, however, the mediation of the camera, and central role of editing, means that a third person perspective is brought to bear on the movement, generating an interplay of perspectives similar to that described by Tomić-Vajagić. For example, the slow-motion effect, rotation of the camera, and the fast-paced editing combines with the movement to generate a sense of unease and trauma, thus Hudson's experience is portrayed through a combination of first and third person perspectives. Furthermore, the viewer is at times engaged with Hudson directly, through clear shots of her face and body. At other points, her body is abstracted. This movement between literal and abstract renderings combines with the mixed perspectives to generate a self/portrait effect. Considering this work in relation to this concept allows us to more clearly comprehend the multiple forms of (self)representation that take place in the work.

\section{Relationality}

In Portraits and Persons, Cynthia Freeland paraphrases Jerrold Siegel's suggestion that there three main dimensions of the self: the bodily (or material), the reflective, and the relational. Freeland remarks, "The bodily nature of the self involves its existence as a physical entity with particular sorts of needs and vulnerabilities, and a specific external appearance. The reflective aspect of the self involves its nature as being endowed with consciousness, capable of assessing and forming itself, shaping actions etc. The relational aspect of the self involves truths about people's membership in groups that impart values and roles." 27 Dance works might appear to present the bodily or material self, manifested in screendance through mediated corporeality. However, I suggest that 52 Portraits and Vis-er-al demonstrate how the relational self 28 is also integral to these works.

Freeland suggests, "To say the self is constituted by various relationships may seem rather obvious, but specifying how such a view can be artistically rendered is harder." 29 52 Portraits and Vis-er-al demonstrate how (screen)dance provides fertile ground for rendering the relational self. For instance, in the case of 52 Portraits, the micro/macro work structure shows how the artists featured are part of a larger picture (or group). Although they are individual artists (or artistic partnerships), they are also members of something bigger than themselves. Members of the group might disagree about specific values, ideas, or movement concerns, but watching the pieces back-to-back, 30 it appears that there are sufficient overlapping values between members of the group to generate a network or 'community' of practitioners who are in relation to one another, even if this relation is indirect. The relations between the artists are constructed from the third-person perspective. Contextualization is provided through the team's curation and framing. As viewers, our engagement with each artist's portrait and consideration of the way their selfhood is communicated happens in relation to the other portraits within the work. Thus, the third-person rendering of the relational self, informs our reading of the artist's (self)representation, further 
complicating the interplay between first and third person perspectives and contributing to the self/portrait effect.

In the case of Hudson's work, the relational self is generated through the context within which it is shown. It is screened at festivals dedicated to screendance as well as at video art festivals and events. Being shared in these venues contextualizes Hudson's work as constructed in relation to other artists, emphasizing the place of the work within particular areas of practice. For example, relationality between Hudson and her contemporaries is demonstrated by her decision to place the work alongside other artists' practices, such as Katye Coe and Charlie Morrissey, as described in the opening section. Furthermore, in the case of the 9 Evenings event, the work was contextualized in relation to avant-garde performance practices in the 1960s. This arose through Hudson's reference to Yvonne Rainer's "No Manifesto," and the wider context of the 9 Evenings event, initiated by Vivid Projects. The combination of Hudson's curatorial choices, and the broader framework of the series further demonstrates the multiple perspectives that contribute to the work's contextualization, and its positioning in relation to historical and current practices.

In each example, the artist expresses themselves, mediated via a third person perspective and in relation to others. Thus, self-expression is one component of a larger network of expressive, aesthetic factors. Recognizing that (self)representation is partly concerned with the relational self in these examples helps us to further reveal their layers of representation and composition. Freeland suggests that in visual art, rendering the reflective and relational aspects of self has always been a challenge, in comparison to the relatively straightforward depiction of the material body.31 In dance, while the material body is central to the form, the relational self might also manifest, even in solo works, through the contexts of their transmission. Furthermore, we might want to argue that the muddling of perspectives evident in these works starts to erode the distinction between the material and relational self, implying our material corporality arises in relation to others, and is constructed through a confluence of internal and external perspectives.

Examining 52 Portraits and Vis-er-al in relation to the visual art convention of portraits and self-portraits shows how contemporary (screen)dance practices cultivate ambivalent forms of (self) representation through the blending of multiple authorial and mediatized perspectives, resulting in self/portrait effects. This brief study raises multiple questions, such as: How might further examination of this area reveal the interplay between movement, choreography, and self-expression? How might screendance practices undo, disrupt, or complicate thinking in visual art about (self) expression and representation? And how might different forms of circulation and transmission extend and transform the relational self? I leave these questions here as a way to stimulate thinking about some of the complex forms of (self)expression that screendance can generate. 


\section{Biography}

Dr Hetty Blades is a Postdoctoral Research Assistant in the Centre for Dance Research (C-DaRE) at Coventry University. Her research considers the philosophical questions posed by dance practices in both live and mediatized spaces. Hetty is published in Performance Philosophy Journal (2017, 2016), Performance Research (2015) and Choreographic Practices (2015). Hetty is Editorial Assistant for Journal of Dance and Somatic Practices. She was Researcher in Residence at the Digital Catapult in 2016.

Email:ac1417@coventry.ac.uk

\section{Notes}

1 Tamara Tomić-Vajagić, "The Self/portrait Effects and Dance Performance," 82.

2 I borrow this construct from Tomić-Vajagić.

3 Yvonne Rainer, "Some Retrospective Notes."

4 According to Cynthia Freeland, portraits can also be of animals. See Portraits and Persons.

5 Idem, 21.

6Tomić-Vajagić, 82.

7 lbid.

8 lbid.

9 Idem, 81.

10 Idem, 82.

11 Judith Mackrell, "52 Portraits," n.p.

12 "Kwame Asafo-Adeji," 52 Portraits, Dir. Jonathan Burrows, et al.

13 lbid.

14 "Claire Cunningham," 52 Portraits.

15 lbid.

${ }_{16}$ Tomić-Vajagić, 82.

17 Tomić-Vajagić provides a detailed analysis of how the self/portrait effect is generated in some of Dijkstra's portraits, suggesting that is is particularly present in three out of five, 86.

18 Tomić-Vajagić, 82.

19 lbid.

20 Idem, 83.

${ }_{21}$ Burrows et al, 52 Portraits program.

22 Ibid.

23 Ibid.

24 lbid. 
25 Tomić-Vajagić, 82

${ }_{26}$ Burrows et al, 52 Portraits program.

${ }_{27}$ Freeland, Portraits and Persons, 81-81.

28 Here I follow Freeland's use of the term to describe "the self in its various social relations and public roles" (97). The term is also used to refer to the self as it is constructed through relationships with people we are close to such family and friends. 29 Idem, 98.

30 As I did during a screening at Sadler's Wells on 25 January 2016.

${ }_{31}$ Freeland, 83.

\section{References}

52 Portraits. Dir. Jonathan Burrows, Matteo Fargion, Hugo Glendinnig, and Claire Cunningham. UK, 2016. Sadler's Wells. http://52portraits.co.uk/

Burrows, Jonathan, Matteo Fargion, and Hugo Glendinning. 52 Portraits. Program Note. 2017.

"Claire Cunningham," 52 Portraits. Dir. Jonathan Burrows, Matteo Fargion, Hugo Glendinnig and Claire Cunningham. UK, 2016. Sadler's Wells.

http://52portraits.co.uk/home/2016/5/2/claire-cunningham

Freeland, Cynthia. Portraits and Persons. London and New York: Oxford University Press. 2010.

"Kwame Asafo-Adeji," 52 Portraits. Dir. Jonathan Burrows, Matteo Fargion, Hugo Glendinnig and Kawme Asofo-Adeji. UK, 2016. Sadler's Wells.

http://52portraits.co.uk/home/2015/12/18/kwame-asafo-adjei

Mackrell, Judith. "52 Portraits: a year of solos capturing dancers' fears and freedom." The Guardian. 09 August 2016. https://www.theguardian.com/stage/danceblog/2016/aug/09/52-portraits-dancers

Making Lemonade. Dir. Polly Hudson. Camera Rebecca Pittam. Composer Darren Pickles. Lighting Catherine Cullinane UK, 2016.

Rainer, Yvonne. "Some Retrospective Notes on a Dance for 10 People and 12 Mattresses Called 'Parts of Some Sextets,' Performed at the Wadsworth Atheneum, Hartford, Connecticut, and Judson Memorial Church, New York, in March, 1965." The Tulane Drama Review 10.2 (1965): 168-178. https://doi.org/10.2307/1125242 
Tomić-Vajagić, Tamara. "The Self/portrait Effects and Dance Performance: Rineke Dijkstra's The Krazyhouse and William Forsythe's the second detail." Performance Research 19.5 (2014): 82-92. https://doi.org/10.1080/13528165.2014.958362

Vis-er-al. Dir. Polly Hudson. Director of Photography Matthew Beckett. Composer Darren Pickles. UK, 2016. 


\title{
Visual Politics in American Dance Film: Representation and Disparity
}

Cara Hagan, Appalachian State University, Director and Curator for ADF's Movies by Movers

\begin{abstract}
This article explores stylistic and demographic commonalities in American dance film through the curatorial lens of American Dance Festival's Movies by Movers, an international dance film festival. While calling into question how the dance film community can be more aware of the culture created on screen by makers and presenters, I reveal instances of representational disparity found in American dance film while examining the relationship of dance film to ideologies perpetuated by mass media and the world of professional dance.
\end{abstract}

Keywords: race, gender, mass media, curating, American Dance Festival

As director of the internationally recognized American Dance Festival's Movies by Movers (founded in 2010 as Movies by Movers; hereafter referred to by its official name, ADF's Movies by Movers), I see hundreds of dance film projects every year through submissions, artist inquiry, social media, other dance film festivals, and my own searching through internet platforms. Like many dance film enthusiasts, makers, and curators, I am invested in the cultivation and promotion of dance film. To that end, I am interested not only in seeing what is being made for the sake of creating a program each year, but I am compelled to question what I see within the projects I view, to better understand the landscape and trajectory of this art form I serve.

In recent years, I've begun to notice the stylistic and demographic commonalities seen across dance films as possessing a particular kind of visual politics. While the term visual politics is not new, I propose to use the term to consider the vast collection of dance films received through the submission process to ADF's Movies by Movers and the resultant culture that reveals the values and ideals inherent in our art form and our community.1 In this writing my focus will be on American projects, as the largest number of submissions to ADF's Movies by Movers come from the United States, and the complexities of demographics (most specifically racial demographics) across the world beg more explanation than this short provocation can provide.

To further define the term in this context, I consider visual politics to refer to the people and situations we see on screen with respect to the culture created by dance 
film makers and presenters. It is a scene influenced by socio-cultural norms in the real world, and affected by the lens through which we view the arts and arts industries. For dance film that means that while we strive for our art form to be an experimental, open-source platform, the challenges to stylistic and demographic diversity found in mainstream media and professional dance are our own. This is not to say that dance film is not innovative or unique in comparison to professional dance and mainstream filmmaking, though I would argue that to truly challenge the status quo, the dance film community must begin to question those things that keep us bound to the whims and aesthetics of our forerunners.

In order to understand the visual politics of dance film, I started by looking at its stylistic repetitions. What kind of movement is being featured most often? What kinds of spaces and locations are people using in their films? What type of sound or music is being used most often? What do the stylistic representations found in dance film say about the ways we perform and perpetuate ideas of societal constructs like race and gender? And while some homogeny is necessary in any art form to separate one form from another and to create boundaries for definition, too much restraint on what might be included in the parameters of an art form is limiting. For example, most projects that I receive could be categorized as featuring modern or contemporary movement. This is no surprise, as many of those we consider pioneers in dance film practiced modern and contemporary aesthetics. Modern and contemporary dance is also the primary movement practice taught in the Western collegiate/university system and the primary aesthetic found at large dance festivals across the country, including the American Dance Festival. Because of this, we are often compelled to believe that this is the aesthetic for dance film. While modern and contemporary dance is experimental, includes a range of dynamic qualities, and allows the creativity of both the choreographer and the dancer to be accentuated, the overarching philosophies found in arts education today do not account for or recognize the same experimental spirit found in dance forms not privileged in the academy-hip hop, for example.2

Hip hop is historically an experimental art form in the sense that it developed as a fringe endeavor by teenagers in the streets of 1970s New York, and practitioners pride themselves on originality of movement and style as a primary tenet of the form. The hip hop we often see in mainstream media coming from Hollywood and television networks-ideological entities that largely influence our perception of the form-do not often reference this history of invention and largely leave out the aesthetics we might find in non-commercial spaces, like a hip hop battle. It is here, inside the cypher (battle circle), where dancers/choreographers face off to see who can be the most spontaneous and innovative. While over the past three seasons of curating ADF's Movies by Movers, I have seen a marginal rise in the number of submissions featuring hip hop, forms other than modern/contemporary still appear to be fighting for a place 
among the dance film constellation. At the same time, hip hop continues to find a place in mainstream media and more specifically in music videos-a genre of filmmaking that has become increasingly bound to digital platforms such as Tidal, Vevo, and iTunes as networks like MTV show less music in favor of reality TV.

Like dance film, music videos are meant to push the boundaries of kinetic and musical imagery. The music videos of this millennium look vastly different than those of the early days of music videos, boasting complex choreography, cutting edge editing effects, and innovative conceptual aesthetics. Rapper Missy Elliott has been consistently praised for cinematic inventiveness and choreography in her videos throughout her two-decade career in hip hop music. One of her most recent videos, Where They From (2015), directed by Dave Myers and choreographed by Nadine "HiHat" Ruffin, features all the tenets of what is generally agreed upon as a dance filmit's site specific, camera specific, and edit specific.s And while it has a commercial purpose, the video features several movement sections that speak to the experimental aims of dance film. The most experimental section of the piece appears near the end of the video. There is a series of cardboard boxes arranged in a grid on the floor. A group of dancers dressed in non-gender-conforming plastic outfits pop in and out of the boxes, jumping from one to another, creating different configurations of dancing groups. Sometimes only legs are visible coming out of the tops of the boxes, sometimes dancers are seen from the waist up, contorting their shoulders and arms into asymmetrical shapes. The camera sees the dancers from a frontal view, in closeup, and from above. It makes quick movements with the dancers as they pop and lock. The box scene is perhaps the most compelling part of the video and taken out of context, could stand alone as a non-commercial exploration of space and shape. Further, with an almost exclusively of-color cast, the video goes against demographic norms found in dance film which I discuss later. Similar examples can be made of world dance forms and "non-dance" movement practices so often left out of the conversation in Western arts training and performance, especially those which feature improvisation or individualistic expression (unlike ballet, for example, that asks practitioners to adhere to a codified set of standards of practice) as a main aesthetic of the form.

As I've sought to understand the visual politics of dance film, I've also delved into the demographics associated with the films received through the submission process. In terms of issues of gender, race, age, and ability, the dance film world boasts shining examples of why dance film has the potential to be such a transcendent platform for featuring bodies not considered suitable for the concert stage or a Hollywood movie. However, in considering the demographics found through observing the submission process to ADF's Movies by Movers, there are areas of disparity that demand examination. For the purposes of this provocation, I will focus on gender and race, while recognizing that age and ability are important pieces of the puzzle to 
understand the cultural landscape of dance film. The numbers presented below are estimates, as it is impossible for me to know how each performer, choreographer, and director tallied self-identifies. To ensure as much accuracy as possible, I have used artist social media profiles, websites, and additional video work to determine if my initial impression of a participant is correct. Trends have appeared over the past four seasons that are compelling and speak to the landscape and culture we (makers, curators, and educators) are actively building, which I hope to illuminate through my analysis.

In 2015, I explored what it means to be a feminist in the 21 st century and what it means to make feminist art in the context of dance film. In that research I stated:

For many women and feminist allies, dance film has created a space apart from mainstream media and the traditions of professional dance to practice principles of feminism, including rectifying the presentation of the female body, confronting issues of race, class, and cultural identity, while making room for the kind of creative, intentional activism that has continued to characterize third-wave feminism.4

I also expressed concern over the limited inclusion of men in dance film, bringing into question concepts of male oppression through societal conditioning and structural repression which silences men's voices in favor of a constructed masculine persona.5 We know that in American dance film, male bodies are seen less often than female bodies due to the persistent view of dance being an emasculating activity. 6 While we have seen some progress in male representation in dance through mass media, gender norms persist in non-dance-related media where men and women move in prescribed gendered vocabularies in dance-centric movies and shows like So You Think You Can Dance. In 2005 for example, the show harshly berated dancer Anthony Bryant for being "too feminine" in his dancing with a rhythmic gymnastics ribbon during his audition.7 Even after inviting Bryant back the following season to reconcile the incident, the show largely continues to present traditional gender norms through the choreography presented in the show. Other shows like Dancing with the Stars further perpetuate traditional gender norms and feature male dancers as providers of spectacle and little else.

In all 24 seasons of Dancing with the Stars, spanning from 2005 to 2017, there have been male athletes featured on the show. These male athletes are praised for their physicality, but are not generally encouraged to take up dancing as more than a hobby. While all of the men who have danced, or are dancing on the show are not athletes, most fit into the heteronormative view of masculinity and in some way help to perpetuate a hyper-masculine ideology through the ways they speak, and are spoken about on the show, and how the dance numbers are choreographed, costumed, and performed. Chaz Bono, a transgender activist, made his appearance on the 13th season (September-November 2011) of the Dancing with the Stars, and 
because of his non-gender-conforming identity and his less-than-athletic build, he was subject to ridicule from both the general public and the judges. Most notably, Judge Bruno Tonioli called Bono a "Penguin" and an "Ewok," when describing his body in movement.8 On the show, Bono said, "You know, I came on this show so I could show America a different kind of man. And I know that if there was somebody on TV like me when I was growing up, my whole life would have been different." 9 So while dance studios and collegiate dance programs may be experiencing slowly rising numbers of male dancers in their ranks due to the increased visibility of dance in mass media, young men continue to endure stigma and harassment in their pursuit of this art form. 10

In 2017, just 30 percent of the performers counted in American-based projects submitted to ADF's Movies by Movers were men, and that number was only slightly higher for the 2015 and 2016 seasons, at around 35\%. According to the 2016 USA census, women account for $51 \%$ of the population, and men account for $49 \%$ of the population. What would dance film look like if the numbers of men and women seen on screen across projects were more representative of the American population? Would we see more varied expressions of gender? Would we see greater diversity of dance styles represented in dance film? It is not only in front of the camera where we see a gender disparity in dance film, it exists behind the camera, too. White, female choreographers consistently account for over half of all choreographers represented in any given season of ADF's Movies by Movers submissions, while male choreographers have accounted for only about one quarter of all choreographers in the submission pools across the 2015, 2016, and 2017 seasons. The picture is similar for directors, with male directors representing on average, 35\% of all directors represented in the submission pools for the 2015, 2016, and 2017 seasons. In the mainstream world of filmmaking, women continue to fight for better representation both on screen, and off. As mentioned earlier, dance film is an answer to that desire for greater freedom of expression for women and an opportunity to take on leadership roles traditionally reserved for men. However, does dance film get to claim that it creates a platform for equality, if the representational tables are turned because of a societal stigma toward men in the arts?

With regard to race in dance film, bodies of color are seen far less often than white bodies, as the struggle to normalize bodies of color on stage and on screen in the mainstream is ongoing. It is widely reported that the structure and availability of arts education in the United States often leaves would-be artists of color behind.11 This is echoed in the projects that are submitted to ADF's Movies by Movers, with the majority of the makers having honed their skills in American institutions of higher education. In fact, $66 \%$ of all the performing bodies featured in American submissions to ADF's Movies by Movers for 2017 were white, and numbers were similar for the 2015 and 2016 seasons.12 Numbers of performers of color rose steadily in alignment with rising 
submission numbers overall between 2012-when the number of white performers versus performers of color was found to be above 80 percent-and 2014. While the increase in performers of color is encouraging, it still means that curatorial options featuring bodies of color continue to be more limited then selections featuring white bodies, and this impacts how many bodies of color actually make it to the screen each year to be seen by the public. Since numbers have plateaued since 2015, the number of bodies of color seen on screen in ADF's Movies by Movers remains around 35\%. This year, $18 \%$ of all the bodies featured in the American submissions to the 2017 festival were female bodies of color. More than twice that amount accounts for the numbers of white female bodies seen in 2017.13 Men of color represented 16\% in 2017, and that number was only $10 \%$ in 2016 . Men of color are consistently the least represented performers in projects submitted to ADF's Movies by Movers. If there is a spike in the numbers of men of color seen in the submission pool, it is almost always attributed to films that feature a large number of people of color that skew the data, and not an even distribution of people across projects.

In 2017, the UCLA Ralph J. Bunche Center for African American Studies published their annual report on the entertainment industry, Hollywood Diversity Report: Setting the Record Straight. In addition to noting that minorities seen on screen are consistently underrepresented and have been since the first report was published in 2014, the authors also pointed out discrepancies behind the camera.14 In 2015 (the year which the 2017 report examines), just $10 \%$ of Hollywood directors were people of color. From 2015 to 2017 directors of color made up 20\% of ADF's Movies by Movers films. While this may be high in comparison to the film industry, dance film seems a long way from having a directorial landscape representative of the growing minority in the United States.15 The same is true of choreographers, with only $25 \%$ of all choreographers tallied in 2017 being choreographers of color. Again, men of color are the least represented in this group. If dance film were to become more representative of our population in the United States, what would change about dance film? Could better racial representation in dance film help the arts community as a whole be more open to variations in the types of bodies that are considered pleasing or compelling to watch? How can dance film disrupt the notion that young, white, female bodies are the most desirable bodies in dance film? How can we set ourselves apart from the mainstream, not just in our conceptual explorations, but in who carries out these explorations? Anecdotally, it seems that more of the films received through the submission process between the 2015 and 2017 seasons especially, address issues of identity politics, social justice, cultural heritage, and ask what experimentation looks like across those contexts.

If we consider dance film to occupy the same space as mass media-a space which perpetuates ideology - these questions are in keeping with Stuart Hall's exploration of race in mass media: 
The media are not only a powerful source of ideas about race. They are also one place where ideas are articulated, transformed and elaborated.16

While dance film does not occupy the same space or enjoy the same amount of visibility of more mainstream offerings, the dance film community must admit that what is produced, screened, and viewed matters. We are part of a larger conversation and we have the power to sway opinions about the bodies in front of and behind the camera. We have the power to make commentary on aesthetics too. In our reluctance to confront the issues I've discussed head-on, I believe we are hampering ourselves from emerging fully into the ethos of the 21 st century, a century where art and mass media are more intertwined than ever before, the minority will soon become the majority in our citizenry, and women and men may be on the verge of gender equality. My hope is that by sharing the ongoing aesthetic and demographic research through the ADF's Movies by Movers, others might be inspired to become more active participants in creating a culture of art that speaks to our collective strengths and moves to creatively address our pitfalls.

\section{Biography}

Cara Hagan is an interdisciplinary artist whose practice is informed by movement, words, and digital space. A recipient of several grants and awards, most recently Cara received a 2014-2015 NCAC Choreographic Fellowship, a 2015 Sustainability in the Arts Grant, and a 2015-2016 University research Council Grant. Currently Cara is under contract to complete her first book, due out in 2018.

Email: hagangelbercm@appstate.edu

Website: http://www.carahagan.net

\section{Notes}

1 As stated in my definition of visual politics, the products we make, coupled with the presentation of those products is a culture unto itself. What we make, and how we present and talk about dance film speaks to the ideals we hold as a creative community.

2 Julie A. Kerr-Berry, "Dance Education," 50.

3 "WTF (Where They From)." 
${ }_{4}$ Cara Hagan, "The Feminist Body Reimagined," 49.

5 Idem, 63.

6 Maxine Leeds Craig discusses dance and contemporary popular culture, citing SYTYCD and Dancing with the Stars, noting that if men are expected to dance, they are expected to uphold ideals of masculinity. Sorry I Don't Dance, 15.

7 "Anthony Bryant."

${ }_{8}$ Aaron Parsley, "Chaz Bono," n.p.

9 lbid.

10 Both Leeds Craig and Douglas Reisner describe the societal stigma that follows boys and men who dance, both socially and professionally. It is most interesting to compare Leeds Craig's study of men and dance in the mainstream and Reisner's study of men in the realm of professional dance; the stigma begins in childhood and ultimately means less men make it to the professional level of dancing.

${ }_{11}$ Kerr-Berry, 48.

12 The numbers of white performers for the 2015 and 2016 seasons was $65 \%$ for both seasons.

${ }_{13} 46 \%$ of performers tallied for the 2017 season were white women.

14 Darnell Hunt, et al, 2017 Hollywood Diversity Report, 2-4.

15 According to the US Census, minorities make up nearly $40 \%$ of the population and are on track to become the majority by 2050 . Hunt, et al reference these numbers in the 2017 Hollywood Diversity Report.

16 Stuart Hall, "The Whites of Their Eyes," 82.

\section{References}

ADF's Movies by Movers. Curated by Cara Hagan. American Dance Festival, North Carolina. 2015-present.

"Anthony Bryant." So You Think You Can Dance. Season 1, 2005. YouTube https://www.youtube.com/watch?v=02ORL_kXaA8

Dancing With the Stars. ABC. 2009-2015. Television.

Hagan, Cara. "The Feminist Body Reimagined in Two Dimensions: An Exploration of the Intersections Between Dance Film and Contemporary Feminism." In Telory D.

Arendell and Ruth Barnes (Eds.) Dances Duet with the Camera: Motion Pictures. London: Palgrave Macmillan, 2016.49-65. https://doi.org/10.1057/978-1-137-59610-9_3 
Hall, Stuart. "The Whites of Their Eyes: Racist Ideologies and the Media." In Gail Dines and Jean M. Humez (Eds.) Gender, Race, and Class in Media: A Critical Reader. Thousand Oaks, CA: SAGE Publications, 2011.81-85.

Hunt, Darnell, Ana-Christina Ramon, and Michael Tran. 2017 Hollywood Diversity Report: Setting the Record Straight Rep. Vol 4. Ralph J Bunche Center for African American Studies, UCLA. http://www.bunchecenter.ucla.edu/index.php/2017/02/new-2017hollywood-diversity-report/

Kerr-Berry, Julie A. "Dance Education in an Era of Racial Backlash: Moving Forward as We Step Backwards." Journal of Dance Education 12.2 (2012): 48-53.

https://doi.org/10.1080/15290824.2011.653735

Leeds Craig, Maxine. Sorry I Don't Dance. New York: Oxford Press, 2014.

Parsley, Aaron. "Chaz Bono: Dancing Judges' Animal Comments are 'Disrespectful."' People. October 25, 2011. http://people.com/tv/dancing-with-the-stars-chaz-saysjudges-animal-comments-are-disrespectful/

Risner, Douglas. Stigma and Perseverance in the Lives of Boys Who Dance: An Empirical Study of Male Identities in Western Theatrical Dance Training. Lewiston, NY: Mellen, 2009.

So You Think You Can Dance. Fox. 2005-Present. Television.

"WTF (Where They From) Ft. Pharrell Williams." Dir. Dave Myers. Missy Elliott. 2015. YouTube. https://www.youtube.com/watch?v=KO_3Qgib6RQ 


\section{Influences}

Tracie Mitchell, artist/educator/producer/advocate, Australia

Keywords: influences, history, Merce Cunningham, David Hinton, Meredith Monk, Maya Deren

Dance, which is to natural movement what poetry is to conversational prose, should, like poetry, transcend pedestrian boundaries.

- Maya Deren 1

When I see dance on a screen-any screen, whether it be in a cinema, an art gallery, an outdoor public screen, or on a television, computer, or smart phone-l am drawn to how the body and the screen come together as movement composition, and how the design and aesthetic of the images are woven together to create content and meaning. Watching a dance on screen work extends my curiosity and fires my imagination of the body and technology and the potential for their interaction. High or low production values do not matter; more likely it is the individual elements of screen works that will capture my attention: the dancers, the idea, the technology, the music, or simply that I admire the art maker. I understand watching a dance screen work to be an interactive process - a type of conversation with the art maker-and I am drawn towards work in which I can sense the artist's questioning and searching.

It was documentaries about mid to late 20th century artists that changed the way I read dance on screen. It was as though a light came on in me-how can I explain this reaction without sounding too corny? It was like jumping into cold water, all my senses had been woken up, yelling at me, "make no assumptions, there is no set way to create or construct dance work, everything is up for grabs!" I gravitated to the work of artists who were exploring ways to incorporate the camera into their choreography-Alwyn Nikolais, Trisha Brown, Steve Paxton, Meredith Monk, and Merce Cunningham - their approaches were innovative and experimental.

Trisha Brown used a film by Robert Whitman in her work Homemade (1966). She strapped a projector to her back and as she danced, so too did the film-the projector throwing images out into the space.

It was the investigation of motion that led Alwyn Nikolais to create Kaleidoscope (1953) and Totem (1960). His aim was to make every element in each work move. Experiments with light and reflection were significant in his work: he designed costumes using 
reflective materials and explored projecting images onto surfaces including walls, costume, and the dancers' bodies.

Steve Paxton used externally sourced films to make Beautiful Lecture (1968). In it Paxton performs live and his dancing is juxtaposed between two extremes-on one side is a filmed performance of Swan Lake and on the other is a pornographic film.

In Meredith Monk's seminal work, 16 Millimeter Earrings (1966), three films are synchronized with live performance. The films are set to come on at varying times and are screened on different surfaces in the performance space including the back wall, a small rostrum, and a dome-like head dress that Monk wears over her face for a section of the performance. Pre-recorded images project her face shifting in and out of grotesque type postures onto the dome.

Seeing how these artists worked with the camera in their dance making was inspiring - it was as if the camera had been used as a provocation that enabled them to push against what they understood dance making to be. Their works played with scale, timing, repetition, effort, recorded image, texture, place, space, and weight. I was invigorated by their rebellion against assumptions and what the camera was bringing to their work; they were unpacking and questioning everything they understood about dance making and testing notions of dance and choreography as forms. I started to understand the significance of process in making a work and I wanted to introduce the camera to my practice to see what it might reveal. But first I needed to figure out how to use a camera! I realised that both dance and the camera deal with movement; their potential together was demonstrated to me in Locale (1978) and Roamin' (1979) by Merce Cunningham, and La La La Human Sex Duo No.1 by Édouard Lock (1987).

Cunningham was interested in how looking through the lens of a camera offered different ways to think about the use of space in dance: "The first thing that struck me was that the space I was looking at wasn't at all like the stage, you didn't have to think that way." ${ }_{2}$ Collaborating with video artist Charles Atlas and the dancers, Cunningham explored the relationship between physical space, dancing, and the camera. Locale and Roamin' unite the movement capacities of body and camera. Their construction involves both the camera and the dance moving at the same time in the live space, as if the camera and performers are dancing with each other: colliding, sinking, sweeping, blocking, and then moving away. The focus shifts from close-ups of body parts such as a curved spine that frames a trio in the background, or the palm of a hand sweeping across the frame. Dancers enter and exist in and out of view, trios and solos are seen, and isolated body parts shift attention from gesture to an entirely different configuration of bodies in another area of the space. The space, the walls, the floor, and the ceiling all keep shifting, making the dancing bodies the focus of the 
movement. It was the first time I saw work that could only exist through the relationship between the dancing body and the camera.

In 1987 Canadian choreographer Édouard Lock and film director Bernar Hébert reformatted part of a live work into a short seven-minute black and white film called La La La Human Sex Duo No.1.3 It was performed by Louise Lecavalier and Marc Béland, and where Cunningham was exploring screen space, Lock was interested in illusion. Lecavalier lifts Béland high above her head as her legs prance out a march, and then she brings him down to the ground. She throws her body at him, he catches her weight, and together they fall to the floor, rolling, and returning to standing. The performers repeat the movement motif as the ballroom begins to fill with water which compromises the dancing by the performers. Eventually, fully submerged, the motif becomes just a trace-an illusion of itself-and the performers swim away. When I realised that dance could be freed from gravity, that speed of movement could be varied by the turn of a dial on the camera, and that the physical quality of the environment could be distorted, I started to understand the potential of the relationship between dance and the camera.

From 1990 to the early 2000s there was a surge of activity in screendance. Up to then I had been working largely in isolation, but by chance I saw a photograph from DV8's Dead Dreams of Monochrome Men (1988). I eventually saw Dead Dreams when it was screened on Australian public television. It was a dance work that reflected current issues and was like nothing I had seen before. Magnified sounds of breathing, dragging, banging, and slapping, as well as pumping club music underpinned the world created-it was sexually charged and felt on the edge of a violent explosion. Director David Hinton and choreography Lloyd Newson had combined a film narrative with a theatrical aesthetic to explore notions of isolation, loneliness, desire, and trust. The dancing was contemporary but the five male performers seemed to slip in and out of actions and gestures that shaped individual characters. Dead Dreams of Monochrome Men was its own reality and as I watched I became kinesthetically engaged with the dance; that is to say, I understood and experienced the work and its world through movement.

In 2000 David Hinton's Birds was a controversial winner of the prestigious Dance Screen Award at the IMZ festival. It generated substantial debate as to whether it was in fact a dance film. Where were the dancers? What was the work about? Who was the choreographer?

Birds was different from everything else that was screening around the time. It had no dancers on tables, or street corners, or stuck to walls, or in run down warehouses, no dancers flying in the air or dancing under water. David Hinton had sourced black and white archival footage of birds and collaborated in the editing suite with choreographer Yolande Snaith. Initially, I felt that in Birds Hinton was primarily making 
a comment about screendance editing processes. But the more I thought about it, the more I felt that movement dominated the work. It simply used footage of birds being birds: flying, looking around, and ruffling feathers, in solos, duets, or trios, and also as large flocks of birds flying in unison. This is not to say that the work is in any way simplistic-quite the opposite. The composition of the shots was meticulously considered and resulted in the work's subtle ebb and flow. Birds is not a loud work-its soundtrack is of tweeting birds and watching the work made me want to take time in and with it while feeling enriched and full of thought.

Birds was incredibly important to my practice, but also I believe that it was a pivotal moment for dance on screen-it was as though someone had opened a window in a smoke-filled room. Hinton's film encouraged artists to think in new ways about what dance on screen was, and what it could be.

Martina Kudlacek's documentary, In the Mirror of Maya Deren (2001), presents Maya Deren as an artist whose life was filled with a passion to explore dance and film. Her writing, thinking, and making were interwoven, each supporting the other. Her seminal work "An Anagram of Ideas on Art, Form and Film" is what Deren calls an "organization of ideas in an anagrammatic complex." 4 In it she sets out her theories about film as an art form. Watching In the Mirror of Maya Deren prompted me to consider how craft and creativity are both formal and fluid processes. Deren was bold and she was an explorer. She was immersed in a life of creative venture and her art practice crossed over into making, thinking, writing, talking, and doing. It is important to me how she was invested in the exploration of film and the integration of dance, and how relentless she was in testing assumptions-especially her own.

At a time when I was questioning the possibilities and potential of integrating dance and the camera, I was nourished by the work of Hinton and Deren. I was nourished not only by their inventive work and thinking, but also their love of film, their complete conviction that dance was a perfect partner for the camera, and that, together, the two forms presented an opportunity for the creation of a new art form-a form unique unto itself. My observation and investigation of their practices encouraged me to step forward into the unknown.

\section{Biography}

Tracie Mitchell PhD, created and teaches the dance screen unit at Melbourne University. Her award winning artworks have toured globally and are held in major collections including the Tanz Museum in Cologne and the Australian Centre for the Moving Image. She is recipient of the prestigious Australian Council for the Arts 
Fellowship. In 1999 she founded the Dance Lumiere Festival and was Director of ReelDance Inc. (2008-2010). She wrote the chapter "Scriptwriting Dance: The First Point of Integration for a Dance Screen Work," The Oxford Handbook of Screendance Studies (New York, Oxford University Press, 2016).

Email: tthemitch@fastmail.fm

\section{Notes}

1 Maya Deren, "Choreography for the Camera," 221. 2 Merce Cunningham, The Dancer and the Dance, 106.

${ }_{3}$ Human Sex was the full length work made for theatre and it was a significant work for Lock's dance company La La La Human Steps. It won a Bessie Award and travelled internationally for two years. http://digitalcollections.nypl.org/items/23a52af0-b2c50131-e08d-3c075448cc4b.

${ }_{4}$ Deren, "An Anagram of Ideas on Art," 4.

\section{References}

16 Millimeter Earrings. Chor. Meredith Monk. 1966. YouTube.

https://www.youtube.com/watch?v=EUfPmc_8E6c

Beautiful Lecture. Chor. Steve Paxton. 1968. 16mm film.

Birds. Dir. David Hinton. Chor. Yolande Snaith. 2000. DVD.

https://www.youtube.com/watch?v=VPAPKuRpDfk

Brown, Carolyn, Merce Cunningham, Laura Kuhn, Joseph V. Melillo, Thecla Schiphorst, and David Vaughan. "Four Key Discoveries: Merce Cunningham Dance Company at Fifty." Theatre 34.2 (2004): 104-111.

Dead Dreams of Monochrome Men. Dirs. David Hinton and Lloyd Newson. 1988. DVD.

Deren, Maya. "Choreography for the Camera." In Bruce McPherson (Ed.) Essential Deren: Collected Writings on Film by Maya Deren. New York: Documentext, 2005. 220-224. 
----. "An Anagram of Ideas on Art, Form and Film." In Bruce McPherson (Ed.) Essential Deren: Collected Writings on Film by Maya Deren. New York: Documentext, 2005. 34109.

Homemade. Chor. Trisha Brown, Dir. Robert Whitman. 1966. YouTube. https://www.youtube.com/watch?v=OrrNrfucoB0. Film of performance.

Human Sex. Chor. Édouard Lock. 1985.

In the Mirror of Maya Deren. Dir. Martina Kudlacek. 2001. DVD.

Kaleidoscope. Chor. Alwyn Nikolais. 1953. 16mm film.

La La La, Human Sex Duo No.1. Dir. Bernar Hébert. Chor. Édouard Lock. 1987. YouTube. https://www.youtube.com/watch?v=mRt5Y439dvU.

Locale. Dirs. Charles Atlas and Merce Cunningham. 1978. YouTube.

https://www.youtube.com/watch?v=uBTPGMzysdo

Roamin'. Dirs. Charles Atlas and Merce Cunningham. 1979.

Totem. Chor. Alwyn Nikolais. 1960. YouTube. https://archive.org/details/totem_201702 


\section{INTERVIEWS}





\section{Starting with Sight: A Conversation between Rosemary Lee and Anna Heighway}

Rosemary Lee, C-DaRE (Centre for Dance Research), Coventry University

Anna Heighway, Roehampton University

The following is a conversation between Rosemary Lee and Anna Heighway on July 2016, at Alexander Palace, London. The talk centers on Lee's practice, Liquid Gold is the Air (2014), and what it means to be a visual choreographer.

Keywords: choreographic practice, Liquid Gold is the Air, visuality

\section{https://vimeo.com/205526169}

(We sit on wicker chairs, overlooking a garden. Rosemary is looking at me and I am looking at her.)

AH: If you could dance a duet with anybody, dancer, non-dancer, dead or alive-who would you choose?

(Weighs up several partners)

$\mathrm{AH}$ : You can only have one!

RL: Dave Capps.1

$\mathrm{AH}$ : Could you have that dance now? Could you close your eyes, perhaps, and talk us through what unfolds?

$R L:$ (Closes eyes)

Ok. Because he's in America I see him in a chair opposite me, but miles away in a different time zone-with the thought that it might be some sort of a Skype duet. I see a lot of stillness. He's misty because I'm imagining him far away. He's quite small and there is a deep perspective-so it's very cinematic. He's sitting facing me but we can't speak. And there's a sense, that in the stillness, through light or maybe because I'm starting to see him-feel him on screen, rather than feeling you here beside me-of weather and seeing it cross him, of seeing grey clouds and rain come and go again and the light clear, so that he seems more vivid, seems nearer and then seeing him fade again. But I don't see him moving and I don't see myself moving. He can see me with the same thing happening with the weather and light changing. 
$\mathrm{AH}$ : Is there any other sensory information there?

RL: There would be something about the seated-ness and the stillness. I'm becoming aware of my sitting bones, spine and collarbones and I can sense that my elbows are out as if I am about to do something and I'm really aware of that. I'm ready to go (eyes still closed, elbows tense and pushed outwards away from the body) and I'm thinking of that book $\mathrm{H}$ is for Hawk so I'm just going to relax and see-maybe that's the dance. In $\mathrm{H}$ is for Hawk Helen Macdonald talks about the hawk being ready to go at any point. I'm kind of tense enough that I am ready to fly but I don't know where I'm going to fly to and my feet are like talons on a perch but I'm on this wicker chair (smiles) and I feel like he's the same. We are both rooted to the spot but there's all this movement of the elements and probably weather inside us, and maybe this elbow thing. (Opens eyes, laughs)

There we go.

AH: Thanks for that. We met briefly at Bath's opening of Liquid Gold is the Air. In our chat you described yourself as a visual choreographer.

RL: Bit obvious with that task wasn't it? (Laughs)

$\mathrm{AH}:$ What do you mean by 'visual'?

RL: Firstly, I get images in my head like I just did then-quite sort of cinematic. If I'm working in a more site-specific context (Looks out at garden) I would be sitting here and I'd be looking and trying to figure out where the dancer would be-where they might move to in space. Already I'm just looking at it like a kind of a set for figures to be in. In that sense its kind of visual again.

$\mathrm{AH}:$ Have you always experienced things in this way?

RL: Although I was dancing as a child, I was also looking at Renaissance art a lot. I thought an artist was a painter. I wanted to be an artist but as a choreographer. I think I couldn't separate the two in a way.

AH: Is this visual approach manifest in your practice in any other ways?

RL: In Liquid Gold it is fairly obvious, because I've actually made my first triptych. Also, with any site-specific work, I view it in an architectural way. For example, with Under the Vaulted Sky what I'm trying to do for the audience is give them the best view of the site, and this for me was standing looking down the nave. For about two years I was thinking, I've got to give the audience that, but how do I give 300 people that view? That's very manifest in the way that I lead an audience round-that the views that I think are the most stunning and harmonious, dictates how I place people within it, to enhance what you see of the site, but also make sure the dancers look their strongest. 
And I suppose it manifests itself because I make films. The visual side that may have begun as artists being people who painted on a flat canvas, you see in the site-specific work and the film because I'm treating the site or the stage as a canvas. I'm sure everyone is, aren't they? Maybe not.

$\mathrm{AH}$ : That was going to be my next question. I'm wondering what types of choreographic behavior your account of the visual might exclude you from?

RL: Well, I guess for some choreographers it's more about atmosphere or the energy or dynamic. I do think that's very important in my work too, but I'm not so interested in athleticism and what the body can do, especially in terms of extremes-so that's never present in my work. I think some peoples' concern is the plasticity of the body, whereas my concern is the presence of the person in space. Even if I'm making a piece for a hundred people I'm hoping that within the ensemble, which often moves as a flock-that you can also see individuals. That's another thing I'm interested in, individuality and the collective. I think the visual is not the only aspect.

$\mathrm{AH}$ : Undoubtedly. Nonetheless, one of the reasons we are sat here is because of how I felt after watching Liquid Gold is the Air. Four months on, I can't remember what I had for breakfast but I can still recount the shot of the grey-haired women staring at me, grinning, whilst surrounded by flickering gold palms. I've since discovered that there is a moment from every Rosemary Lee work I have seen that similarly snags on my mind. (I describe the moment in boy, when he peeks through a horizontal shape of the arms,2 and a moment from Common Dance when a sea of people floats horizontally across the stage whilst stood on the backs of others, a movement coined 'camel.'s) This got me interested in a possible connection between your ability to create memorable images and the visual nature of your practice.

RL: I am trying to do what you've just described. I'm trying to create images that will burn into your retina, like paintings that stay with you. Exactly what's stayed with you is what I want to stay with you. And it's interesting that you chose that moment from Common Dance because that's a moving image, so it isn't just still figures in space that we are talking about, is it? It's also movement images.

$\mathrm{AH}$ : Are there any choreographers who provide a similar experience for you?

RL: You've reminded me of a work I saw when I was in my twenties in New York in the early 80's by Martha Clarke called Garden of Earthly Delights. I was bowled over by it then. It had Hieronymus Bosch-like images. People became boats and were riding galleons, but in the bodies. In hindsight now I wonder if I might have subconsciously nicked something like 'camel' from there. Her work had these moments that just went ZING and hit you as imagery and those images stayed with you. I love that sort of thing. 
$\mathrm{AH}$ : In an era of visual bombardment, your ability to bring moments to the surface is no small achievement. I'd like to try and understand how you are able to do this. It might help if I could get a clearer impression of the scope of your visuality. What about your initial moments of insight? Do they always present themselves as an image?

RL: (Closes eyes) I had to close my eyes to see, so that means they probably do. Do you see what I mean? I had to do that to get the visual out. It depends. If it's site specific, I'm starting with the site, so I sit there and I look, I don't see things, I don't have a sort of hallucination (Looks out towards garden) but I'd think about where I would put someone-so I am imagining someone still, sitting in a chair there, but l'd also be getting a feel for it. There are lots of things that would be going through my mind. For example, when I went to see the four squares in London for Square Dances, I walked through loads of different squares and would get despondent because nothing would come except a sort of character. I'd get a man in a tail suit and think, That's so typical of me. I can't do that again. Others l'd think, ugghhh, because nothing was coming. And that's to do with the feel of the square as well as the look of it. You can't really pull those apart because whatever the square is, is what's making its mood. There is a mood thing, an atmosphere or vibe too that is part of the insight.

$\mathrm{AH}$ : With the Dave duet you improvised earlier, you went from the visual, to a sort of visual 'feel' of Dave and then into a more somatically orientated awareness of body. Is this a habitual connection?

RL: I think this might link back to my traditional training. In my third year at Laban, I'd been doing Graham and rather hated it. The teaching I'd had was about where your muscles were, counts, action-nothing about the meaning, the dynamic or the sensation and no metaphors. I knew something was lacking. I found it really dry and cold. And then Bonnie Bird had to teach a warm up because the teacher was ill. She got us sitting before we were about to perform and she said "Imagine your ears are like fox's ears" and I thought-now we're talking.4 I've had three years of this and now I know the path I want to follow, I know how I want to work. And that led me into a more somatic practice. I think it's that-that imagery and metaphor is what I use to get people dancing and I only use that: fox's ears, spine like a sea otter's, camel, flock, dissolve, melt, rise, or snap-open like Himalayan Balsam (when the seeds come out)-all of those words are metaphors. The visual into the body is what makes sense to me as a dancer and it's how I teach. I think that's where the body and the visual thing as a choreographer might link up for me.

$\mathrm{AH}$ : You make work for a range of contexts. Does your visual approach change when making screendance work?

RL: Yes. I have more control over what the audience can see and I love that. I can move your eye from boy's mouth chewing the grass, to him as a distant figure in the sand. 
And although I can try and do that with site-specific live work, I can't quite force you to look at it.

$\mathrm{AH}$ : If screendance could be neatly packaged into different genres, which would your films belong to? Feel free to make up a nonsense title.

RL: (laughs) Oh my god-what on earth can I say to that? Something to do with nonverbal connection to landscape? Body and landscape? What would you call that? Poetics maybe-something about poetry I think.

$\mathrm{AH}$ : What would the iconography be?

RL: Close detail and the opposite-where a person is tiny in the landscape, so being very powerful but very humble within the same setting-vulnerable. No speech, elemental on some level-so you feel the weather, you feel the wind and the temperature. Very little artificial light. Strong atmospheric sound-score that enhances the environment you're in and a sense of the presence of the person.

$\mathrm{AH}$ : Could you tell us about Liquid Gold is the Air? How did the work come about?

RL: Under the Vaulted Sky is the live work that took place in the arboretum in Milton Keynes called The Cathedral of Trees.5 I was invited by Milton Keynes International Festival to be an artist in residence. I then did a two-year feasibility study. The reason I was invited was a) they wanted that space animated and b) they wanted to bring more local people into the work of the festival. I was given that site. At the very end of those two years we didn't think we would find the funding for my ambition but The Stables 6 put in a bid for an Arts Council Exceptional Award and we got it. Part of the stipulation of the grant was that they felt that the live work wouldn't reach enough people and that I should make a film as well. I have to say that initially I was very worried about that because I didn't think that I could make a work for a live audience and in my head also be considering shooting a film the day after.

$\mathrm{AH}$ : What was it about that prospect that troubled you?

RL: Well, they are two very different ways of working and they are two different works. They didn't want a documentary-they wanted something that could tour the dance film festivals, so to me initially that looked like a single screen project-a bit like boy or greenman and I knew that this had taken me two years to make. The way I thought I could tackle it in the end is to make an installation that could have a different sense of time and could be really episodic-so that I could just focus on images rather than the progression through with a beginning and an end. Roswitha Chesher-the filmmaker who I invited to collaborate with me on the project-was excited by this concept. And I wanted to make a triptych because Under the Vaulted Sky is set in the Cathedral of Trees and The Cathedral of Trees is set in the footprint of Norwich Cathedral. 
$\mathrm{AH}:$ What does that mean?

$\mathrm{RL}$ : It means that the trees are roughly planted where the pillars would be and the dimensions of the cross of the church are there. If you looked at it from above, you'd see that. The trees become the architecture of the cathedral. I grew up with Norwich Cathedral being the nearest to my home. I loved it as a child. It has the most number of Green Men carved into its roofs. There was a lot of imagery and the thoughts of Norwich Cathedral that came back into the Cathedral of Trees: the icons of early Renaissance art, the gold leaf around the figure, the carvings in the cloisters that have figures that look like they have teeth coming out of them-like images from Mexicowhich is partially where the gold hands around the figures came from, were images that I thought would bring the arboretum to life in the way a cathedral is brought to life. I wanted to add the bling of a Medieval Cathedral to the shaded vernal one.

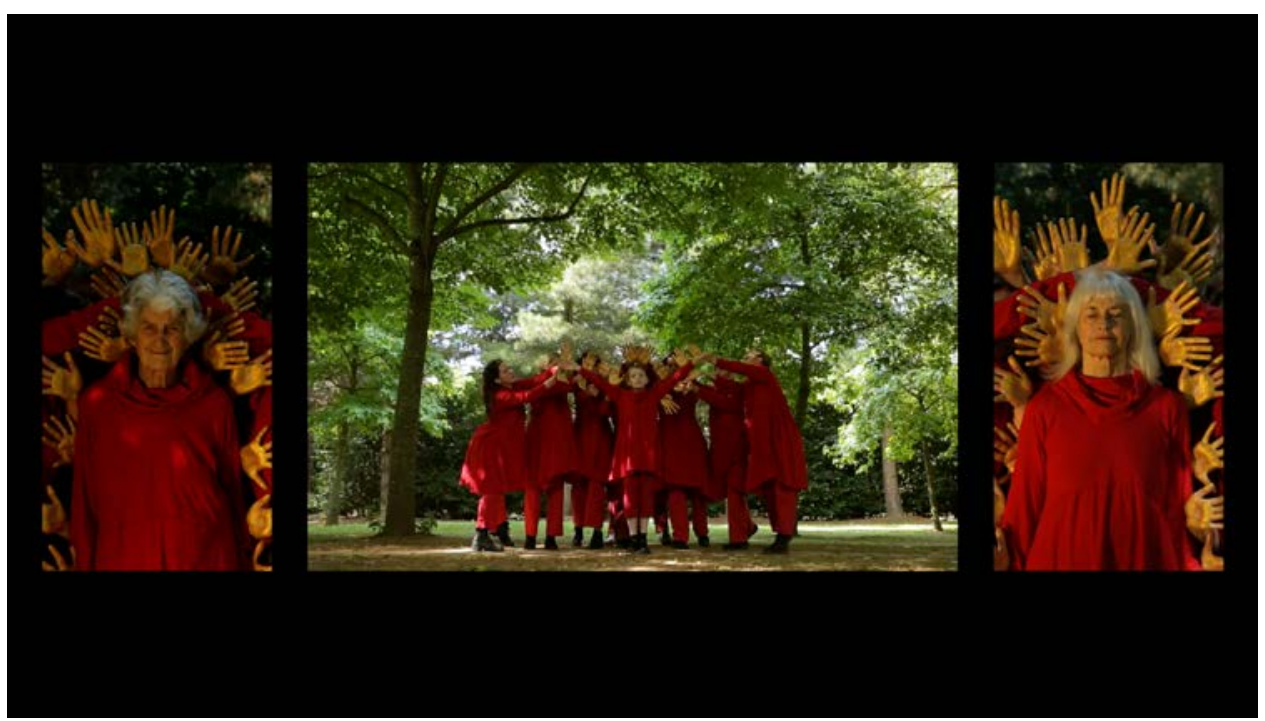

Screenshot, "Liquid Gold is the Air"

$\mathrm{AH}$ : Some people may be surprised by your choice of a multi-screen format as a remedy for lack of time.

RL: (Laughs) Maybe, but also let's not forget that Roswitha had worked with me a lot. She filmed Common Dance brilliantly and made On Taking Care with me so she knows how I work. When I suggested a triptych, she said "What are you talking about, course we can do it." That was great. We could be much more abstract. What she was doingspeaking of visual-was collecting a scrapbook (from Under the Vaulted Sky) of-I want to do that long shot and I'd like the camera here. We could find our favorite shot of the nave for example and we could use it, whereas I couldn't give that to the audience in Vaulted because they couldn't always fit there. It was a joy on some levels because we could look at the site afresh. 
AH: Liquid Gold's status seems complex. Post credits, it's written that Gold is "inspired by" Under the Vaulted Sky. Is it adaptation, documentation, or is it an autonomous screendance work?

RL: I think it's an autonomous screendance work. I think it stands alone. It certainly isn't documentation.

$\mathrm{AH}$ : Is there no duplication between the live work and the installation then?

RL: Well there's definitely lots of stuff that comes from it, but the new context of the installation also transforms it. Adaptation, I think you probably could argue. But again, the works are so different. This business of making another work out of the same inspiration happened with Beached. This was a live piece for three women but I felt that there had been so much imagery, stories, and characters that were resonating with me-that this piece was just one aspect of the foundation and I was feeling frustrated because it felt like it hadn't lived its life properly. Then the wonderful late Niki Pollard 7 who I was working with at that time agreed with me that we should do another Beached, so we wrote a book-it's a book of our notebooks, her questioning of the notebooks and poems-and that's called Beached: A Commonplace Book and that's another work, but it's not an adaptation and it's not a documentation-it's another art form but it comes out of the same roots of the stimulus-of this thing which is imagery, but it's also the whole vibe of it. As I was trying to explain with Gold-this sort of atmosphere: cathedrals, icons, gold, vernal cathedrals, and all the resonance of those ideas and images, I feel like they've come out again but in a new art form.

$\mathrm{AH}$ : When I watched Liquid Gold I was experiencing a transposition of Norwich Cathedral into The Cathedral of Trees on three screens whilst sat in a church in Bathanother complex aspect of the work.

RL: You're right, it is complex and sorting out the copy with it in terms of what you give to people, how you explain it-it's difficult. I also don't want it to be viewed as necessarily religious just because it's in a cathedral. That's very important. It can equally sit in a gallery, a historic building-a meeting room. But I don't think we should shy away from complexity and try to disentangle everything cleanly. In cathedrals there is a rich historical and visual complexity that beautifully reveals the messiness, the over-lapping-ness of a culture. Take the Green Man image-we identify it as folklore, paganism, whatever it is, we don't really know, but the male spirit of nature as opposed to Mother Nature, it's certainly nothing to do with Christianity. I love to think of the skillful people that made those cathedrals carefully carving multitudes of strange creatures-I do enjoy bringing a vernal cathedral into this setting. To have ordinary people in a stand of trees within an alter piece-like context-I feel privileged that all of us who made Liquid Gold is the Air can add something to this continuum of artifact making. 
AH: Let's move on to the soundscape. Was it post-scored?

RL: Yes and we never change an edit-the sound has to fit the visuals. It's complex again because the music for brass instruments and the gamelan sounds-the metallophones music-was the sound composition for the live work by Terry Mann. I realized that music wasn't right for a film installation, so we decided to invite Graham Miller to create a new musical soundscape that incorporated beautiful sections of Terry's music, which we recorded in a large empty church.

$\mathrm{AH}$ : What would Liquid Gold be like without the sound?

RL: Not as dark. Not as suggestive of other green spaces. Not as heightened and intense. Not as suggestive of other elements like fire. There are techniques that he uses within the score like birdsong played backwards and slowed right downbeautiful hidden conceptual ideas that we enjoy together. With Graham it's a really interesting collaboration and he's made all the sound for my work except Snow. He gets my work and intuitively knows exactly what it needs-he realized it for me. We did say we wanted a kind of underlying darkness and that he could add this undercurrent, which I can't always do with my side of the work.

$\mathrm{AH}$ : Why the darkness?

RL: Well, if you don't want to see it, you don't. But then if you plant the suggestionsome people will. For example, with boy, most people see play- they don't see anything dark in it at all, but I showed it to some boys of his age and they all saw it. They were like, "Why is he all alone?" "Why did he jump off the cliff at the end?" "Does he come back?" "Has he killed himself?" I think that with everything in life, you've got black and white and I don't like things that don't allow you not to feel the gamut of the meaning of something.

$\mathrm{AH}:$ I'd like to return to your use of the triptych. It seems to impact on the film in ways that make Gold stand apart from your other works for me. The image is flat, there is no camera movement, very little cutting into moments, so whereas much of your work has that sense of inviting us into and through a world, in Gold it is brought to us, its presented. The visuals belong to the medium of moving images but they register more as pictures.

RL: That's exactly what I wanted.

$\mathrm{AH}$ : I find it interesting that you have used technology to create a sense of archaism. The formality of the Triptych device also draws a distinct boundary line between the viewer and subject that denies the viewer that sense of intimacy that you often capture. Did you have a sense of Liquid Gold's uniqueness in this respect? 
RL: I think that's interesting. I think you're right. I think it is that flatness and because there isn't a narrative leading you towards something of meaning and perhaps it's something to do with time and the fact that it's installation-where in boy you can get drawn into his world in a sense.

$\mathrm{AH}$ : The focus of the subject in Liquid Gold is often directed at us; the audience. Why did you decide to do this?

RL: I am quite interested in people looking directly at you. It's in loads of my work. Infanta does it-she knows you're looking at her. It's in Remote Dancing and in Common Dance. We are doing it now because we are getting used to one another and we're talking, but when I'm giving a talk I can't look at the audience. Maybe it's something about my personal desire for intimacy and my difficulty with that. But it's more than that. I do think that we are reminded of our differences rather than commonality in the media. When I was eight my mum asked me what I wanted for my Christmas present and I said that I wanted this Rembrandt print of this older woman. I had it on my wall when I grew up. It's probably because I loved old people and felt that we were pulled away from them. I loved their wisdom and I loved looking at their faces. I loved the way she looked at me like she looked into my soul. I must have sought that connection with her and I think a lot of my work is about investigating this sense of intimacy that is nonsexual. It's an intimacy that's not about that-it is an intimacy of our souls, our spirits. We are all existing and sharing the same oxygen, and regardless of all the ways we have been brought up there is some unspoken connection. And one other thing I'm trying to give which links back to your memory of Hazel looking at you.8 I grew up with a Quaker background. The maxim of Quakerism-there's no doctrine-but the one thing they might say is that the inner light-the divine-is in everybody. One of the ways you should live your life is to draw out the potential in everybody. You could say that Liquid Gold is about you noticing the inner light in Hazel, and Hazel noticing the inner light in you.

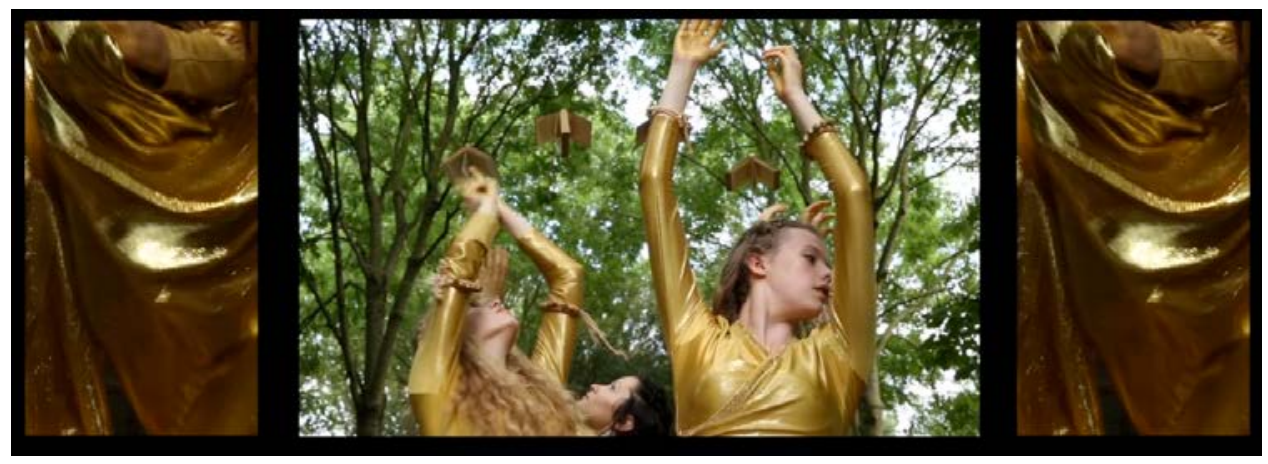

Screenshot, "Liquid Gold is the Air"

$\mathrm{AH}$ : You mentioned earlier, an interest in communicating "the presence of the person in space." There certainly is a sensory quality to Gold that gets beyond the eyes. It's a 
textural, tactile experience. You get the impression of wind on the skin-of the feeling of the performers' experiential connection between motion and site. Despite the distancing effect of image-as-picture, there is a perceptual depth, or at least the impression of it. Let's talk about some of the ways that you achieve this; the first talking point is hands.

RL: There are lots of reasons why I work with hands. I'm working a lot with nondancers. Everybody's hands are expressive and people learn how to use them very quickly. It's practical. The hands suggest people, as feet do-and shoes; they suggest personality. I also use hands because I think that's how we know the world. If you see hands gesturing we must be suggesting something about the rest of the world and our knowledge of it-because that's how we know-we touch. I'm reminded of the line From Michael Donaghy's poem, Touch: "She touches my hand to know ..."9

$\mathrm{AH}$ : And the dancers, how am I experiencing such a strong sense of them 'experiencing-the-experience' if you like?

RL: Well I think this comes from a link between the somatic side of what I'm trying to get the dancers to experience and what I'm trying to do in the film. For example the only way I will teach movement is through imagery and through them sensing that image-so its felt. They always work with their eyes closed. Although I'm a visual choreographer the first thing I do, is take away the visual from the experience of the dancer. They must imagine and embody that image. We always use touch-it's all through skin. It's hands on, and moving with the hands-pushing into the space. Seeing them do this helps you as the viewer, move into your own body-so as well as wanting to create something imagistic as you say, I'm wanting people to sense their bodies more present in the space at the moment of watching. It's also because of the simplicity of the images. They're opening their arms to the sky, they're listening, they're swaying-the leg isn't up by the ear-you (the audience) immediately feel that you could be there doing that, so then it puts you in the dancer's body and you start feeling your own body.

AH: Time also lends a 'felt' quality to Gold. The pacing is steady-there's temporal space allowed for images to unfold. It's practically palpable-you could sink your teeth into it.

RL: I think you're right-time does allow for a more haptic response. And I can allow for time with an installation, with a five minute film it's harder. If you don't give yourself time to taste something you will always skim it. If you allow it to unfold at a certain pace and you give people time, their heart rate will probably slow a bit. I think it does happen with Gold-people do leave in a different state, like they've had a meditative experience, and this means they'll see in a different way-I mean 'see' in all senses. They'll sense in a different way. 
$\mathrm{AH}$ : There is also a sense of 'otherworldliness,' of things being more than they seem in your work. People apparate then dissolve, they move in reverse, they can walk through the confines of the frame-like ghosts walking through walls. Where is this coming from?

RL: Mystical experience-I'm really interested in what that is. As a child, I wanted to see an angel-I wanted to sense one. I desperately wanted to believe that there was more out there than the grit of the ordinary day-to-day-more than the familiar world. I sensed the world a bit like boy is sensing the beach. I think I was very dreamlike as a child so that's all in there. I mean I'm not Christian with a belief system but I think I'm quite spiritual-whatever that might mean-who knows. With Liquid Gold, there's also something else going on because if you make people appear and disappear you are also suggesting death and life. boy was more about magic, but in Gold, where they fade in and out, it might suggest 'Dust to dust' and 'Ashes to ashes' as well. They are magical but they're also real. As well as the reality of eye-to-eye, skin-to-skin in the present moment, I want to remind people that life isn't permanent. I know that sounds very cruel but I feel it's quite important that we treasure it more, but also that we don't have that hubris-that arrogance of permanence-because we are like a fleck of dust. It's about the mystery of life but also the grittiness and holding those two things together at once. The sense of permanent impermanence, the vitality of life and the closeness of death, the feeling of death when you give birth, or the feeling of birth when you die-all of those passages. I think those are the mystery-that's the mystical bit that is so extraordinary, so I suppose I'm trying to get a little flavor of that.

\section{Biographies}

Rosemary Lee is known for working in a variety of contexts, Rosemary has created large-scale site-specific works with cross-generational casts, solos for her-self and other performers as well as video installations and short films. Her work is characterized by an interest in creating a moving portraiture of both individuals and of the close performing communities she brings together. Regardless of the scale of these projects she creates a unique intimacy with her audience whilst also exploring and highlighting our relationship with our environment. Rosemary also writes, guest teaches and lectures internationally. Recipient of both a Bonnie Bird Award and a Jerwood Choreographic Research Project Award in 2013, she is an Artsadmin Artist, a Work Place artist, a DanceEast Artist Associate 2015, a Senior Research Fellow at CDaRE Coventry University, a ResCen Research Associate Artist (Middlesex University) and holds an honorary doctorate from Roehampton University. 
Anna Heighway is a Dance Artist and Lecturer currently living in Bath. Many years spent studying dance and film alongside a career in television is reflected in the breadth of her practice. Anna is currently studying for a PhD in screendance practice and philosophy at Roehampton University.

Email: a.heighway@bathspa.ac.uk

\section{Notes}

1 David Capps is Associate Professor at Hunter College, New York City. He and Rosemary danced together when she lived in NYC in her early 20's. At 6ft 4in, he was one of the few people who could help her 'fly.'

2 boy, Lee and Anderson.

3 Common Dance, Lee.

4 Bonnie Bird was a dancer with the original Martha Graham Company. She became Director of the Dance Theatre Department at Trinity Laban in 1974.

5 The Cathedral of Trees was designed by landscape architect Neil Higson in 1986 and is planted in the outline or 'footprint' of Norwich Cathedral.

6 The Stables is a live music venue based in Milton Keynes. It also initiated and funds The Milton Keynes Festival.

7 Niki Pollard was a writer and researcher who worked closely with Rosemary on a number of projects. http://www.rescen.net/archive/n_pollard.html\#.V7TV-4RluCQ ${ }_{8}$ See the late Hazel Powell in the first screenshot, far left. 9 Michael Donaghy, "Touch."

\section{References}

Beached. Chor. Rosemary Lee. Perf. Ch4pter. UK, 2001. Site-specific live.

boy. Dir. Rosemary Lee and Peter Anderson. Chor. Rosemary Lee. London: MJW Productions, 1995. Film.

Common Dance. Chor. Rosemary Lee. UK, 2009. Live work.

Donaghy, Michael. "Touch." Michael Donaghy: Collected Poems. London: Picador, 2014. greenman. Dir. Rosemary Lee and Peter Anderson. Chor. Rosemary Lee. London: MJW Productions, 1997. Film. 
Infanta. Dir. Rosemary Lee and Peter Anderson. Chor. Rosemary Lee. London: MJW Productions, 1998. Film.

Lee, Rosemary and Niki Pollard. Beached: A Commonplace Book. London: Rescen Publications, 2006.

Liquid Gold is the Air. Dir. Rosemary Lee and Roswitha Chesher. Chor. Rosemary Lee. UK, 2014. Film.

Macdonald, Helen. H is for Hawk. London: Vintage, 2014.

On Taking Care. Chor. and dir. Rosemary Lee. UK: Rescen Publications, 2012. DVD.

Remote Dancing. Chor. Rosemary Lee. Dev. Nick Sandiland. UK, 2004. Installation.

Snow. Dir. Rosemary Lee and David Hinton. London: Arts Council/BBC, 2003. Film.

Square Dance. Chor. Rosemary Lee. UK, 2011. Live work.

The Garden of Earthly Delights. Chor. Martha Clarke. USA, 1984. Live work.

Under the Vaulted Sky. Chor. Rosemary Lee. UK, 2014. Live work. 


\title{
An Interview with Eiko Otake
}

\author{
Rosemary Candelario, Texas Woman's University \\ Eiko Otake, Independent Artist
}

Keywords: video, installation, collaboration, photography, A Body in Places

Rosemary Candelario-You and Koma had already been working together for more than ten years when you made your first dance for camera in 1983, Tentacle, with Jeff Bush and Celia Ipiotis. What made you to turn to video at that time?

Eiko Otake-We were approached by Celia and Jeff, who were working as a couple and were eager to develop dance for camera.1 You know, we are practical. They approached us with a vision for a piece, we listened, it was workable, we did it, and we learned something new and important from the process. Then in 1985, the Walker Art Center commissioned us to make Lament and paired us with James Byrne. We were still young at that time and tended to take what came our way. And media people, videographers and the media department of the Walker, were eager to work with us. We always respond to passion.

Through these experiences, I began to learn what it is to edit video, and with the existence of the NEA video dance division, it became possible for us to imagine, apply for, and work on video projects during the time that we didn't have performance engagements.2 You can look at the video as soon as you shoot it. It was very much a cyclic process: you shoot, you look at it, see what works and what does not, discover who likes what for what reason, respond to suggestions, and then shoot again. You know, it was a whole different process from performance, because performance is not repeatable. But you can look at video and make judgments and keep working on it until it feels right. That was a kind of luxury we never had as performing artists. So I was fascinated by this, and by the opportunity to develop our own aesthetic and collaboration strategy. However after feeling some frustration in relying on edits too much, we decided to shoot Husk (1987), in the manner of Tentacle, with no postproduction edit. We realized, "Oh we can do this on our own!" I feel like Husk is very much its own world.

RC - Tell me about how you started making video documentaries of your work.

EO_In 2004 Koma and I were given the Samuel H. Scripps/ADF Award for Lifetime Achievement from American Dance Festival. We were told that we needed to provide a video to be projected at the beginning of the ceremony, and they sent us some examples of other award winners that showed the choreographers' work on stage and 
in the studio, and that included many important people speaking about how wonderful the artists receiving the award are. We wanted to make something different. So we decided to show what we cannot show on the stage and asked our younger son Shin to produce a documentary. The resulting video was My Parents $(2004$,$) a family project. Shin who edited the video and spoke the narration was only$ 17 years old. We looked into old film footage and photos from our youth to give the sense of where we came from and our older son Yuta wrote a script that revealed how we work, think and talk. Even though it was made for the Scripps Award, I continue to show it. The beauty of video work is that you can continue to share it. It introduces us, it offers background information and our artistic concerns.

A year later we created The Making of Cambodian Stories (2005) to publicize the US tour of Cambodian Stories (2006,) which featured nine young Cambodian painters. The video was actively shown on cable TV in places where we would be touring as a way to prepare the audiences by showing the lives of these young artists in Phnom Penh, where the work was created as an inter-disciplinary, inter-generational collaboration. Like My Parents, The Making of Cambodian Stories was a need-based documentary that served its purpose well. Learning from that experience, for our Retrospective Project (2009-2012), the first thing we did was to create a video documentary, The Making of River (2009) with the help of Shoko Letton. River (1995) was a memorable piece of ours that we performed in many rivers. It was not only a physically difficult piece to perform but also to video. We were in dark rivers and were separated from the audience by water. We had little performance footage of adequate quality. So we decided to use day time rehearsal video, which helps viewers to see the very rivers we performed in that become dark masses of water at night. As a result, this video documentary showed something that performances could not. We made each of these documentaries for specific reasons, but after the immediate need is met, we can still show them because the content is solid and real.

RC-Speaking of your Retrospective Project, it was during that time that you began experimenting with new ways of working with performance documentation, producing edits of performance video for use in museum exhibitions, starting with 38 Works by Eiko \& Koma, and continuing into a number of video installations.

EO-Yes, in addition to 38 Works, I produced what I call video "wells" for our exhibitions at the Chicago Museum of Contemporary Art, the New York Public Library for the Performing Arts, and other locations. These freestanding wooden boxes had monitors placed at the bottom of them, each showing a video edited from archival footage. In choosing the footage and editing it, it was important to me that each one have a different length, but that it shouldn't be any longer than necessary. This is my general philosophy about the length of works, whether a live performance or a video. Editing, after all, is a time-based art. But an edited video should also deliver the same sense as the original performance work. At the Chicago MCA exhibit, I saw people 
looking into these video wells and watching the entire video from beginning to end and then going to the next box, and again watching from beginning to the end, I realized given the context and the space, people are willing to watch dance video for its own sake, without knowledge of who I am or what the piece was originally for. That made me even more serious about editing our archival video for use in video installations.

Because Koma never really cared much about video editing, it has become my work. He likes painting, he likes objects and the structures he makes. But I actually like the process of editing. It's like cooking in a way because you work from source material. But I prefer working with another person because it can get too intense doing it alone. I also can't edit with expensive professionals because that would oblige me to make decisions quickly. So I'm very happy to have a young, talented collaborator, Alexis Moh. The thing about the edit is it doesn't matter whose idea it is. Sometimes I am right and sometimes she is right, but we both can see that. Of course there are many different ways to be right. The most important thing is I can take time to see different possibilities, and then choose what feels right.

$\mathrm{RC}$-Our discussion about your process in relation to video and editing seems to me to fundamentally be you wanting people to be able to encounter your work in as many ways as possible. How do the "video postcards" that you started making as part of your 2016 solo Platform series at Danspace, A Body in Places, fit into this?

EO-That was Judy Hussie-Taylor's idea.3 My Platform lasted six weeks and we were doing so many things each day, including site performances around the East Village for small audiences, film screenings, a book club, video installations, and guest performances. Basically, we knew nobody could come to see everything. And all the performances were sold out. So the idea was to quickly make short videos during Platform so people could go to the website and see, oh, Eiko performed in all these different places. We called these video postcards, like if you're traveling and you can't say everything you've been doing, and you write like three lines: "Hi Mom, This is an amazing place. Wish you were here." So that is the idea of the video postcard. During Platform, we put these online every week. This allowed me to disseminate what I did without having a very thorough edit. It was a fast way to share what was happening that particular week: Eiko was here, there, and more. That's very different than the 20minute edited video, A Body in the East Village (2016), which recently screened at the Lincoln Center as part of the Film Society's Shorts Program. That is much more a meditative piece that allows you to imagine you could have been there. Then I have to make decisions about what do I want to show in a way that people can actually get a sense of each performance. A video postcard is not an edited video work that I make as a performer. There's a difference between making a creative archive of a performance work and making video postcard. 
RC - It seems like you hope with these different kinds of videos that your audiences will have different experiences with them. With the video postcards, it seems that you're really trying to extend access, which is a theme throughout your career: How can we make our work accessible to different people?

EO-Yes, the video postcards were very conscious of social media: a way to say hi and quickly see what Eiko is doing (as opposed to watching).

$\mathrm{RC}$ - I want to change topics to talk about your photography project with William Johnston, A Body in Fukushima (2014). Photography has long played an important role in your work, sometimes even being part of the way you develop ideas for pieces, for example with Tree (1988) and the photos you shot with Marcus Leatherdale. How does your collaboration with Johnston compare to your previous photographic work?

EO-It's different! No other photographer has ever offered us, or me, copyright. The work Bill and I do together, we actually co-own it. Usually photographers, no matter how great of people they are-and many of them are wonderful friends-they own it. They come, they shoot. It's my costumes, my set, my dance, my thoughts in my body but it's their work. With Bill, not only did I not pay him, but I actually co-own the work. Dancing, moving, that's totally my thing. I decided to go to Fukushima, then we both began choosing places. But until recently he has never said to me, "How about this?" And I'd almost never suggest to him how to shoot. During the shooting process he does whatever he wants, and I do whatever I want. Afterwards, we select photos together. We have a 1-5 scale: 1 is "not over my dead body," 5 is "you really have to include this." But 2, 3, 4 we can negotiate. What he chooses looks good from a photographic point of view. Me, as a dancer and choreographer, my approach is to look at the whole picture, myself, and my relationship to the whole picture. If something is 2 for him and I understand why, I would not use it in an exhibition, but I can use his 2 in my video work-even if it's blurred, or if it's not quite right. Such selections sometimes interest me as a choreographer. In creating a video from photographs, I do not want to line up just great photos. We need different textures and dynamics to make a video as an art work. We are both very concerned about the environment. He is a scholar, he is a wonderful photographer. I am not a scholar, I am a dancer, a performer. So we have different places that we operate from. I learn a lot from him through the negotiation. We understand the other person's point of view. And that has been the process. Then I make videos from our photos and I often design our exhibitions. He's a full-time professor, so I have a little more time to work on these things and I have more communication with my producers. He sometimes has suggestions, however, and often writes the exhibition text. Bill is good at this of course, so we have different strengths.

In May 2017, we had an exhibition at Topaz Arts, a dance studio and small gallery in Queens. I gave a 2-hour movement workshop followed by an opening reception for 
the exhibition, during which I performed. In the exhibition, half of the photographs were from Fukushima and the other half were from Indian Point, the nuclear power plant just up the Hudson River from New York City. By hanging the photographs on adjacent walls, we were making a connection between the two nuclear plants: what happened to one could happen to the other. In the next room we displayed video of the photographs. I began my performance naked in front of the video, as if I were emerging from the video where my naked body was breathing in Fukushima. I then put on my costume and danced in the gallery in front of my photos. My concern there was how to present my body in a much more raw state. It really gives me a different idea of how to perform because I didn't want to look like just another Eiko though it is clearly the same person as in the photographs; I want this performing body to be more chaotic than the one in the photos. A performing body is of course more than selected images. I took the audience outside into the street and I stopped some taxis because I was literally in the middle of the street performing. Then I took the audience around the corner and ended in front of an electric power structure.

So what I am trying to say here is that this collaboration is giving me a different process to work from. I performed at Indian Point and in Fukushima. Bill shot photos. We selected photos together. The video I made of the Fukushima photos is projected in one gallery, and the photos from Indian Point and Fukushima were exhibited in the adjacent gallery. And then by the time I'm performing in front of his photos I don't want to just be a self-absorbed performer dancing in the midst of my own photos. So I try to make my body a different kind of a body, but still somehow connected. It's been a challenging journey for me because as a solo performer I don't have many different layers. So his photos and my media work and the way I construct the place of the exhibition give me different layers to work with. There is a very clear intention of addressing environmental issues, too.

RC-With your solo project, $A$ Body in Places, you've been directly addressing specific issues like nuclear power and the environment in connection with specific places. And even though you and Koma often performed very close to your audience in your installation work, the way you perform as a solo artist involves a very direct address with the audience. How do you think that developed? Are both of those things coming out of a desire to address issues more directly than you did as Eiko \& Koma, or is it you as a solo performer needing to use your body differently to engage the audience and space differently?

EO-It's a combination. It has a lot to do with the fact that as a solo artist I arrive to a new community alone. If I am touring with Koma, they assume we are having dinner together or that we need time together to plan. But if I am alone, I am more available to the community and I'm working closely with other people. So it just means there is more communication happening in many different ways: talking before the performance, and communicating during the performance with the individual 
audience member. And also remember I'm not performing under theater lights. If I look at one particular person, everybody knows I am looking at that person. And that person knows that everybody is watching. And everybody knows it could have potentially been another person. Or everybody can imagine, "that could have been me." So the evenness of the gaze is totally broken. That's a different kind of excitement between a performer and viewers.

Fukushima is like an exemplary disclaimer-everything that wasn't supposed to happen happened. Bringing in Fukushima also gives a different engagement for people to look at, the way my body is seeing and relating to something. It's a complex relation that gives a certain weight, a certain flavor. The direction to Fukushima is different than the direction to Ireland. I like it in a way that it makes it feel not equal. It's absolutely urgent to me that there has to be some kind of danger in my solo performance, there has to be some kind of effort, some kind of crevasse that I could fall into. I'm thinking those things as I'm performing. Under my antics there could be some kind of a dangerous crevasse.

$\mathrm{RC}$ - It's interesting how audiences have been able to witness through your video documentation of all these different places over the last three years, starting with Fukushima but then Philadelphia, and Hong Kong at a place where there were major protests, and Wall Street, but then also a library, a bookstore, a community center....The accumulation of these very charged places and these very everyday places asks people to question the relationship between their daily lives-the shop they go to every day, the street they go down...

EO-These also give a different function to the performer's body. It's almost like my body becomes that of an ancient traveling performer who used to carry news between different countries, before TV, before telegrams. The performers knew the different communities' news and carried it from one place to another. Being a performer, I think our bodies are open to absorb things. My body has been to Hong Kong so I carry that sense of weight of a place, I carry the decisions I made there about selecting a site and selecting certain moves. My body carries Hong Kong, carries Chile, carries the library, carries the station. I've also been thinking a lot about how some of the people who saw me perform in Philadelphia or Hong Kong could now be dead, the way that my friend died right after seeing me in Chile. My body is almost like a deposit of peoples' gazes. And I like to imagine that certain people, not everyone, feel like "oh my god, this body has been going to so many places. Oh, my body has also gone to these places." So I look at my body and feel my body differently.

In this work, my presenters have become very much collaborators, more so in this project than any other project I have ever done except perhaps River. So that's great. I feel like it's not my own creation. I'm not really that interested in myself. But I'm 
interested in my body becoming a kind of fieldwork that other people have also worked on.

\section{Biographies}

Rosemary Candelario writes about dance and popular culture through the lens of gender, race, and ethnicity. Whether she is addressing the Japanese avant-garde dance, butoh, Asian American dance, vampires, cyborgs, or mass protests, an attention to the political efficacy of moving bodies pervades her work. Rosemary's book, Flowers Cracking Concrete: Eiko \& Koma's Asian/American Choreographies was published by Wesleyan University Press in 2016. She has also published in the Journal of Theatre, Dance and Performance Training, The Scholar and Feminist Online, The International Journal of Screendance, Asian Theatre Journal, and The Oxford Handbook of Dance and the Popular Screen, among others. Her choreography has been produced across the United States, and as a dancer she has performed across the United States and in Brazil, Canada, Germany, and South Africa. Rosemary earned a PhD in Culture and Performance from UCLA and is Assistant Professor of Dance at Texas Woman's University.

\section{Email: RCandelario@twu.edu}

Web: http://www.rosemarycandelario.net

Born and raised in Japan, Eiko Otake is a New York-based movement artist, performer, and choreographer who for more than 40 years worked as Eiko \& Koma. Since 2014, she has directed and performed a solo project, A Body in Places, in which she collaborates with photographer and historian William Johnston to create and present a series of exhibitions showing her dancing in irradiated Fukushima and elsewhere. Using archival footage and photographs of her performances, Eiko has also created media works and video installations that have been shown in galleries and at film festivals. As visiting artist at Wesleyan University since 2006, Eiko has taught interdisciplinary college courses on the Atomic Bomb and other environmental disasters using movement as a means of inquiry. She also teaches regularly at Colorado College and NYU.

Email: eikootake@gmail.com

Web: http://www.eikoandkoma.org 


\section{Notes}

1 Celia Ipiotis and Jeff Bush, through their organization ARC Videodance, were the creators and producers of the long-running PBS show, Eye on Dance, in addition to making a number of videodances (https://vimeo.com/channels/arcvideodance). In addition to Tentacle, Eiko \& Koma made Wallow (1984) and Bone Dream (1985) with Bush.

2 For more on Eiko's work behind the camera and in the editing room, see Eiko Otake, "A Dancer Behind the Lens." 3 Judy Hussie-Taylor is Executive Director and Chief Curator of Danspace.

\section{References}

38 Works by Eiko \& Koma. Dir. Eiko and Koma Otake. Ed. Eiko Otake with Tara Kelton and Shoko Letton. USA, 2009-2012.

A Body in Fukushima. Chor. and perf. Eiko Otake. Photo. William Johnston. Site-based performance and photography. 2014.

A Body in Places. Chor. and perf. Eiko Otake. Site-based performance. 2014-2017.

A Body in the East Village. Dir., chor., and perf. Eiko Otake. USA, 2016. http://eikoandkoma.org/ABodyinEastVillage

Bone Dream. Dir. Eiko and Koma Otake with Jeff Bush and Celia Ipiotis. Prod. ARC Videodance. USA, 1985. http://eikoandkoma.org/index.php?p=ek\&id=1879

Cambodian Stories. Chor. Eiko and Koma Otake with Reyum Painting Collective. Performance. 2006.

Dancing in Water: The Making of River. Dir. Eiko and Koma Otake. 2009. http://eikoandkoma.org/dancinginwater

Husk. Dir. Eiko and Koma Otake. USA, 1987. http://eikoandkoma.org/videoofhusk

The Making of Cambodian Stories. Dir. Eiko and Koma Otake. USA, 2006. http://eikoandkoma.org/themakingofcambodianstories

My Parents. Dir. Eiko, Koma, and Shin Otake. USA, 2004. http://eikoandkoma.org/myparent 
Otake, Eiko. "A Dancer Behind the Lens." In Judy Mitoma (Ed.) Envisioning Dance on Film and Video. New York: Routledge, 2002. 82-88.

River. Chor. and perf. Eiko and Koma Otake. Site-based performance. 1995.

Tentacle. Dir. Eiko and Koma Otake with Jeff Bush and Celia Ipiotis. Prod. ARC Videodance. USA, 1983. http://eikoandkoma.org/index.php? $\mathrm{p}=\mathrm{ek} \& \mathrm{id}=1880$

Tree. Chor. and perf. Eiko and Koma Otake.1988.

Wallow. Dir. Eiko and Koma Otake with Jeff Bush. Prod. ARC Videodance. USA, 1984. 


\section{REVIEWS}





\section{A Steady Pulse: Restaging Lucinda Childs, 1963-78, The Pew Center for Arts and Heritage, 2015, Online publication http://pcah.us/asteadypulse}

Marie-Louise Crawley, C-DaRE (Centre for Dance Research), Coventry University

Keywords: Lucinda Childs, The Pew Center for Art and Heritage, danceworkbook, archive

A Steady Pulse: Restaging Lucinda Childs, 1963-78 is the fourth publication in The Pew Center for Art and Heritage's online danceworkbook series. The series aims to interrogate and document creative practices in dance and, as part of the Center's wider research remit, to engage practitioners in a vibrant exchange of ideas concerning these practices. It has previously explored the artistic processes of Headlong Dance Theater's collaboration with choreographer Tere O'Connor, the work of contemporary dance artist Roko Kawai, and three of dance scholar Susan Leigh Foster's performed lectures. A Steady Pulse explores and re-examines Lucinda Childs' "dances in silence," specifically eight works spanning 1963-1978: Pastime (1963), Street Dance (1964), Museum Piece (1965), Reclining Rondo (1975), Radial Courses (1976), Melody Excerpt (1977), Interior Drama (1977) and Katema (1978).

The online workbook, beautifully designed by Andrew LeClair and Adam Lucas, couples video documentation of these eight early works, re-performed in Philadelphia and Bronxville, New York between 2009 and 2013, with a selection of critical texts. These essays explore the importance of the original "dances in silence" in terms of forging Childs' distinctive compositional voice (especially post-Judson), as well as offer approaches to possible restagings and reconstructions of these historic dance works. Two of the main texts are written by Childs, with another by her artistic associate Ty Boomershine. The central essay in the collection, "The Art of Refusal: Lucinda Childs' Dances in Silence, 1973-78" is by dance historian Suzanne Carbonneau. The rich combination of these three voices is a fitting demonstration of the ways in which this project situates itself at the fruitful intersection of scholarship and practice. The publication also includes an extensive collection of photographs, program notes, and other ephemera, most of which originate from Childs' own personal archive. There are also several of Childs' own scores, including one (the 158-page score for Melody Excerpt) that is fully digitally animated by Jorge Cousineau. Here, the complex choreographic patterns and pathways that are drawn on the visual scores are animated in real time before the viewer's eyes. Childs' visual scores, so important to 
her practice in in terms of creating the architecture of the piece, as well as in establishing the relationship of dancers to one another, are quite literally brought to life both through digital animation and through the video recordings of the reworked dances; that the online platform enables the juxtaposed viewing of these features is both appropriate and exciting.

As the introduction to the publication outlines, this particular danceworkbook is timely not only because it feeds into an essential part of the Center's wider ongoing research into trans-disciplinary artistic practices and processes, but also because it is directly concerned with important questions regarding the matters of the reconstruction, restaging, and re-enactment of historic dance works. Through its online format, the workbook proposes an exciting response to pressing questions, including how we archive dance, and how the past history of a dance work both intersects with its present and points towards its future. As the Center's Director of Performance, Bill Bissell, explained at the launch of the publication in 2015, "Lucinda's is a living archive and we have tried to make that the case in the workbook." 1 The archive is "living" because it is concerned with how dance works are transmitted across generations through the act of dancing. The workbook, precisely because of its focus on the act of recovering dances of the past in the present, in turn itself becomes a living, transmitting archive of these eight works. The flexibility of the online platform means that the viewer-reader can navigate across multiple temporalities with ease: we can watch a re-working of a dance in 2013, then immediately cross-reference it with the "original" score and with photographs or, in the case of Katema for example, with a video recording of the "original" presentation of the work from 1978. The viewerreader is also free to choose the order in which he/she views both the works and their related artifacts so that both chronological and non-linear viewings are possible. The multiplicity of viewing/reading options in itself opens up multiple possibilities for understanding how past works are re-constructed in the present and what those acts of reconstruction entail.

It is important to stress the central role that Childs herself has played in the development of this project. Childs was a driving force behind the reconstructions featured and she remained an essential collaborator throughout the Center's process of finding an innovative way to preserve and disseminate her personal archive. In fact, one of the main strengths of the workbook is the manner in which it has been developed with Childs in this extremely personal way. What is perhaps most striking throughout the workbook is the way in which the voice of Childs' practice speaks loud and clear and is in fact central to the whole archival endeavor. These dances are perhaps not so silent after all.

For this reader-viewer, two of the most striking "artifacts" in this archive are the videotaped readings by Steve Paxton and Yvonne Rainer of letters they wrote to Childs in 1964 and 1968 respectively. Just as the reworked dances (and, of course, the 
dancers involved in both the originals and in the reworkings) are living archives of the work itself, with these two video-recorded readings, the archive literally comes to life before the viewer's eyes. What we might hold in our hands in a traditional archive - a typewritten or handwritten letter from the past - we are able to witness here read aloud by its author in the present (with all the reflexivity embedded in a moment when an author looks back on a past act of writing in the present act of reading). This is more than a touch of the personal; it is yet another layer added to the complex and various temporal strata at play in the archive.

With this publication, the Center's hope is that "in addition to serving as a valuable resource for future scholars of postmodern dance, A Steady Pulse will contribute significantly to the ongoing dialogue around how we, as a society, value and preserve [dance and cultural history]."2 With its successful intersection of the voices of practice and scholarship, as well as (and indeed because of) the flexibility and accessibility of its format, A Steady Pulse: Restaging Lucinda Childs, 1963-78 certainly fulfills this hope. It also continues to open the way for other archival projects to test out innovative ways in which online and other non-traditional archives might enable us to continue probing those essential questions, asking how we rework dances and how we preserve our wider dance and cultural history.

\section{Biography}

Educated at the University of Oxford (B.A. Hons, M.St.) and trained at the Ecole Marceau in Paris, Marie-Louise began her professional performance career with Ariane Mnouchkine's Theatre du Soleil (2003-2009). Since 2010, she has been working in the UK as an independent choreographer and dance artist with companies as diverse as Birmingham Opera Company, Marc Brew, Gary Clarke, Ballet Cymru and Rosie Kay Dance Company. Recent new work has included pieces for a TATE / ARTIST ROOMS exhibit and for the Ashmolean Museum, Oxford. She is currently Artist-in-Residence at the Archive of Performances of Greek and Roman Drama, University of Oxford. MarieLouise is a PhD candidate at C-DaRE, Coventry University (UK), researching dance in the museum.

Email: crawleym@uni.coventry.ac.uk 


\section{Notes}

1 "The Making of A Steady Pulse," https://vimeo.com/129137453

2 A Steady Pulse: Restaging Lucinda Childs,

http://danceworkbook.pcah.us/asteadypulse/about.html

\section{References}

"The Making of A Steady Pulse: Restaging Lucinda Childs, 1963-78 Part 1" (2015). Prod.

The Pew Center for Arts and Heritage. Vimeo. Accessed 27 Jan 2017.

https://vimeo.com/129137453

A Steady Pulse: Restaging Lucinda Childs, 1963-78. Danceworkbook. The Pew Center For Arts and Heritage. Accessed 27 Jan 2017

http://danceworkbook.pcah.us/asteadypulse/about.html 


\section{The Oxford Handbook of Screendance Studies edited by Douglas Rosenberg. 2016. New York: Oxford UP. 816 pp, 107 b\&w screen stills. \$150 hardcover. ISBN: 9780199981601.}

Katja Vaghi, Independent scholar

Keywords: screendance studies, history, theory, practice

The publication of The Oxford Handbook of Screendance Studies edited by Douglas Rosenberg, a pioneering figure in the field, can be seen as the culmination of the everincreasing visibility gained by dance on screen throughout the years. An established art form, its theoretical framework though sitting at "the intersections of performance, media, film and dance studies" 1 has been slower to develop, which is the reason for Rosenberg's enterprise. Taking as a point of departure Yvonne Rainer's words about "the voice of the artist simultaneously framing her practice in theoretical and historical spaces," 2 Rosenberg invited 36 contributions by international curators, researchers, and makers, all involved first hand in the creation and production of dance films, to debate ontological and epistemological issues about screendance. The book's resulting kaleidoscopic views are grouped for convenience into three categories: history, theory, and practice, which Rosenberg acknowledges as "porous and flexible," 3 showcasing the methodological richness and diversity of the field. Seen as a stepping-stone rather than the definitive guide to screendance, the book initiates an interdisciplinary dialog on dance and screen technologies to determine where the field is coming from, what it is doing and where it is going.

The chapters in the historical section focus on several aspects: from the development of screendance in a specific country to the relation with preceding media, such as photography and film, to synchronic studies of one particular point in time. Instead of discussing mainstream films, the contributions focus on more experimental works associated with silent films and visual art. These are works that in the words of Laszlo Moholy-Nagy "create rather than capture images." ${ }_{4}$ Of particular interest is Ana Olenina's contribution on filmmakers Lev Kuleshov's and Dziga Vertov's studies of movement in the choreological laboratory at the Russian Academy of Artistic Science during the 1920s. Non-Western traditions are also included: Pallabi Chakravorty, for example, elegantly writes on the homogenization process occurring in Indian music video industry, and music and dance reality shows under the influence of the Bollywood industry, explaining the different connotation that desire and choreography have in the country. Conversely, Nicolás Salazar Sutil and Sebastián 
Melo explore the origins of the Western scopic tradition in the thinking of Zeno of Elea and Aristotle, and the implications for ways of thinking about and subsequently capturing movement. They further discuss how Henri Bergson's thinking, the development of Italian Photodynamism, and Marcel Duchamp's works challenge the scientific chronophotographic approach of Eadweard Muybridge and Étienne-Jules Marey.

Interestingly, in the middle section on theory, most chapters concentrate on single elements of screendance rather than on general methodological questions. These approaches consider the moving body as a site for resistance questioning assumptions about gender, different corporealities, politics, and postcolonial identities. For example, Frances Hubbard argues that screendance works are "practices of freedom." 5 Other authors address questions of kinaesthetic empathy and of the influence of sound in reception. All contributors point to screendance as creating a new understanding of dance, of the body, and of the moving image. Of particular interest in this section are Pia Tikka and Mauri Kaipainen's neuroscientific study of Maya Deren's At Land, which determines that the film elicits shared viewing experiences similar to mainstream storytelling, and Susana Temperley's reintroduction of aesthetics as a critical term, which allows her to discuss screendance as a practice that creates bodily experiences of aesthetic (dis)pleasure bypassing Romantic or Formalist fixation on the object's aesthetic form.

The third section, on practices, is the most heterogeneous. Some contributions concentrate on the work of influential artists, while others discuss aspects of filmmaking such as editing as a choreographic tool, the long-overlooked importance of preproduction scripts, or the different types of mixed reality that a performance incorporating screens can create. The section also encompasses questions related to the representation of racial and social issues in popular dance on YouTube and in mainstream films. Underlying all chapters is the desire to challenge the apparent transparency of filmmaking technologies and representations to better understand contemporary dance and screendance. Ann Cooper Albright's suggestion that Loïe Fuller's work and reception foreshadows current debates about representation and the body points to the fact that dance and technologies have always been closer than usually considered. Sita Popat shifts the site for future dance works to mixed realities created in live performance as new computing interfaces change our ways of perceiving and engaging with physical reality. Naomi Jackson underlines the subtle power that social media such as YouTube can have in generating social justice and in the future of screendance.

The handbook is definitively a great resource for students as well as seasoned researchers looking for a new approach to screendance. This compendium contains many inspiring contributions, from experimental Soviet film in the 1920s to Brazilian video dance history to the challenge of racial norms in Shirley Temple and Bill 
Robinson's film duets of the 1930s and the (mis)representation of black female sexuality in winnin' dance-videos. The expansiveness of Rosenberg's volume is possibly also its limitation. In its effort to be comprehensive, the book loses cohesion. The hybridity of works listed and theories used gives a well-rounded but merely sketched impression of the screendance field. A necklace of differently shaped pearls, its heterogeneous format allows only for an imbalanced view of specific topics. The book raises awareness of the omnipresence of new technologies and how underanalyzed these are. The wealth of examples stimulates discussion of new modes of understanding our being-in-the-world as viewers and dancers "beyond linguisticallycentered performance conventions and representation," 6 bringing into question what we understand as dance and screendance. The book might not yet create a new mode of (collective) thinking as it promises, but it succeeds in advocating for screendance as a site of resistance to gender, racial, and social normalization in contemporary society.

\section{Biography}

Katja Vaghi, Ph.D., is a Swiss dance maker, movement educator, and researcher. She is specialized in intermediality and the neo-baroque (University of Roehampton) and has worked associated Lecturer at the Rambert School of Ballet and Contemporary Dance and at the University of Northampton. Her performances encompass the use of traditional and non-traditional spaces. She is recipient of the Selma Jeanne Cohen award (2014) and makes regular contributions to the Bachtrack online magazine.

Email: kvaghi@gmail.com

\section{Notes}

1 Douglas Rosenberg, Oxford Handbook, 1.

${ }_{2}$ Quoted in idem, 2.

3 Idem, 1.

${ }_{4}$ Quoted in idem, 6.

${ }_{5}$ Frances Hubbard, "Privileging Embodied Experience," 384.

6 Susan Kozel quoted in Andrea Davidson, "Extending the Discourse of Screendance," 412. Here, Kozel is referencing French feminist philosopher Luce Irigaray. 


\section{References}

Davidson, Andrea. "Extending the Discourse of Screendance: Dance and New Media." In Douglas Rosenberg (Ed.) The Oxford Handbook of Screendance Studies. New York: Oxford University Press, 2016. 389-420.

https://doi.org/10.1093/oxfordhb/9780199981601.001.0001

Hubbard, Frances. "Privileging Embodied Experience in Feminist Screendance." In Douglas Rosenberg (Ed.) The Oxford Handbook of Screendance Studies. New York: Oxford University Press, 2016. 369-388.

https://doi.org/10.1093/oxfordhb/9780199981601.001.0001

Rosenberg, Douglas (Ed.) "Introduction." The Oxford Handbook of Screendance Studies. New York: Oxford University Press, 2016. 1-20.

https://doi.org/10.1093/oxfordhb/9780199981601.001.0001 


\section{Art in Motion: Current Research in Screendance / Art en movement: Recherches actuelles en ciné-danse. Edited by / sous la direction de Franck Boulégue and Marisa C. Hayes. 2015. Newcastle upon Tyne, Cambridge Scholars Publishing, 214 pp. Hardcover \$81.99, paperback \$61.99. ISBN: 1443874132.}

Carol Breen, C-Dare (Centre for Dance Research), Coventry University

Keywords: Festival International de Vidéo Danse de Bourgogne, screendance studies, moving image, film studies

Art in Motion brings together a collection of diverse papers from The Festival International de Vidéo Danse de Bourgogne's first International Screendance Conference, held in April 2013 with additional contributions from affiliated lectures and the festival's Screendance Studies blog. It is inevitable that published conference proceedings contain some papers that are of a higher standard than others, and to some, published proceedings may seem counter productive, traditionally seen as research in progress, or re-workings of papers in other forms. A counterview is that proceedings allow wider audiences access to new research, which would otherwise remain invisible. Art in Motion is a bilingual English/French edition, with every essay published in both languages, which especially affords French scholars the opportunity to share their research with a wider audience while also reflecting on the role screendance scholarship plays in France. The conference co-directors and book editors, Franck Boulégue and Marisa C. Hayes, acknowledge that while the term "screendance" is commonly used in academia, an alternative concept of Art in Motion suggests a more "inclusive" approach, one which examines movement created specifically for screen in many different forms, diverse dance styles, somatic practices, choreography of everyday gestures, and avant-garde film.1 They also defend the variety of other terms used within Art in Motion as a necessary compromise in line with each scholar's specific rationale for their chosen terminology, which reveals conceptual, rather than medium-specific approaches.

Eleven papers written by critics, practitioners, and scholars are divided into four sections: Analysis and Discussion, The Somatic Camera, Heritage, and Artist Perspectives on Practice and Teaching. Art in Motion reinforces existing tensions in the discourse on identity, ownership, and past histories, which has already been examined by Carroll (2000), Pearlman (2010), Pottratz (2016), Guy (2016), and Heighway (2014).2 The collection of papers from different schools of thought provokes additional

The International Journal of Screendance 8 (2017). 
questions with regards to the relationships between avant-garde film, expanded cinema, performance, fine art, dance, mainstream film, choreography, and screendance.

Claudia Kappenberg's paper draws parallels between expanded cinema in the 1960s and 1970s, and the ongoing identity crises surrounding screendance today. Kappenberg's text proposes a case for a more porous screendance, doubting that we could ever write a definitive "laundry list" of what the field includes given the trouble with terminology. The paper adds to the current debate regarding the taxonomies in an experimental hybrid art form. If a "laundry list" is developed, she asks, who should implement it and what happens to work that does not fit the taxonomy? 3

Stephanie Herfeld's text establishes a case for the inclusion of Marie Menken's films within the "dance-film" field, and creates a logical argument demonstrating that Menken's work exists in a "contemporary choreographic paradigm." 4 Herfeld highlights tensions with the term "dance," given that Menken was not a "dancer" but an artist who danced within her practice. In contradistinction to Kappenberg, Herfeld argues that "what dance is" and "what makes it dance" still need to be addressed. 6

Clotilde Amprimoz examines a range of fictional films asking, "Is death in the moving image choreographic?" The inclusion of Amprimoz's paper reminds us of tensions surrounding the term "choreographic" and its ability to destabilize the existing boundaries of screendance. Amprimoz's proposal adds to the existing debate about artists moving beyond the "dance" film category. A range of questions arises from Amprimoz's paper and its surrounding context. For instance, what is the relationship between "choreographic" sequences in fictional films and screendance forms? Where does a choreographic sequence end and a dance begin? Finally, can we locate an expanded concept of screendance within fictional films? Amprimoz's text is thus in dialogue with Roger Copeland's recent essay "The Best Dance is the Way People Die in the Movies (Or Gestures Toward a New Definition of Screeendance)" and his discussion of the problematic ideas by which fictional film sequences are described as "dances," thus by extension meriting their inclusion in the screendance category. 7

Philosopher Noël Carroll has noted that screendance's abilities are sometimes defined in relation to theatre's inabilities.8 Related discussions are continued in Art in Motion, where Sophie Walon claims that screendance is unlike theatrical performance where "dance is most often seen from a distance." 9 Similarly, Paulina Ruiz Carballido suggests that choreographic possibilities on screen allow a break from traditional theatre's preoccupations with the "frontal image of the full length dancing body." 10

Marion Carrot argues that the film industry normalizes the dancing body by fitting it into the "narrative logic of mainstream cinema." 11 Carrot argues that we must look to early experiments that deconstruct these normative representations. Carrot proposes 
that as screendance distances itself from the creation and recognition of the figurative, it opens up new relationships between the audience, dancers and filmmakers.12 This argument mirrors the existing divide in screendance criticism, particularly between preferences for the 'cinematic' or 'figurative' body, versus the 'abstract' or 'metaphorical' figure. Carrot's usage of the term 'mainstream cinema' places screendance in opposition to a very broad set of practices, genres, and categories that themselves beg for more consideration. 13

Art in Motion is a rich collection of diverse papers, which illustrate the breadth of research taking place within the field of screendance. This book offers multiple avenues for further investigation. Some papers could benefit from the inclusion of imagery to help steer the reader through nuances of arguments that refer to very specific visual transitions, or specific moments occurring in the work under discussion. Additionally, the mix of terminology in the publication can lead to some confusion. As the co-editors point out, contributors use individual terms that fit their topics. In the text "Minimalism and Video dance" by Mariann Gaál, for instance, the examples given contradict the proposals in Karen Pearlman's paper on video dance.14 An editorial introduction regarding the terminology, including clarifications regarding the meanings of terms as particular authors use them would have been useful. Similarly, although the co-editors hint at this in the introduction, it would be helpful and informative to the reader to include a contextual summary explaining more about the role geography and cultural backgrounds play in the shaping of these terms.

Kappenberg's "The Politics of Discourse in Hybrid Forms" and Herfeld's "Seeing Moving: The Performance of Marie Menken's Images" particularly shine through in this collection, and highlight the difficulty in identifying where this emerging field begins and ends. In summary Art in Motion makes an invaluable contribution to screendance criticism, by showcasing different schools of thought side-by-side. This publication mirrors the inclusive vision of the festival, by recognizing the importance of location and cultural context while simultaneously enabling the research to circulate outside its own community.

\section{Biography}

Carol is a first year practice-as-research PhD student at Coventry University. She has worked as a lecturer at The University of Lincoln, and Arts University Bournemouth. Carol studied Visual Communication at The Limerick School of Art and Design and completed her MA in Communication Design from Central Saint Martins in 2012. She is a designer and artist working with moving-image.

Email: carolpbreen@gmail.com 


\section{Notes}

1 Franck Boulégue and Marisa Hayes, Art in Motion, xiii.

2 See Noël Carroll, "Toward a Definition"; Karen Pearlman, "If a Dancing Figure," 244;

Priscilla Guy, "Screendance as a Question," 201; and Anna Heighway, "Understanding The 'Dance,'" 44.

3 Claudia Kappenberg, "The Politics of Discourse," 25. This is related to Fred Camper's checklist which authenticates avant-garde films. More recently, Wyn Pottratz addresses Kappenberg's idea of a "laundry list" specifically for screendance, revisiting the $(\mathrm{Hu})$ manifesto's own definition of the form. See Pottratz, "Screendance Cannot Be Everything," 183.

${ }_{4}$ Herfeld, "Seeing Moving," 97.

${ }_{5}$ Idem, 90.

6 Idem, 98.

7 Copeland, "The Best Dance," 228.

${ }_{8}$ Carroll, 114.

9 Walon, "Screendance Sensations," 2.

${ }_{10}$ Carballido, "The Screen as Choreographic Space," 130.

${ }_{11}$ Carrot, "Perpetual Becoming," 114.

12 Idem, 121.

${ }_{13}$ Chia-wen Kuo presents a more nuanced view regarding mainstream cinema, she argues that even from within the narrative conventions of Busby Berkeley's Footlight Parade popular film female bodies have the ability to transcend the male gaze and narrative constraints and problematize the spectator's position. Kuo, "The Digital Sublime," 13.

${ }_{14}$ Pearlman, 244.

\section{References}

Boulégue, Franck and Marisa C. Hayes (Eds.) Art in Motion: Current Research in Screendance / Art en movement: Recherches actuelles en ciné-danse. Newcastle upon Tyne: Cambridge Scholars Publishing, 2015.

Camper, Fred. “Naming, and Defining, Avant-Garde or Experimental Film.” N.d. http://www.fredcamper.com/Film/AvantGardeDefinition.html

Carballido, Paulina Ruiz. "The Screen as Choreographic Space." In Franck Boulégue and Marisa C. Hayes (Eds.) Art in Motion: Current Research in Screendance / Art en movement: Recherches actuelles en ciné-danse. Newcastle upon Tyne: Cambridge Scholars Publishing, 2015. 130-138 
Carroll, Noël. "Toward a Definition of Moving-Picture Dance." The International Journal of Screendance 1 (2010): 111-125.

http://journals.library.wisc.edu/index.php/screendance/article/viewFile/313/307

Carrot, Marion."Perpetual Becoming." In Franck Boulégue and Marisa C. Hayes (Eds.) Art in Motion: Current Research in Screendance / Art en movement: Recherches actuelles en ciné-danse. Newcastle upon Tyne: Cambridge Scholars Publishing, 2015. 114-122.

Copeland,Roger. "The Best Dance Is the Way People Die in Movies (or Gestures Toward a New Definition of "Screendance")" in Douglas Rosenberg (Ed.) The Oxford Handbook of Screendance Studies. New York. Oxford Publishing. 2016. 225-245.

Heighway, Anna. "Understanding The 'Dance' In Radical Screendance." The International Journal of Screendance 4 (2014): 44-62.

http://dx.doi.org/10.18061/ijsd.v4i0.4530

Herfeld "Seeing Moving: The Performance of Marie Menken's Images." In Franck Boulégue and Marisa C. Hayes (Eds.) Art in Motion: Current Research in Screendance / Art en movement: Recherches actuelles en ciné-danse. Newcastle upon Tyne: Cambridge Scholars Publishing, 2015. 89-101.

Guy, Priscilla. "Screendance as a Question: All This Can Happen and the First Edition of the Light Moves Festival of Screendance." The International Journal of Screendance 7 (2016): 200-212. http://dx.doi.org/10.18061/ijsd.v7i0.5469

Kappenberg, Claudia. "The Politics of Discourse in Hybrid Art Forms." In Franck Boulégue and Marisa C. Hayes (Eds.) Art in Motion: Current Research in Screendance / Art en movement: Recherches actuelles en ciné-danse. Newcastle upon Tyne: Cambridge Scholars Publishing, 2015. 21-30.

Kuo, Chia-wen. "The Digital Sublime of Feminine Spectacle in Busby Berkeley's Footlight Parade and Roy Lichtenstein's Nudes with Beach Ball. Female Flesh Represented as Conceptualized Kinesthesia in the Age of Mechanical Reproduction." The International Journal of the Image 5.2 (2014): 7-14.

Pearlman, Karen. "If a Dancing Figure Falls in the Forest and Nobody Sees Here..." Participations Journal of Audience \& Reception Studies 7.2 (November 2010): 236-248. $<$ http://www.participations.org/Volume 7/Issue 2/PDF/pearlman.pdf >

Pottratz, Wyn "Screendance Cannot Be Everything: Defining the Form Ten Years after the (Hu)Manifesto." The international Journal of Screendance 6 (2016): 182-185. http://dx.doi.org/10.18061/ijsd.v6i0.5130 
Rosenberg, Douglas (Ed.) The Oxford Handbook Of Screendance Studies. New York: Oxford University Press, 2016.

Walon, Sophie "Screendance Sensations." In Franck Boulégue and Marisa C. Hayes (Eds.) Art in Motion: Current Research in Screendance / Art en movement: Recherches actuelles en ciné-danse. Newcastle upon Tyne: Cambridge Scholars Publishing, 2015. 211. 


\section{Dance on Camera at 45}

Harmony Bench, The Ohio State University

Keywords: Dance Films Association, screendance festival, New York City

Dance Films Association hosted its 45th annual Dance on Camera festival in New York City in January of 2017. This festival has changed curators and partnerships over the years, and the organization's mission has expanded to include offering grants, building an archive of dance films, and hosting training sessions and workshops. This year, an Emerging Movement Summit accompanied the festival as a way to open the conversation up to new technologies and university curricula. What is sometimes called dance-technology has had a muted presence in the United States in recent years, and it was gratifying to see a possible reemergence of this field alongside and in relation to screendance.

The Dance on Camera festival has been co-presented by the Film Society of Lincoln Center since 1996, and this venue surely has an impact on the curatorial perspective as well as clientele. While the festival makes a space for experimental dance and experimental filmmaking, these are not where the festival earns its bread and butter. Instead, documentary films dominated the festival. And while all of the screenings were well-attended, the auditorium filled to overflowing for films that focused on ballet or uptown modern dance.

Balletomanes were thus well-cared for with highly personal documentary films. Looking at the Stars featured Geyza Pereira of the São Paulo school and company Fernanda Bianchini Ballet Association for the Blind. Both practical and idealistic, Pereira comments of herself and fellow visually impaired dancers, "We like to be inspirational, but you can't build a future on that." ${ }_{1}$ Anatomy of a Male Ballet Dancer followed New York's adopted son American Ballet Theatre dancer Marcelo Gomes as he reminisces about his childhood and early training and struggles with injury. Attempts to make Gomes relatable resulted in belabored daddy issues, but footage of Gomes performing was truly remarkable. Marie's Attitude was too long, but the film's subject, Marie Lindqvist, principal dancer with the Royal Swedish Ballet, appeared a masterful dancer and a grounded yet delightful individual. Filmmaker Kersti Grunditz Brennan was also gratifyingly adventurous in her construction of this film, cutting between rehearsal and performance footage and shooting rehearsals in a manner more familiar in experimental films than documentary. Queen of Thursdays makes footage of Rosario Suárez, former prima ballerina of the Nacional Ballet de Cuba, 
available to audiences for the first time. This intimate film walks viewers through troubles with the famous, and famously jealous, Alicia Alonso, and life as a Cuban exile in Miami. Additional feature-length documentaries included Dancing Beethoven (Beethoven par Béjart), the swing-dance themed Alive \& Kicking, the troubling portrait Storyboard P, a Stranger in Sweden, In the Steps of Trisha Brown (Dans les pas de Trisha Brown), as well as surprisingly moving Into Sunlight, which follows choreographer Robin Becker and her dancers creating a new work about war, built from David Maraniss's book They Marched into Sunlight. Made for the novice dance viewer, Into Sunlight was very much a didactic film, skillfully teaching viewers how to watch and interpret dance. It should appear on any university Dance Appreciation syllabus.

The festival sought a global reach in its offerings, for which I applaud the curators. However, that very globality was heavily filtered through the lenses of ballet and documentary, which misrepresents the diversity of contemporary screendance. In contrast, the short films screened across the festival leaned distinctly in the direction of the United States, and even more distinctly in the direction of New York. Nevertheless, the curators are balancing the needs of distinct interest groups. Without the ballet-hungry and docu-curious, there might not be a strong-enough base of support to continue other aspects of the festival's programming, namely the screening of short films and historical works, which also require local support.

Film shorts accompanied feature-length presentations, exposing audiences to additional artists and dance styles. These were quite strong-Broken Memory, Being and Nothingness, 349 and Exquisite Corps, among them. Although the filmmakers introduced their short films, they were not included in the talk-backs, so there was no formal venue for interacting with the filmmakers if they were not on one of the two shorts programs. Since many screendance festivals consist almost entirely of short films, this seemed to me to be quite a slight for the filmmakers-some of whom traveled no small distance to introduce their films.

There were two shorts programs gathered under the themes of "narrative" and "experimental." Many films on the "narrative" program were baffling in their immaturity. Only two films reflected the prestige of the venue, presenting both aesthetic clarity and emotional weight: Color of Reality and You.

Color of Reality was truly astonishing and devastating. Walls, furniture, and the dancers themselves-director Jon Boogz and Lil Buck-have been painted over in Alexa Meade's impressionistic brush strokes that transform an ordinary living room scene to a magical space. In one particularly moving moment, heavy with the anti-black violence depicted on television, Lil Buck balances on his toes, reaches toward his heart with both hands, and, as if ripping it out of his chest and throwing it to the ground, he tramples it with his footwork. 
You is an excerpt of the late British choreographer Nigel Charnock's 1991 solo work Resurrection, staged for camera. Directed by Graham Clayton-Chance and performed by Dan Watson, the video is part of a larger project of archiving Charnock's performance work. Shot in a simple rehearsal studio, Watson performs Charnock's characteristic dance-theater combinations of rhythmic speech with calibrated, repeating gestures structured by the lyricism of his prose. "You want someone to take you away from all this - to take you away from all this. Someone to come and make things different. Someone with answers. Someone who will make you whole. Someone who will make you complete. Someone to take you away from all this. Somebody to take you away from all this." 2

Both films, the first an original creation and the second an adaptation, find tenderness inside of a fraught moment in history. While anti-gay violence and the AIDS epidemic may have faded somewhat from the collective memory of the LGBTQ community as a long-ago nightmare, the radicalism of staging pride and pleasure in gay male sexual identity in 1991 would have read as a strong political statement. So to does an affirmation of black masculinity against the backdrop of contemporary anti-black violence and the Black Lives Matter social movement. Where Charnock's soliloquy locates the agency of transformation in another individual-the one desired, the one who will change things-Color of Reality implicates viewers in the deaths of the main characters. Jon Boogz and Lil Buck do not seek somebody to intervene in a violent social landscape that produces life always at the edge of death; they seek somebodies. It remains to be seen who will answer their call.

The second "experimental" shorts program productively challenged the limits of dance onscreen. Kathy Rose's wonderfully bizarre The Unpainted Woman (2016) took viewers on a posthuman science-fiction underwater tour, while other films experimented with uses of technology, including drone-mounted cameras and motion capture animations. The program concluded with Eiko's film A Body in the East Village (2016), which is part of her much larger project $A$ Body in Places. Organized under the rubric of experimentation, this program begs the question of what it means to be experimental, whether the focus is technological, aesthetic, political, or something else. Perhaps experimentation is simply a way to describe illegibility and ambiguity in an era that demands transparency of meaning.

The most daring - and perhaps most significant-achievement of the 2017 Dance on Camera Festival was the Tribute to David Gordon, featuring Punch and Judy Get Divorced (1992) and My Folks (1989), with a post-screening conversation with Gordon and Valda Setterfield. The presentation was in conjunction with the New York Public Library's installation David Gordon: Archiveography-Under Construction. Like so many movement artists, Gordon has set about constructing an online archive of recorded performance work, photographs, and writing-available at http://davidgordon.nyc/. The films screened represent two poles of Gordon's work, from the carefully 
choreographed investigation of identity and heritage in My Folks to the uproarious chaos of Punch and Judy Get Divorced. Though small compared to other audiences, those who stayed for the talk-back were awed by Gordon's achievements and took away a real sense of the history of postmodern dance and dance onscreen. This sense of history and the festival's commitment to that history was further bolstered by the screening of a re-mastered version of Merce Cunningham's Crises (1961) and the classic film by Peter Glushanok of Martha Graham in A Dancer's World (1957).

The format of the Dance on Camera Festival has continued to mature with age, and the festival is managing to balance competing interests as they assemble films and experiences that appeal to the widest possible audience, including both the academically inclined and dance fans. Dance onscreen has long been dominated by artists in North America, the United Kingdom, and Europe, but the balance has shifted in the past decade or more. In an era of increasing nationalism and xenophobia, I hope that festivals such as Dance on Camera find the political will to use their prestige to highlight the best new work from around the world. The screendance field can only benefit from participating in the screening and circulation of films that challenge audiences to see differently, whether because they refer to unfamiliar movement vocabularies, cultural frameworks, or systems of aesthetic value. After 45 years of continuous programming, audiences should be able to expect both greater variety and greater challenge from the dance films produced and screened in such venues.

\section{Biography}

Harmony Bench is Assistant Professor of Dance at The Ohio State University, where she is affiliated faculty with Theatre; Women's, Gender, and Sexuality Studies; and Translational Data Analytics. She co-edits The International Journal of Screendance with Simon Ellis. She is currently working on a database of early 20th century touring dance companies and, with Kate Elswit, exploring the touring and travel of choreographer Katherine Dunham. These projects in progress can be found at Movement on the Move.

Email: bench.9@osu.edu

Website: www.harmonybench.com 


\section{Notes}

1 Looking at the Stars, Peralta.

2 You, Clayton-Chance.

\section{References}

349. Dir. Kristen Lauth Shaeffer. USA, 2015.

A Body in the East Village. Dir. Eiko Otake. USA, 2016. Vimeo.

https://vimeo.com/184753117

A Dancer's World. Dir. Peter Glushanok. USA, 1957.

Alive \& Kicking. Dir. Susan Glatzer. USA: Magnolia Pictures, 2016.

Anatomy of a Male Ballet Dancer. Dir. David Barba, James Pellerito. USA: Retribution Media, 2017.

Being and Nothingness. Dir. Alejandro Alvarez. 2016. Vimeo.

https://vimeo.com/ondemand/beingandnothingness

Broken Memory. Dir: Tomoko Mikanagi. 2016. Vimeo. https://vimeo.com/162722020

Color of Reality. Dir: Jon Boogz. 2016. YouTube.

https://www.youtube.com/watch?v=Dq1tm5TqYsg\&t=20s

Crises. Dir. Merce Cunningham. USA: Motion Pictures, 1961.

Dancing Beethoven (Beethoven par Béjart). Dir. Aranxta Aguirre. Switzerland, 2016.

Exquisite Corps. Dir: Mitchell Rose. 2016. YouTube.

https://www.youtube.com/watch?v=B3pFxsYPLgU

In the Steps of Trisha Brown (Dans les pas de Trisha Brown). Dir. Marie-Hélène Rebois.

France, 2016.

Into Sunlight. Dir. Ron Honsa. USA: Moving Pictures, 2016.

Looking at the Stars. Dir. Alexandre Peralta. Brazil, 2016.

Marie's Attitude. Dir. Kersti Grunditz Brennan. Sweden, 2016.

My Folks. Dir. David Gordon. USA, 1989. 
Punch and Judy Get Divorced. Dir. David Gordon. USA, 1992.

Queen of Thursdays. Dir. Orlando Rojas. USA, 2016.

Storyboard P, a Stranger in Sweden. Dir. Matthew D'arcy. Sweden: Amp Film, 2016.

The Unpainted Woman. Dir. Kathy Rose. 2016. YouTube.

https://www.youtube.com/watch?v=iubvTFPFmqk

You. Dir. Graham Clayton-Chance. UK, 2015. 